\title{
QUEEN'S
UNIVERSITY
BELFAST
}

\section{A Review of Non-Thermal Plasma Technology: A novel solution for CO2 conversion and utilization}

\author{
George, A., Shen, B., Craven, M., Wang, Y., Kang, D., Wu, C., \& Tu, X. (2021). A Review of Non-Thermal \\ Plasma Technology: A novel solution for $\mathrm{CO} 2$ conversion and utilization. Renewable and Sustainable Energy \\ Reviews, 135, [109702]. https://doi.org/10.1016/j.rser.2020.109702
}

Published in:

Renewable and Sustainable Energy Reviews

Document Version:

Peer reviewed version

Queen's University Belfast - Research Portal:

Link to publication record in Queen's University Belfast Research Portal

\section{Publisher rights}

Copyright 2020 Elsevier.

This manuscript is distributed under a Creative Commons Attribution-NonCommercial-NoDerivs License

(https://creativecommons.org/licenses/by-nc-nd/4.0/), which permits distribution and reproduction for non-commercial purposes, provided the author and source are cited.

\section{General rights}

Copyright for the publications made accessible via the Queen's University Belfast Research Portal is retained by the author(s) and / or other copyright owners and it is a condition of accessing these publications that users recognise and abide by the legal requirements associated with these rights.

Take down policy

The Research Portal is Queen's institutional repository that provides access to Queen's research output. Every effort has been made to ensure that content in the Research Portal does not infringe any person's rights, or applicable UK laws. If you discover content in the Research Portal that you believe breaches copyright or violates any law, please contact openaccess@qub.ac.uk. 


\section{A Review of Non-Thermal Plasma Technology: A Novel Solution for $\mathrm{CO}_{2}$ Conversion and Utilization}

Adwek George ${ }^{\mathrm{a}, \mathrm{d}}$, Boxiong Shen ${ }^{\mathrm{a}^{*}}$, Michael Craven ${ }^{\mathrm{c}}$, Yaolin Wang ${ }^{\mathrm{c}}$, Dongrui Kang ${ }^{\mathrm{a}}$, Chunfei

$$
\mathrm{Wu}^{\mathrm{a}, \mathrm{b}^{*}}, \mathrm{X} \text { in } \mathrm{Tu}^{\mathrm{c}^{*}}
$$

${ }^{a}$ School of Energy and Environmental Engineering, Key Laboratory of Clean Energy Utilization and Pollution Control, Hebei University of Technology, Tianjin, China

${ }^{\mathrm{b}}$ School of Chemistry and Chemical Engineering, Queen's University Belfast, Belfast, BT7 $1 \mathrm{NN}, \mathrm{UK}$

${ }^{c}$ Department of Electrical Engineering and Electronics, University of Liverpool, Liverpool, L69 3GJ, UK

${ }^{\mathrm{d}}$ Department of Energy and the Built Environment, Mount Kenya University, General Kago Rd, Thika, Kenya

Corresponding authors: Professor Boxiong Shen (E-mail: shenbx@hebut.edu.cn)

Dr. Chunfei Wu (E-mail: c.wu@qub.ac.uk)

Prof. Xin Tu (E-mail: xin.tu@liv.ac.uk) 


\begin{abstract}
Recently, carbon dioxide $\left(\mathrm{CO}_{2}\right)$ conversion into higher-value platform chemicals and synthetic fuels has drawn great attention as a result of global warming. Non-thermal plasma (NTP)-catalytic $\mathrm{CO}_{2}$ conversion has emerged to significantly reduce the reaction temperature. However, this technology requires a paradigm shift in process design to enhance plasma-catalytic performance. $\mathrm{CO}_{2}$ conversion using NTP and catalysts has great potential to increase reaction efficiencies due to the synergetic effects between the plasma and catalysts that can provide mutual improvement in their performances. It is crucial to present the recent progress in $\mathrm{CO}_{2}$ conversion and utilization whilst specifying a research prospects framework and providing future research directions in both industries and laboratories. Herein, a review of encouraging research achievements in $\mathrm{CO}_{2}$ conversion and utilization using NTP in recent years is provided. The topics reviewed in this work are recent progress in different NTP sources in relation to product selectivity, conversion, and energy efficiency; plasma-based $\mathrm{CO}_{2}$ reactions and applications; $\mathrm{CO}_{2}$ conversion integrated with $\mathrm{CO}_{2}$ capture; and process development of NTP in terms of potential large-scale applications processes. The high market value of the possible products from the NTP process, including chemicals and fuels, make the commercialization of the process feasible. Developing a suitable catalyst with effective sensitivities and performance under intricate conditions can improve the selectivity of these carbon-based liquid chemicals. There is a need for more studies to be performed in this field.
\end{abstract}

Keywords:

Non-thermal plasmas; Plasma-catalysis; $\mathrm{CO}_{2}$ conversion and utilization; $\mathrm{CO}_{2}$ capture 


\section{Table of Contents}

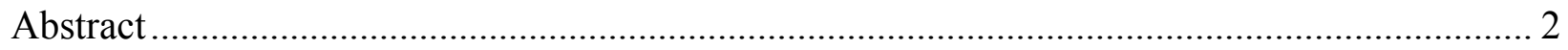

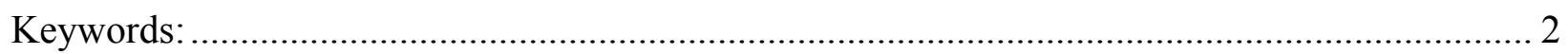

List of abbreviations .......................................................................

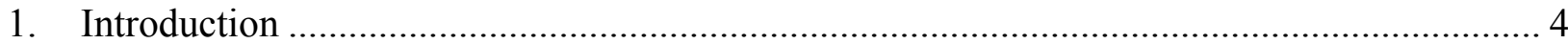

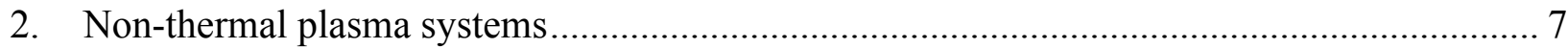

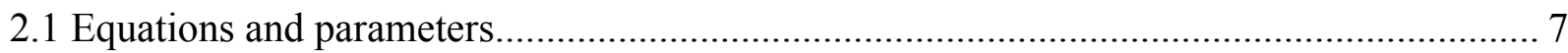

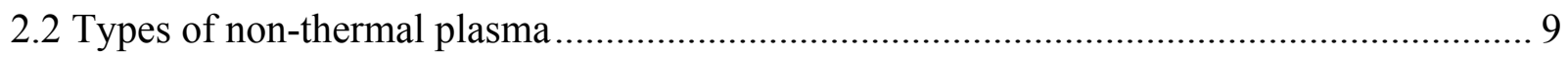

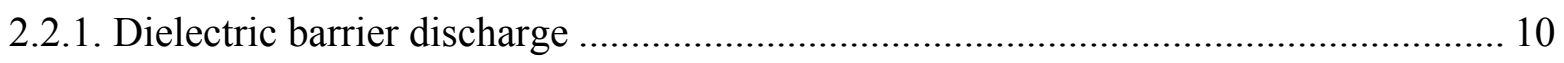

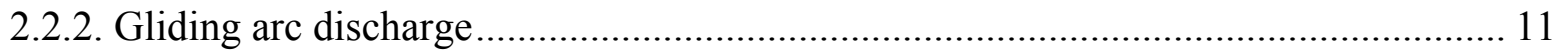

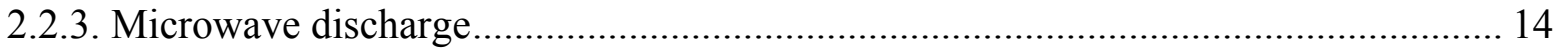

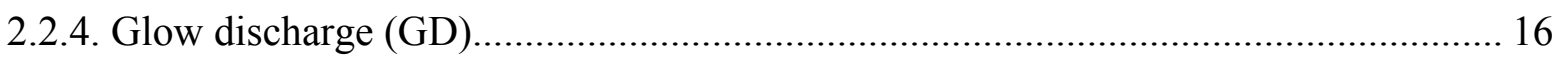

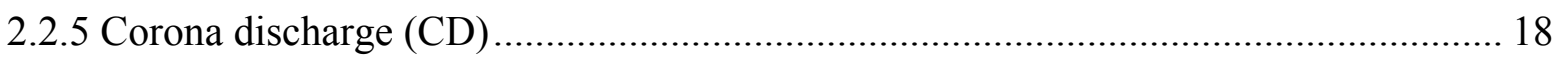

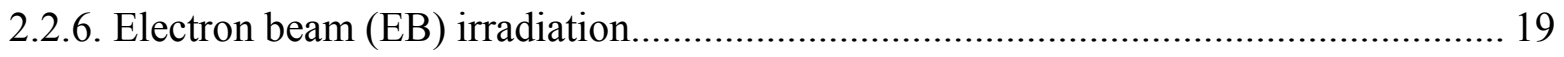

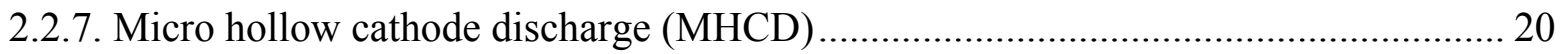

2.2.8. Spark discharge (SD) ..................................................................................... 20

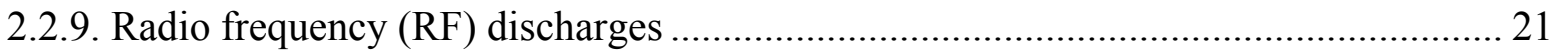

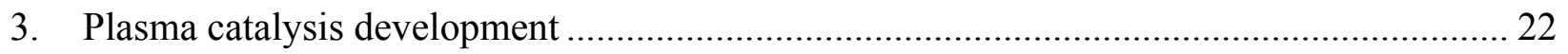

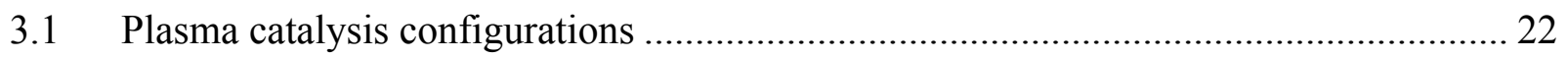

3.2 Interactions and synergies between non-thermal plasma and catalysis .............................. 23

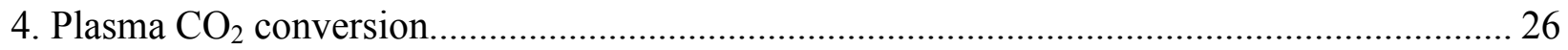

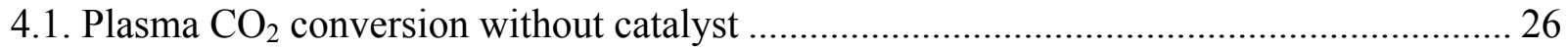

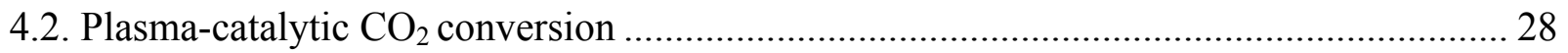

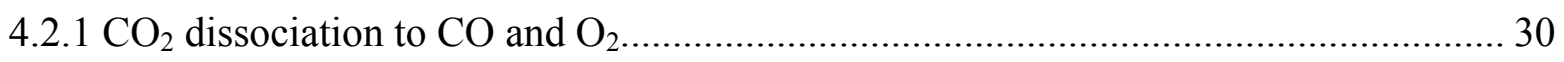

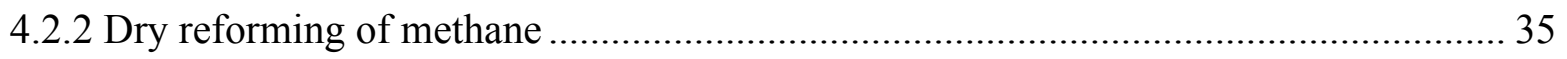

4.2.2.2. Dry reforming of methane for the synthesis of oxygenates ........................................ 40

4.2.2.3. Dry reforming of methane for synthesis of higher hydrocarbons $\left(\mathrm{C}_{\mathrm{x}} \mathrm{H}_{\mathrm{y}}\right)$.................. 42

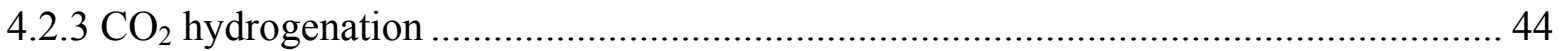

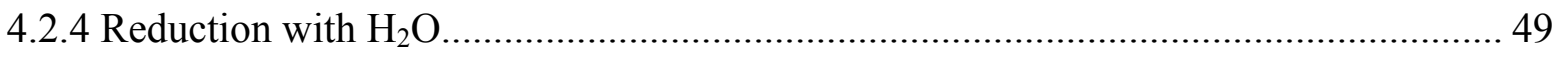

5. Technology development of plasma $\mathrm{CO}_{2}$ conversion and utilization...................................... 49

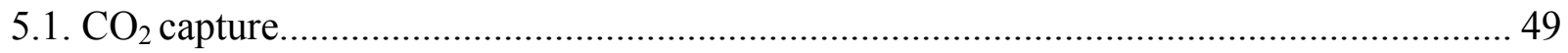

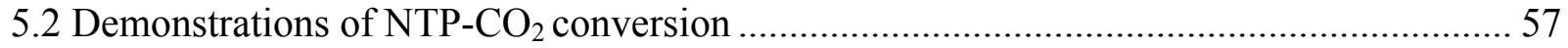


6. Concluding remarks and future perspectives 58

Acknowledgement

60

\section{Introduction}

The concentration of $\mathrm{CO}_{2}$ has been increasing significantly in the biosphere over the past century. It accounts for approximately 55\% of total yearly anthropogenic greenhouse gas emissions (49 Gt $\mathrm{CO}_{2}$ eq in 2010) responsible for global warming. The increasing concentration of $\mathrm{CO}_{2}$ has resulted in destructive effects to the ecosystem, such as a change in hydrological and vegetation patterns, surface temperature increase, and frequent incidences of disastrous weather [2-5]. Thus, a significant reduction in $\mathrm{CO}_{2}$ emissions has received noticeable consideration and substantial progress in recent years. $\mathrm{CO}_{2}$ conversion into value-added platform chemicals or synthetic fuels $\left(\mathrm{CO}, \mathrm{CH}_{4}\right.$, Dimethyl ether $(\mathrm{DME})$, methanol $\left.\left(\mathrm{CH}_{3} \mathrm{OH}\right)\right)$ using a variety of methods has attracted significant attention due to its potential to reduce $\mathrm{CO}_{2}$ emissions and utilize them as a useful carbon source. The combination of $\mathrm{CO}_{2}$ utilization together with the conversion of $\mathrm{CH}_{4}$ through the syngas path is being weighed as an up-and-coming process due to the high heating value $\left(34 \mathrm{MJ} / \mathrm{m}^{3}\right)$ in $\mathrm{CH}_{4}$ [6-8]. $\mathrm{CO}$ and $\mathrm{H}_{2}$ are the major chemical feedstocks for the production of oxygenates (alcohols, acetic acid) and for Fischer-Tropsch synthesis to generate liquid hydrocarbons [9].

Different processes have been developed and investigated for $\mathrm{CO}_{2}$ conversion to value-added fuels and chemicals, namely electromechanical [10-12], photochemical [13-18], plasma catalytic process [19-23] and biological fixation [24-27]. Selecting which $\mathrm{CO}_{2}$ storage and utilization processes to use requires an understanding of both the chemical and physical properties of $\mathrm{CO}_{2}$. $\mathrm{CO}_{2}$ utilization efforts target the development of valuable applications of $\mathrm{CO}_{2}$ where geologic storage may not be a favorable solution. Fig. 1 shows the main pathways for $\mathrm{CO}_{2}$ utilization [16, 24, 28, 29]. 


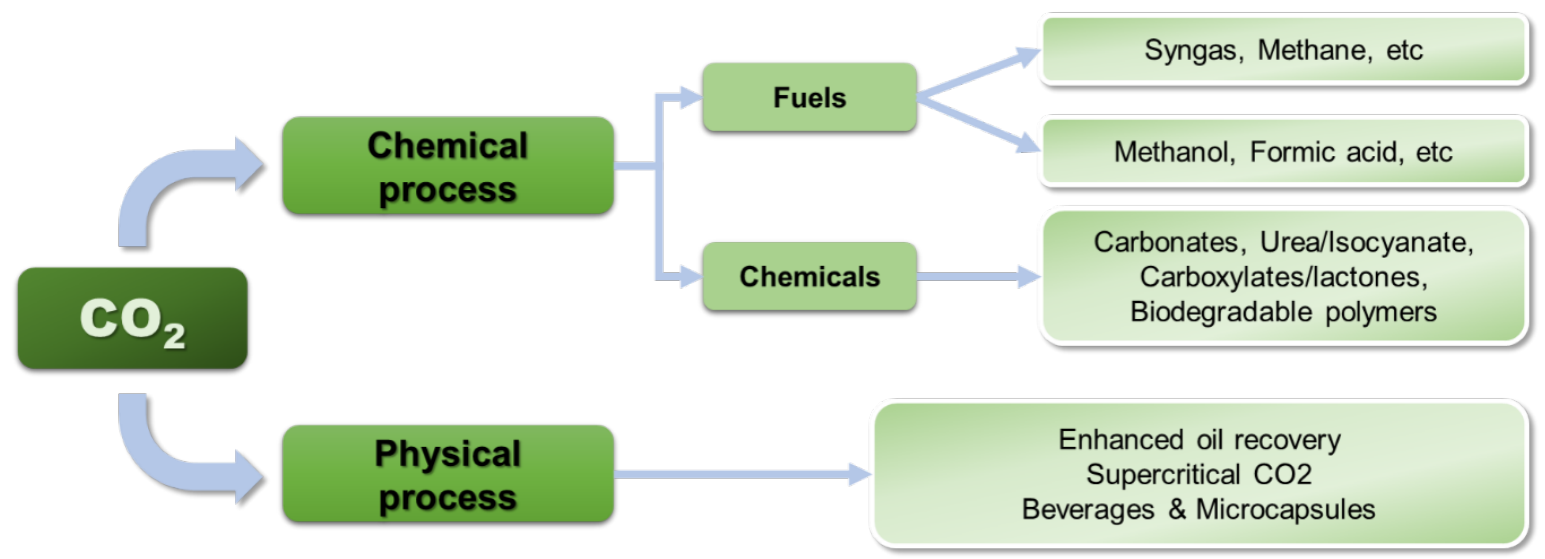

Figure 1. Main pathways of $\mathrm{CO}_{2}$ conversion and utilization

The major challenge related to the conversion of $\mathrm{CO}_{2}$ is in overcoming the high stability of the $\mathrm{CO}_{2}$ molecule as a large amount of energy is needed to dissociate the molecule and break the double bond(s) of $\mathrm{O}=\mathrm{C}=\mathrm{O}[30]$. The application of plasma is a promising and innovative technique that provides an attractive solution for the efficient conversion of $\mathrm{CO}_{2}$ into beneficial chemicals and fuels [31-34]. This is because plasma has the potential to enable thermodynamically adverse chemical reactions to occur at ambient conditions. Furthermore, plasma technology is faster and simple structures are required compared to other existing methods, such as photochemical/photocatalytic processes $[16,35,36]$, enzymatic/biochemical processes $[16,37$, 38], electro-catalytic/electrochemical [39, 40], and catalytic conversion [41, 42]. NTP performs at non-equilibrium conditions, low temperature and at atmospheric pressure. Without using an advanced pulse power supply, reaction rates are high and quickly attained. Meanwhile, the energetic electrons produced in the plasma have an average temperature of $1-10 \mathrm{eV}$ and are capable of activating $\mathrm{CO}_{2}$ molecules by ionization, excitation, and dissociation, thus creating an avalanche of reactive species such as excited atoms, ions, molecules and radicals for propagation and initiation of chemical reactions [43-45]. In addition, the compactness, ease of installation and flexibility of NTP systems provide great potential for integration with technologies that harvest energy from renewable resources (e.g. solar panels and wind turbines), which could enable them to serve as a potential energy storage system for surplus electricity from renewable energy during peak moments on the grid. This could, in turn, lead to a carbon-neutral network as the technique can be scaled up for industrial applications [46, 47]. 
The major challenges in $\mathrm{CO}_{2}$ conversion using NTP are in improving the plasma process energy efficiency, and in increasing its competitiveness [48]. Combining catalysts with NTP creates a hybrid plasma-catalytic process $[49,50]$ with an enormous capacity to produce a plasma-catalyst synergy that can enhance the conversion of $\mathrm{CO}_{2}$ [51], and the selectivity and yield of target products [52-54]. This plasma catalytic effect results from a specific excited species, formed in the plasma, having the ability to interact with the catalyst surface - and subsequently reacting before relaxation occurs [55]. Nonetheless, it is difficult to find cost-effective and exceptionally active catalysts for the plasma catalytic $\mathrm{CO}_{2}$ conversion into $\mathrm{CO}$ and $\mathrm{O}_{2}$. Plasma reactor modification or new design concepts might open the route for improving the energy efficiency of the NTP process for $\mathrm{CO}_{2}$ conversion. Various routes have been investigated for $\mathrm{CO}_{2}$ conversion using NTP, namely dry reforming of methane (DRM), which is the combined conversion of $\mathrm{CH}_{4}$ and $\mathrm{CO}_{2}$, (R1) [56-61], $\mathrm{CO}_{2}$ hydrogenation using hydrogen or water (R2 and R3) [49], [62-66] and $\mathrm{CO}_{2}$ decomposition to $\mathrm{CO}$ and $\mathrm{O}_{2}$ (R4) [67-69], as illustrated in Fig. 2. DRM has received much attention due to the benefit that it entails simultaneous conversion of two greenhouse gases (GHGs), $\mathrm{CO}_{2}$ and $\mathrm{CH}_{4}$, specifically for desired syngas ratio, low syngas ratio, etc [70]. It is mostly carried out using dielectric barrier discharge (DBD). Use of gliding arc (GA), and microwave plasma (MW) NTPs is uncommon for DRM, although GA and MW have higher energy efficiencies compared to DBD plasma in DRM, as well as in $\mathrm{CO}_{2}$ splitting [71, 72].

$$
\begin{array}{ll}
\mathrm{CO}_{2}+\mathrm{CH}_{4} \rightarrow 2 \mathrm{CO}+2 \mathrm{H}_{2}, & \Delta \mathrm{H}^{0}, 298 \mathrm{~K}=247 \mathrm{~kJ} / \mathrm{mol} \\
\mathrm{CO}_{2}+4 \mathrm{H}_{2} \rightarrow \mathrm{CH}_{4}+2 \mathrm{H}_{2} \mathrm{O}, & \Delta \mathrm{H}^{0}, 298 \mathrm{~K}=-165 \mathrm{~kJ} / \mathrm{mol} \\
\mathrm{CO}_{2}+\mathrm{H}_{2} \rightarrow \mathrm{CO}+\mathrm{H}_{2} \mathrm{O}, & \Delta \mathrm{H}^{0},{ }_{298 \mathrm{~K}}=41.2 \mathrm{~kJ} / \mathrm{mol} \\
2 \mathrm{CO}_{2} \rightarrow 2 \mathrm{CO}+\mathrm{O}_{2}, & \Delta \mathrm{H}^{0}, 298 \mathrm{~K}=283 \mathrm{~kJ} / \mathrm{mol}
\end{array}
$$




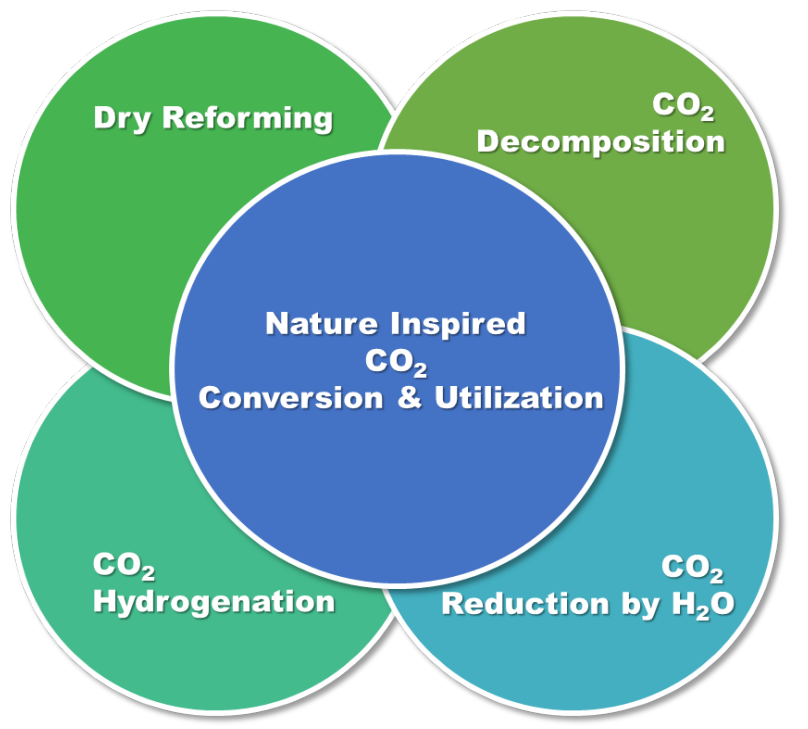

Figure 2. $\mathrm{CO}_{2}$ hydrogenation routes [30]

This paper is based on an extensive literature survey on NTP- $\mathrm{CO}_{2}$ conversion and utilization with purposes to define the scope, limitations, and opportunities for $\mathrm{NTP}-\mathrm{CO}_{2}$ conversion. This work reviews the progress on (a) $\mathrm{CO}_{2}$ conversion using different types of NTP, (b) the interactions and synergies between catalysts and NTP, and their subsequent effects on $\mathrm{CO}_{2}$ conversion and utilization, (c) the process development on NTP assisted $\mathrm{CO}_{2}$ conversion and utilization with $\mathrm{CO}_{2}$ capture.

2. Non-thermal plasma systems

\subsection{Equations and parameters}

In this section, an overview of the various expressions for the specific input energy (SIE), conversion $(\chi)$ and energy efficiency $(\eta)$ are given, which are used in the subsequent sections. Plasma power $(P)$, specific input energy (SIE), gas flow rate $(\mathrm{Q})$, and energy density $\left(\mathrm{E}_{\mathrm{d}}\right)$ can be calculated from SIE. The energy efficiency $(\eta)$ is determined using the following formulas;

$$
\text { The conversion of } \mathrm{CO}_{2}\left(\chi_{\mathrm{CO} 2}\right)=\frac{\text { Moles of } \mathrm{CO}_{2}}{\text { Initial moles of } \mathrm{CO}_{2}} \times 100
$$

The conversion of $\mathrm{CH}_{4}\left(\chi_{\mathrm{CH} 4}\right)=\underline{\mathrm{CH}}_{4}$ converted $(\mathrm{mol}) \times 100$ 


$$
\begin{aligned}
& \operatorname{SIE}(\mathrm{kJ} / \mathrm{L})=\frac{\text { discharge power }(\mathrm{kW})}{\text { Gas flow rate }(1 / \mathrm{min})} \times 60(\mathrm{~s} / \mathrm{min}) \\
& \operatorname{SIE}\left(\mathrm{J} / \mathrm{cm}^{3}\right)=\frac{\text { discharge power }(\mathrm{J} / \mathrm{s})}{\text { Gas flow rate }\left(\mathrm{cm}^{3} / \mathrm{s}\right)} \\
& \eta(\mathrm{mmol} / \mathrm{J})=\frac{\mathrm{CO}_{2}}{\text { Discharge power }(\mathrm{kW})} \\
& \eta(\%)=\frac{\mathrm{CO}_{2}}{\text { Discharge poned }(\mathrm{mol} / \mathrm{s}) \times \Delta \mathrm{H}_{\mathrm{R}}(\mathrm{kJ} / \mathrm{mol})} \times 100 \% \\
& \eta(\%)=\frac{\Delta \mathrm{H}_{\mathrm{R}}(\mathrm{kJ} / \mathrm{mol}) \times \chi_{\mathrm{CO} 2}(\%)}{\operatorname{SIE}(\mathrm{kJ} / \mathrm{l}) \times 22.4(1 / \mathrm{mol})}
\end{aligned}
$$

where $\Delta \mathrm{H}_{\mathrm{R}}$-the reaction enthalpy, $\chi_{\mathrm{CO} 2}-\mathrm{CO}_{2}$ conversion. Note that this equation is only applicable for pure $\mathrm{CO}_{2}$ splitting (at room temperature and atmospheric pressure) and the absorbed power is determined by the Lissajous method. This formula is also used for other gases, however, in these equations another $\Delta \mathrm{H}_{\mathrm{R}}$ is applied to account for both $\mathrm{CO}_{2}$ conversion and conversion of other gases in the mixture. Since SIE can also be presented as $\mathrm{J} / \mathrm{cm}^{3}\left(1 \mathrm{~kJ} / \mathrm{l}=1 \mathrm{~J} / \mathrm{cm}^{3}\right)$ or in $\mathrm{eV} / \mathrm{molec}(\mathrm{eV}$ per molecule) applying the formulas [73]:

$$
\operatorname{SIE}(\mathrm{eV} / \mathrm{molec})=\underline{\mathrm{E}_{\mathrm{d}}\left(\mathrm{J} / \mathrm{cm}^{3}\right) \times \mathrm{eV} / \mathrm{J} \times \mathrm{cm}^{3} / \mathrm{mol}} \frac{\mathrm{molec} / \mathrm{mol}}{\mathrm{mol}}
$$

For $\mathrm{CO}_{2}, \mathrm{H}_{2} \mathrm{O}, \mathrm{H}_{2}$ or $\mathrm{CH}_{4}$ conversion, calculations for the absolute conversion ( Eq. 7) and effective conversion (Eq. 8) are mostly used. The absolute conversion is calculated based on the molar flow rates of the reactants

$$
\begin{aligned}
& \chi_{\text {abs, reactant, } \mathrm{i}}=\underline{\underline{\vartheta}}_{\text {reactant, i, inlet }} \underline{\underline{\vartheta}} \text { reactant, i, outlet_- }_{-} \times 100 \\
& \vartheta \text { reactant, i, inlet }
\end{aligned}
$$

Where $\vartheta$ - molar flow rate for the reactant species, i.

The effective conversion considers the dilution effect when the feed gas mixture contains more than one gas.

$$
\chi \text { eff, reactant, i }=\frac{\chi_{\text {abs, reactant, } \mathrm{i}}-\vartheta_{\text {reactant, } \mathrm{i} \text {, inlet }}}{\sum_{\mathrm{i}} \vartheta_{\text {reactant, } \mathrm{i} \text {, inlet }}}
$$

And the total conversion is given by; 


$$
\chi_{\text {Total }}=\sum_{\mathrm{i}} \frac{\vartheta_{\text {reactant }, \mathrm{i}, \text { inlet }}}{\sum_{\mathrm{i}} \vartheta_{\text {reactant, } \mathrm{i}, \text { inlet }}} \times \chi_{\text {abs, reactant, } \mathrm{i}}=\sum_{\mathrm{i}} \chi_{\text {eff, reactant, } \mathrm{i}}
$$

The selectivity (S) and yield (Y) are calculated as:

$$
\begin{gathered}
\mathrm{S}_{\mathrm{CO}}(\%)=\frac{\mathrm{CO} \text { produced }(\mathrm{mol})}{\mathrm{CO}_{2} \text { converted }(\mathrm{mol})} \times 100 \\
\mathrm{~S}_{\mathrm{CH} 4}(\%)=\frac{\mathrm{CH}_{4} \text { produced }(\mathrm{mol})}{\mathrm{CO}_{2} \text { converted }(\mathrm{mol})} \times 100 \\
\mathrm{~S}_{\mathrm{H} 2}(\%)=\frac{\underline{\mathrm{H}}_{2} \text { produced }(\mathrm{mol})}{\mathrm{CO}_{2} \text { converted }(\mathrm{mol})} \times 100 \\
\mathrm{Y}_{\mathrm{CH} 4}=\mathrm{S}_{\mathrm{CH} 4}(\%) \times \chi_{\mathrm{CO} 2}(\%)
\end{gathered}
$$

The $\mathrm{H}_{2} / \mathrm{CO}_{2}$ molar ratio in the product is determined as:

$$
\frac{\mathrm{H}_{2}}{\mathrm{CO}_{2}}=\frac{\mathrm{H}_{2} \text { produced }(\mathrm{mol})}{\mathrm{CO}_{2} \text { produced }(\mathrm{mol})} \times 100
$$

A correlation factor is used for the equation since gas expansion as a result of $\mathrm{CO}_{2}$ splitting (R4) is not put into consideration in Eq. 7 (for details, refer to [74]). The specific input energy and energy efficiency are calculated as given in Eq. 3 and Eq. 5 respectively, using a temperature of $0{ }^{\circ} \mathrm{C}$ and a pressure of 1 atm [75-78].

\subsection{Types of non-thermal plasma}

The electrons in NTP can attain an average temperature range of 10,000-100,000 K (1-10 eV) even though the gas temperature can remain as low as room temperature. The high electron temperatures dictate the unusual chemistry of NTP [79-81]. Various non-thermal plasma methods have been employed in the conversion of $\mathrm{CO}_{2}$ depending on the applied pressure, electrode geometry, and plasma generation mechanism. The main three types of NTP for $\mathrm{CO}_{2}$ conversion are dielectric barrier discharge or silent discharge, microwave discharge and gliding arc discharge (GAD) [8287]. In addition, the following types have been experimented with as well: corona discharge (CD) 
[88], radio frequency (RF) [89], glow discharge (GD) [90, 91] capillary discharge [90, 91], and nanosecond pulse discharge [92].

\subsubsection{Dielectric barrier discharge}

Also known as a silent discharge, DBD has been experimentally investigated for more than a hundred years. DBD has been applied extensively in various technical aspects, including pollution control [93, 94], surface modification [95, 96], sterilization, using water as an electrode and for cooling [97, 98], chemical vapor deposition, ultraviolet excimer lamps, bio treatment of microorganisms [99-101], ozone generation [102, 103], and the decomposition of $\mathrm{CO}_{2}$ [104]. A typical DBD reactor has two electrodes asymmetrically positioned on both sides of a dielectric barrier material, such as quartz, glass, ceramic material or polymers [105]. The physical properties of the dielectric barrier can influence the DBD by not only limiting the number of charges but by also distributing micro discharges over the complete barrier surface area [106]. The main purpose of dielectric barrier material is to limit electric current, hence inhibiting spark formation [107, 108]. The main difference between DBD and other discharge types is that other types of plasma discharges use electrodes that are directly in contact with the plasma and discharge gas leading to corrosion and electrode etching [107, 109]. DBD applications in $\mathrm{CO}_{2}$ conversion has drawn significant consideration due to the following advantages as DBDs produce a homogenous discharge with low energy consumption $[110,111]$ and they can avoid the formation of sparks in the streamer channels. The avoidance of spark formation avoids overheating and reduces noises and local shock waves $[112,113]$. In addition, DBD has low operational cost, simple structure, feasible scalability and a proven effectiveness for many reactions [114].

The main drawback of using NTP for the conversion of $\mathrm{CO}_{2}$ is that further improvement is required to ensure that the plasma process is more competitive and attractive. Thus finding an exceptionally cost-effective and active catalyst for plasma catalytic conversion of $\mathrm{CO}_{2}$ is very important $[115$, 116]. Plasma catalytic conversion of $\mathrm{CO}_{2}$ into value-added fuels and chemicals is greatly determined by a range of plasma processing parameters, such as gas composition, feed flow rate, dielectric material, discharge gap/length, carrier gas, electrode configuration, discharge, frequency, and discharge power [117-120]. Table 1 shows a summary of the characteristics parameters of DBD $[79,81]$. 
Table 1. Typical characteristic parameters of dielectric barrier discharge [79, 81].

\begin{tabular}{lc}
\hline DBD Parameters & \\
\hline Electric field $(\mathrm{kV} / \mathrm{cm})$ & $0.1-100$ \\
Degree of ionization (variable) & $10^{-4}$ \\
Reduced field (Td) & $1-500$ \\
Electron density $\left(\mathrm{e} \AA^{-3}\right)$ & $10^{14}$ \\
Average electron energy $(\mathrm{eV})$ & $1-10$ \\
\hline
\end{tabular}

Nanosecond pulsed DBD (NP-DBD) is distinguished by higher mean electron energies, which lead to a higher rate of dissociation and higher $\mathrm{CO}_{2}$ conversion $[121,122]$. In NP-DBD, the peak plasma density can be as high as $10^{15} \mathrm{~cm}^{-3}$ with a relatively low cost of power, since NP-DBD uses a high voltage in a very short span $[123,124]$. NP-DBD in most cases is in a highly nonequilibrium condition due to comparable long excited-state relaxation timescales [125, 126]. Nonequilibrium NP-DBD has been applied in $\mathrm{CO}_{2}$ dissociation [127], aerodynamic flow control [128] and stabilizing combustion $[128,129]$. When $\mathrm{CO}_{2}$ splitting for $\mathrm{CO}$ production using an NP-DBD was carried out at a very high voltage $(15 \mathrm{kV})$ over a very short period $(10 \mathrm{~ns})$, an electrical discharge was obtained that produces as much as $0.4 \mathrm{~mJ}$ of energy and a maximum energy efficiency and conversion rate of $11.5 \%$ and $7.3 \%$, respectively, at a frequency of $30 \mathrm{kHz}$ and with a pressure variation range of $2.4-5.1 \mathrm{~atm}$ [130]. The major products obtained from the conversion of $\mathrm{CH}_{4} / \mathrm{CO}_{2}$ (1:1) using a nanosecond repetitively pulsed discharge were $\mathrm{H}_{2}, \mathrm{CO}_{2}$, solid carbon, and $\mathrm{C}_{2} \mathrm{H}_{2} .40 \%$ energy efficiency was achieved for syngas $\left(\mathrm{H}_{2}+\mathrm{CO}\right)$ production [92]. Furthermore, it was realized that NP-DBD improved the selectivity to end products $\left(\mathrm{CO}, \mathrm{H}_{2}, \mathrm{C}_{2} \mathrm{H}_{2}\right)$ at the expense of oxygenated and liquid hydrocarbon compounds [131].

\subsubsection{Gliding arc discharge}

Gliding arc discharge is a promising plasma source for the conversion of $\mathrm{CO}_{2}$ into fuels and valueadded chemicals [132-136]. GAD combines both the advantages of the non-thermal and thermal discharge systems (a transient type of discharge) [137-140]. They are generally known as 'warm' discharges, which are distinguished by a better energy efficiency compared to other forms of plasma discharge [141]. Warm plasma, examples of which include microwave discharge (MW) 
and GAD plasmas, is an intermediate case between thermal and non-thermal (cold) plasmas. The gas can attain a temperature of $\geq 1000 \mathrm{~K}$ while the electron temperature is generally $\sim 1 \mathrm{eV}$, which is conducive for populating $\mathrm{CO}_{2}$ vibrational levels. In comparison, in a $\mathrm{DBD}$ (a nonequilibrium or cold plasma) the gas is more or less at room temperature, and the electrons are heated to temperatures of $2-3 \mathrm{eV}$ by the strong electric field in the plasma $[55,142]$. Warm plasmas are more beneficial in relation to processing energy efficiency than either thermal or non-thermal plasmas.

Fig. 3 provides a schematic of the diagram of a GAD and a picture of a GAD reactor. Because GAD offers efficient vibrational excitation of chemical molecules [143-146], which is viewed as the most energy-efficient means to split $\mathrm{CO}_{2}$ molecules [146-148], the physical and chemical characteristics of GAD have been extensively explored both experimentally [148-151] and through modeling [152-157]. The GAD generates a string (weakly ionized gas) between two horn-shaped electrodes in a gradually diverging electrode gap. The gas is supplied at the electrode base, creating a potential difference between the electrodes. An electric arc plasma is established at the narrowest gap. The newly generated arc string is then moved slowly by the gas flow towards the top of the electrodes along the diverging gap, causing the arc string to gradually elongate. Eventually, the arc string elongates to a length that is no-longer sustainable, the arc is extinguished, and a new arc is ignited in the shortest electrode gap. More precisely, the arc column length (l) increases with an increase in arc voltage until the critical value $\left(U_{c r i t}\right)$ is exceeded. The arc voltage $\left(U_{a}\right)$ gradually increases with a small reduction of arc current $\left(\mathrm{I}_{\mathrm{a}}\right)$ until it attains the breakdown voltage $\left(\mathrm{U}_{\mathrm{Br}}\right)$ value of the starting gap [152]. At this moment, heat losses from the arc plasma column start to surpass the supplied energy. It is impossible to maintain the arc plasma in its local thermodynamic equilibrium state (LTE), considering its fast transition into a non-local thermodynamic equilibrium state. The arc discharge speedily cools to attain the gas temperature; however, due to the high electron temperature, which is best applicable for efficient vibrational excitation of $\mathrm{CO}_{2}$, plasma conductivity is kept constant. The discharge is systematically submitted to the ignitionlengthening-extinction cycle $[152,158,159]$. During the cycle, nearly $70-80 \%$ of energy is dissipated in the non-local thermodynamic equilibrium zone. To improve GAD applications, especially in $\mathrm{CO}_{2}$ conversion, both chemical and physical features of GAD have been widely 
examined; for instance, high-speed photography, and spectroscopic and electrical measurements $[151,152,160-163]$.

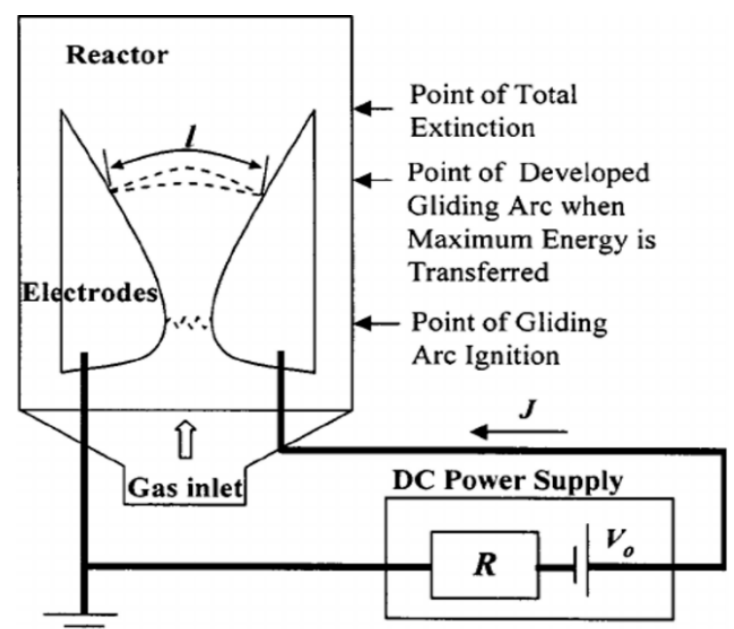

(a)

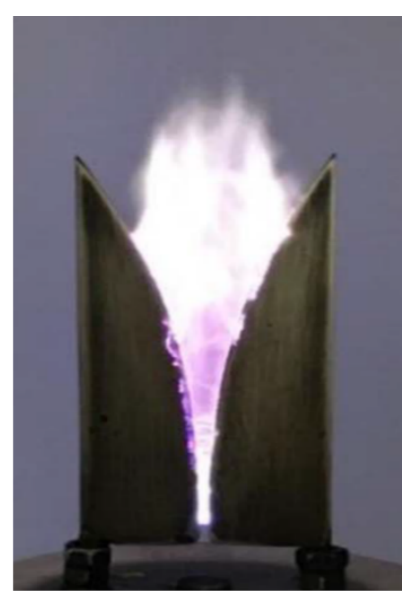

(b)

Figure 3. (a) Gliding arc, schematic diagram (b) a picture of a GAD reactor [8, 132]

The GAD, nevertheless, has some drawbacks. For example, it is less compatible with some industrial systems due to the flat $2 \mathrm{D}$ electrode geometry. Furthermore, the $\mathrm{CO}_{2}$ conversion is quite non-uniform and limited because a substantial amount of the gas does not pass through the active discharge region. In addition, in order to drag the arc, a high gas flow rate is required and hence limits gas residence time resulting in limiting $\mathrm{CO}_{2}$ conversion.

The effect of vortex flow configuration on $\mathrm{CO}_{2}$ conversion was investigated by Nunnally et al. [137] using a rotating gliding arc[164]. Comparing reverse vortex flow and forward vortex flow, a high level of thermodynamic efficiency (approximately 40\%) was attained due to 3D vortex stabilization. GAD has shown a high energy efficiency in the range of 30-35\% using reverse vortex flow at atmospheric pressure with a $\mathrm{CO}_{2}$ conversion of about $10 \%\left(\mathrm{CO}_{2}\right.$ splitting $)$. This high efficiency in GAD may be attributed to a high-temperature gradient existing between the surrounding gas and GAD, resulting in fast quenching. Li et al. [165] experimented with a combination of $\mathrm{GAD}$ with a Ni/CeO$/ \mathrm{Al}_{2} \mathrm{O}_{3}$ catalyst in a heat-insulated reactor. An energy efficiency of $86 \%$ was obtained with a $\mathrm{CO}_{2}$ conversion and $\mathrm{CH}_{4}$ conversion of $23 \%$ and $92 \%$, 
respectively. The distance of the catalyst-bed to the GAD played a role in increasing both $\mathrm{CO}_{2}$ and $\mathrm{CH}_{4}$ conversions. The Ni-based catalysts may have been reduced by the warm plasma (containing the outgoing gas) during the set-up, which may have also helped to improve the conversion of both gases.

\subsubsection{Microwave discharge}

MW discharge is created by electromagnetic waves with frequencies (f) greater than $300 \mathrm{MHz}$. MW wavelengths are in the limits of millimeters $(\mathrm{mm})$ up to several tens of centimeters $(\mathrm{cm})$. The most frequently used MW discharge frequency is $2.45 \mathrm{GHz}$. There are various kinds of MW plasma discharges, such as surface wave discharge, electron cyclotron resonance, cavity induced discharges, and freely expanding atmospheric plasma discharge torches. MW discharges are used for medical and industrial applications, and scientific usage [166, 167]. Furthermore, MW discharge was classified into four major areas of application, namely [168]: 1) plasma discharge resonance heating and current drive (high average power oscillators); 2) radio-frequency charged particle acceleration in high energy linear colliders; 3) radar and communications systems (generally moderate power); and 4) high-peak-power sources for exploratory development and weapons-effect simulation. Surface wave (SW) discharge is most regularly used for the conversion of $\mathrm{CO}_{2}[169,170]$.

MW discharge can be created either in pulse or in the continuum wave spectrum at incident MW powers ranging from several Watts $(\mathrm{W})$ to hundreds of kilowatts $(\mathrm{kW})$. The MW Discharge absorbed power is approximately $90 \%$ of the supplied incident power. Low pressure MW discharges often operate with the plasma density $\left(\mathrm{n}_{\mathrm{p}}\right)$ greater than the given critical density $\mathrm{n}_{\mathrm{c}}$, $\mathrm{nc}$ $\left(\mathrm{cm}^{3}\right) \approx 1.24 \times 10^{10} \mathrm{f}^{2}(\mathrm{GHz})[146-147]$, compared to other types of discharges. Some of the merits of MW discharge are 1) plasma generation is simple (with absorbed power level either $>100$ $\mathrm{W} / \mathrm{cm}^{3}$ or $<1 \mathrm{~W} / \mathrm{cm}^{3}$; 2) MW discharge is electrodeless, hence low maintenance cost and a wide range of operating pressures $\left(10^{-5}\right.$ Torr to atmospheric pressure); 3$)$ it has a high electric utilization efficiency (approximately $85 \%$ conversion of electric to microwave energy at a frequency of 815 $\mathrm{MHz}$ ); 4) no contamination of the gas-phase or electrode corrosion occurs during plasma generation; and 5) MW discharge can be generated in both small and large chambers (as well as 
in free space), providing great flexibility for reactor design and potential for scale-up. Besides, the MW discharge internal structure can be changed by controlling electrodynamic characteristics. The energy efficiency of MW can be improved through the realization of the interaction between the electromagnetic field and the plasma, prompting variations in generator design that can produce highly efficient MW for different plasma applications [171-177]. example schematic and image of a MW discharge are shown in Fig. 4. Fig. 5 shows the schematic for a nozzleless waveguide-supplied coaxial line-based MW plasma used for $\mathrm{CH}_{4}$ reforming.
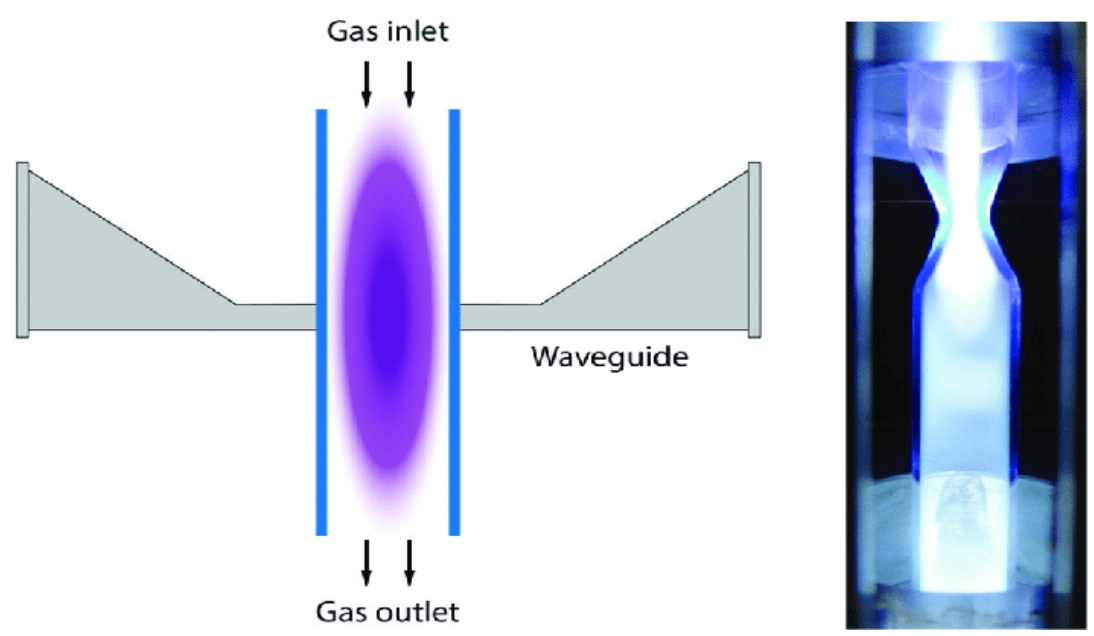

Figure 4. Schematic (left) and image (right) of a MW discharge [158] 


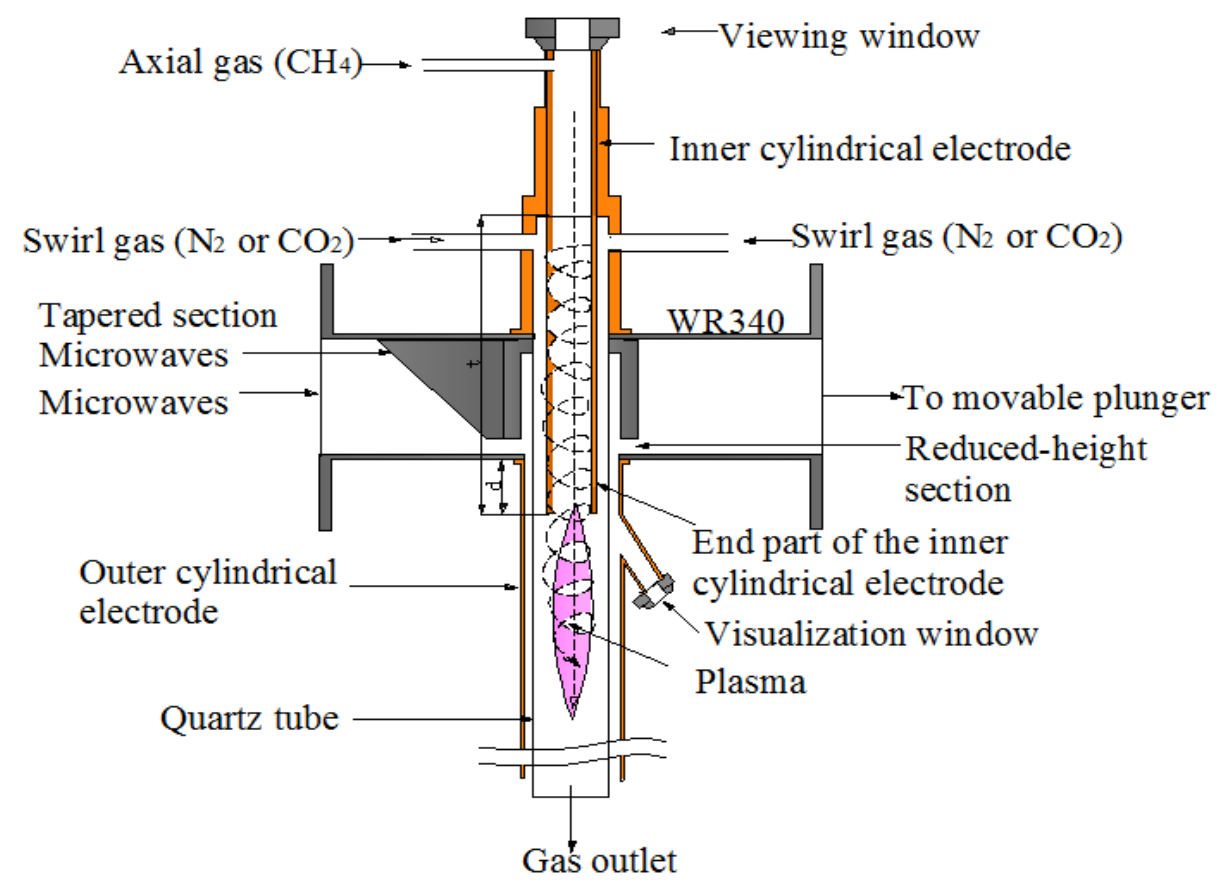

Figure 5. Schematic view of the nozzleless waveguide-supplied coaxial line-based microwave plasma source $[178,179]$.

The mechanism of MW discharge generated by a virtual cathode oscillation was investigated and it was concluded that the frequency dependence of MW power gain is affected by both the current of the modulated electron beam and oscillating electric field [180]. The major disadvantages of the MW discharge method are that it is less cost-effective and has low energy efficiency [181, 182]. Thus, continuous improvement of electrical-based systems is crucial for the commercial applications of the MW discharge method [183-186].

\subsubsection{Glow discharge (GD)}

GD is a low pressure (0.1-10 mbar) discharge normally operating between two flat electrodes. The electrons in GD are usually highly energetic with sufficient energy to dissociate, ionize, or excite any molecules or neutral atoms with which they may collide [187-189]. The glow discharge chemistry entails $\mathrm{CO}_{2}$ reduction and the formation of noticeable concentrations of additives i.e. $\mathrm{CO}, \mathrm{O}_{2}, \mathrm{OH}$, water vapor, and nitric oxides in the laser gas chamber. These additives, to a large extent, can reduce efficiency and laser output power which interferes with the kinetics of 
ionization, excitation and recombination processes [190-192]. The excitation collision results in the generation of excited species which decay to lower levels by the emission of light, leading to its characteristic name "glow" discharge [193-196]. Several reported research works focus on atmospheric pressure glow discharge (APGD) [197-199], partial discharges (pulseless discharge) [200], cold plasma processing [201] and lasers [202]. APDG has various applications in combustion, aerodynamic flow control, biomedical, surface treatment, and biological and chemical decontamination [203]. Li et al. [83] carried out DRM to syngas using APDG. The highest conversions of $90.3 \%$ for $\mathrm{CO}_{2}$ and $98.5 \%$ for $\mathrm{CH}_{4}$ (conversion ability was $12.2 \mathrm{mmol} / \mathrm{kJ}$ ) were achieved within the input power range of $49.5 \mathrm{~W} \sim 88.4 \mathrm{~W}, \mathrm{CH}_{4} / \mathrm{CO}_{2}$ of 0.43 to 1.5 , and total feed flow rate range $360 \mathrm{mLmin}^{-1} \sim 4000 \mathrm{ml} / \mathrm{min}$. This was achieved mainly due to the benefits of APDG, such as the ability to offer a vast array of chemically active species without increasing gas temperatures. An investigation conducted for $\mathrm{CO}_{2}$ reforming of $\mathrm{CH}_{4}$ using APGD attained a conversion of $83.2 \%$ and $91.9 \%$ for $\mathrm{CO}_{2}$ and $\mathrm{CH}_{4}$, respectively, under the following conditions: input power range of $240-600 \mathrm{~W}, \mathrm{CH}_{4} / \mathrm{CO}_{2}$ of 0.2 to 1.0 , and total flow of $140-500 \mathrm{ml} / \mathrm{min}$ [84]. This indicates that the electron energy distribution is not affected during the discharge even though the electron density is directly proportional to the input power. Furthermore, increasing $\mathrm{CH}_{4}$ content may lead to serious carbon deposition on electrodes. The synthetic gas produced contained a low $\mathrm{H}_{2}$ to $\mathrm{CO}$ ratio, which is highly preferentially used for liquid hydrocarbon production. The major challenge encountered was carbon deposition which led to rapid catalyst deactivation. Generally, the benefits of APGD are that continuous conversion can be attained and it is effective. However, the drawbacks are in complications involved in forming a uniform plasma in the fulllength volume of the reactor, higher voltages are needed for gas breakdown, and there can be difficulties in sustaining GD [204]. Table 2 provides a summary of GD characteristic parameters, the glow discharge pressure, electron density, degree of ionization and other parameters.

Table 2. Typical characteristics of glow discharge $[68,70,300]$

\begin{tabular}{lc}
\hline Glow Discharge Parameters \\
\hline Electric field (V/cm) & 10 \\
Degree of ionization & $10^{-6}-10^{-5}$ \\
Pressure (mbar) & $0.1 \sim 10$ \\
\hline
\end{tabular}




\begin{tabular}{lc}
\hline Reduced field (Td) & 50 \\
Electron density (e $\left.\AA^{-3}\right)$ & $10^{8}-10^{11}$ \\
Average electron energy (eV) & $0.5-2$ \\
\hline
\end{tabular}

\subsubsection{Corona discharge (CD)}

A Corona discharge (CD) is comprised of many streamers that extend from the tip of the electrode into the gas space where they eventually extinguish. The name is derived from the crown-like appearance of the streamers, which are formed when the voltage surpasses a certain value and creates a sufficiently large electrical field in the gas space surrounding the electrode for accelerated electrons to ionize gas molecules and create an electron avalanche $[205,206]$. The subsequent formation of ions by the electron avalanche creates an additional electrical field that extends the length of the streamers. An ionization zone is then formed around the electrode in which the discharges are produced. The streamers are extinguished A discharge gap $\geq 10 \mathrm{~cm}$ is highly suitable for large scale application [207]. CD is, therefore, an inhomogeneous discharge, generated without the use of dielectric [208,209]. From an industrial perspective, CD can be used in handling a large volume of gas because it can be generated at a low temperature at near to or higher than atmospheric pressure. $\mathrm{CD}$ has various industrial applications, e.g. ozone generation, $\mathrm{NO}_{\mathrm{x}} / \mathrm{SO}_{\mathrm{x}}$ reduction, destruction of toxic compounds, etc. The main advantage of the $\mathrm{CD}$ is that it can be set up relatively easily compared to other cold plasma processes [88]. The effect of $\mathrm{CD}$ and $\mathrm{Ni}$ supported catalyst was investigated for $\mathrm{CO}_{2}$ reforming of $\mathrm{CH}_{4}$ at temperature $\mathrm{T}<523 \mathrm{~K}$. A favorable rise in $\mathrm{CO}_{2}$ and $\mathrm{CH}_{4}$ was realized when the ratio of $\mathrm{CH}_{4} / \mathrm{CO}_{2}$ was 1:2 [210]. This resulted in an increase in selectivity to $\mathrm{CO}$, and fewer by-products (oxygenates and hydrocarbons) were formed. When $\mathrm{CH}_{4}$ partial oxidation was conducted in humid $\mathrm{CO}_{2}$ or $\mathrm{O}_{2}$ using a pulsed $\mathrm{CD}$, the primary products obtained were $\mathrm{C}_{2} \mathrm{H}_{4}, \mathrm{C}_{2} \mathrm{H}_{2}$ and $\mathrm{C}_{2} \mathrm{H}_{6}$, in addition to oxygen-containing hydrocarbons, namely methanol and ethanol [211]. Furthermore, ketones, methyl formate, aldehydes, and dimethyl ether were also obtained in lower concentrations; direct bond cleavage breaks down $\mathrm{CO}_{2}$.

Pulse $\mathrm{CD}$ is a promising technique using a high voltage discharge which can be controlled and operated in a wide temperature range. Other advantages of pulsed CD treatment are: insensitive 
to contamination, high destruction efficiency, compact, easy to install, no demands on pressure and temperature, and little service required [212]. However, due to the restricted area of CD, it has limited applications in environmental pollution control. To overcome this problem, dielectric packed-bed corona reactors have been developed. Table 3 provides the typical characteristic parameters of the $\mathrm{CD}$.

Table 3. Typical characteristics of corona discharge $[81,213]$

\begin{tabular}{lc}
\hline Corona Discharge Parameters & \\
\hline Electric field (V/cm) & $0.5-10$ \\
Degree of ionization: & small, variable \\
Reduced field $(\mathrm{Td})$ & $2-200$ \\
Electron density $\left(\mathrm{e} \AA^{-3}\right)$ & $10^{13}$, variable \\
Average electron energy $(\mathrm{eV})$ & $3.5-6$ \\
\hline
\end{tabular}

\subsubsection{Electron beam (EB) irradiation}

Currently, there are great interests in radiation technology applications as they offer new opportunities in dealing with environmental challenges. Matzing et al. [214] and Getoff et al. [215] reported that EB irradiation performance is comparable to the state of art techniques available for water and air pollution. Apart from environmental applications of EB radiation, it has also been used in modifying various solid catalysts, such as $\mathrm{CuO}-\mathrm{Al}_{2} \mathrm{O}_{3}$ [216, 217], leading to significant changes in catalytic properties (improving catalyst performance). Jun et al. [218] investigated the enhancement of DRM by application of EB irradiation. The conversion of $\mathrm{CO}_{2}$ and $\mathrm{CH}_{4}$ after EB irradiation treatment (2 MGy) was 5-10\% higher compared to untreated catalyst. The effect of EB irradiation on the conversion of $\mathrm{CO}_{2}-\mathrm{CH}_{4}$ mixture $\left(\mathrm{CH}_{4}: \mathrm{CO}_{2}: \mathrm{He}=1: 1: 1\right)$ into syngas $\left(\mathrm{H}_{2} / \mathrm{CO}\right)$ at $500{ }^{\circ} \mathrm{C}$ over $\mathrm{Ni} / \gamma-\mathrm{Al}_{2} \mathrm{O}_{3}$ catalysts was investigated. This validated the fundamental investigation carried out on radiation-induced $\mathrm{CO}_{2}$ utilization for the production of value-added products [219]. The main limitation in electron beam irradiation assisted $\mathrm{CO}_{2}$ dissociation is scalability for industrial applications due to low efficiency, the inability to sustain large mass flow rates $[55,163$, 220-222], and low $\mathrm{CO}_{2}$ conversion efficiency [223]. 


\subsubsection{Micro hollow cathode discharge (MHCD)}

MHCD is a specific kind of microplasma in which several hundred-micrometer diameter holes are drilled through an anode-dielectric-cathode structure. MHCD is an up-and-coming technique for producing a stable, non-equilibrium plasma discharge in a small volume at high pressure [224, 225]. Due to the high density, a large number of active species and accelerated radiation are produced by the MHCD [226]. The region of stability occurs at a power density of approximately $100 \mathrm{kWcm}^{-3}$ [227]. Taylan et al. [228] studied $\mathrm{CO}_{2}$ dissociation using MHCD plasma reactor. The maximum energy conversion efficiency of $14 \%$ was achieved at a specific energy input of $1.1 \mathrm{eV} /$ mole, whereas the maximum $\mathrm{CO}$ yield of $10.5 \%$ was obtained at a specific energy input of $4 \mathrm{eV} / \mathrm{mole}$, indicating that MHCD is a promising technique. MHCD finds it's applications in different fields, namely: environmental pollution control [229, 230], medical fields (cancer cell treatment and sterilization) [231], light sources [232], optical electromechanical systems [233] materials surface treatment [234], micro propulsion [235], and laser applications [236]. There has been increased interest in MHCDs due to their ability to operate at sub-atmospheric pressure and at atmospheric pressure [237].

\subsubsection{Spark discharge (SD)}

A SD develops when the electric field strength between the electrodes surpasses a certain threshold value in $\mathrm{v} / \mathrm{cm}$. This causes a short-lived rise in ion concentration between the two points, transiently allowing the gases between the electrodes to act as an electrical conductor [238]. The $\mathrm{SD}$ in an adjustable reactor highly promotes the conversion of $\mathrm{CO}_{2}$ and $\mathrm{CH}_{4}$ into syngas at lowmedium power[239]. An investigation of DRM using SD attained a $\mathrm{CO}_{2}$ conversion of $65 \%$ and $\mathrm{CH}_{4}$ conversion of $71 \%$ at an input power of $20 \mathrm{~W}$, a $\mathrm{CO}_{2} / \mathrm{CH}_{4}$ molar ratio of $1: 1$ and a flow rate of $100 \mathrm{ml} / \mathrm{min}$. The selectivities to $\mathrm{CO}$ and $\mathrm{H}_{2}$ attained were $86 \%$ and $78 \%$, respectively, and the energy efficiency was $2.3-2.4 \mathrm{mmol} / \mathrm{kJ}$ [240]. A greater discharge stability was reported for 1:1 $\mathrm{CO}_{2} / \mathrm{CH}_{4}$ compared to when ratio was increased to 1.5 . This was because a reverse water gas shift (RWGS) reaction occurred at a 1.5 ratio, favoring formation of $\mathrm{CO}$ and producing $\mathrm{H}_{2} \mathrm{O}$ as a byproduct which affects the discharge stability. Fig. 6 shows a graph of all the data collected from 
the literature on $\mathrm{CO}_{2}$ splitting using different plasma discharges, showing the energy efficiency as a function of the conversion.

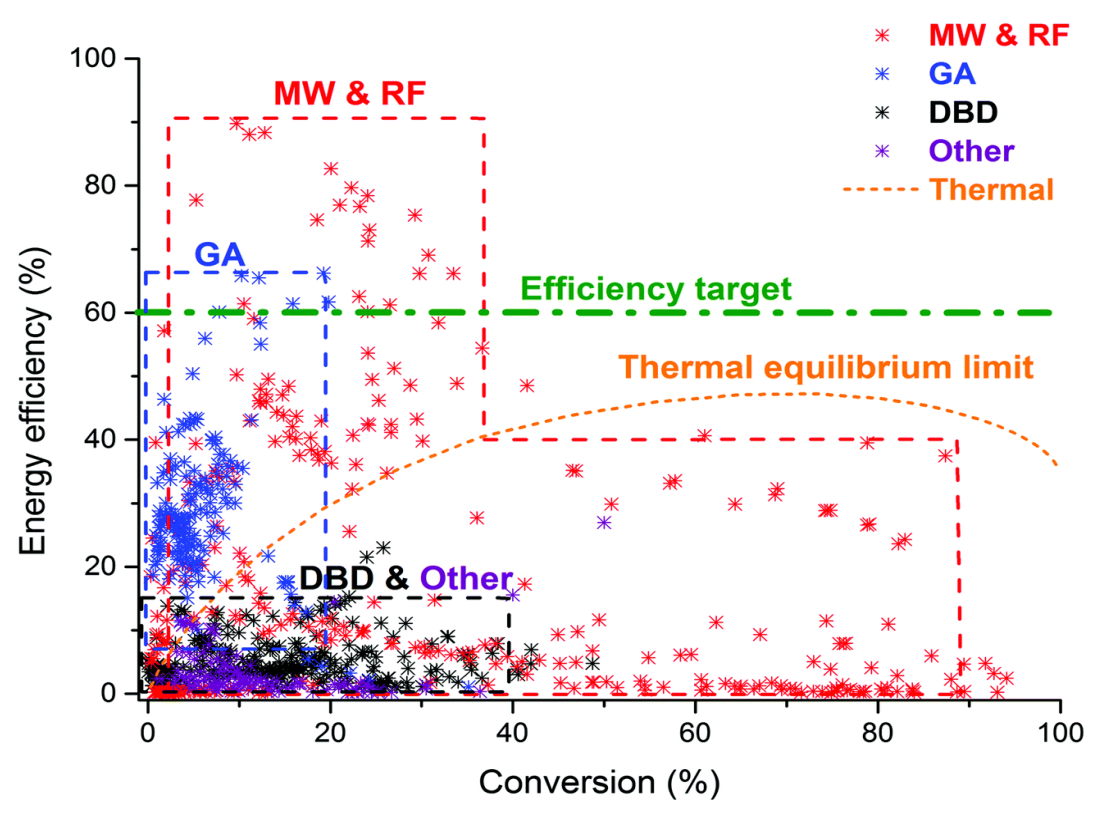

Figure 6. A summary of all the data collected from the literature on $\mathrm{CO}_{2}$ splitting using different plasma discharges, showing the energy efficiency as a function of the conversion. The thermal equilibrium limit and the $60 \%$ efficiency target are also indicated [158].

\subsubsection{Radio frequency (RF) discharges}

RF electromagnetic fields can be applied in the generation of weakly ionized plasma at low pressures, generally in the range $1-103 \mathrm{~Pa}$. At higher pressures, the collision frequency increases leading to change in the properties of the RF discharge, resulting in a discharge approaching a thermal regime when close to atmospheric pressure. In most industrial applications of RF discharges, a frequency of $13.56 \mathrm{MHz}$ and a wavelength of $22 \mathrm{~m}$ are commonly used [241]. Homogenous plasmas are formed by the RF discharge method as a result of the large wavelength corresponding to the size of the discharge chamber.

In the 1970 s and 1980s, the use of RF discharge in the conversion of $\mathrm{CO}_{2}$ was already widely researched both theoretically and experimentally. However, it regained much interest with the increased environmental challenges due to anthropogenic $\mathrm{CO}_{2}$ emissions [55, 242]. RF normally operates within a 1-100 MHz frequency range, leading to a corresponding wavelength in the range of 300-3 m, which is greatly exceeding the plasma reactor dimensions. The decomposition of $\mathrm{CO}_{2}$ 
and $\mathrm{CH}_{4}$ molecules is a result of direct electron collision by excitation of an unstable electronic state. In RF, inductive or capacitive coupling can be used, leading to inductively or capacitively coupled plasma. Some of the applications include plasma etching, thin film deposition, use in mass spectrometry as an ion source, and in materials sputtering [158] in addition to $\mathrm{CO}_{2}$ conversion applications [243-248]. The advantage of using $\mathrm{RF}$ discharge for $\mathrm{CO}_{2}$ conversion applications is its ability to obtain high electron densities at a low gas temperature [249-252].

3. Plasma catalysis development

\subsection{Plasma catalysis configurations}

The two main combinations of plasma-assisted catalysis are in-plasma catalysis (IPC) and postplasma catalysis (PPC) as illustrated in Fig. 7.

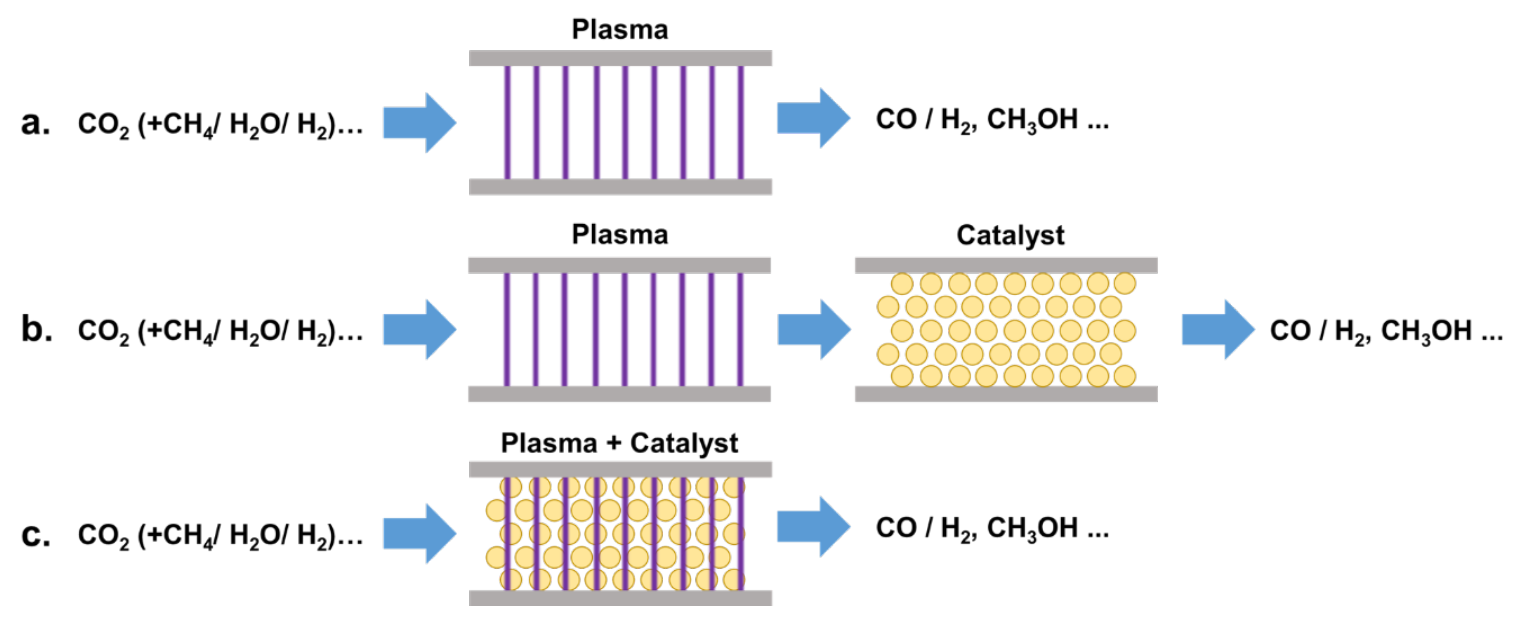

Figure 7. Schematic of the different plasma-catalyst configurations: (a) NTP only (without a catalyst); (b) Post-plasma catalysis; and (c) In-plasma catalysis [158, 253, 254].

In the PPC system, the end-products and the long-lived intermediate species produced in the plasma will interact with the catalyst, which is positioned downstream of the discharge [170, 255]. In the IPC configuration, the catalyst is situated in the plasma discharge zone and so it can interact with all the short-lived species produced in the plasma, e.g. radicals, electrons, excited species, radicals, and photons. In addition, due to its position inside the discharge zone, the catalyst properties are influenced by the plasma discharge and vice versa, as illustrated in Fig. 7 (c). Additionally, for plasma-catalytic $\mathrm{CO}_{2}$ conversion, the preparation techniques and catalysts 
modification by plasma treatment is gaining increased attention, particularly for catalysts with low thermal stability [256-259].

\subsection{Interactions and synergies between non-thermal plasma and catalysis}

Interesting interactions between the catalyst and plasma for $\mathrm{CO}_{2}$ conversions generally results in the increase of $\mathrm{CO}_{2}$ conversion, product yield, energy efficiency, and product selectivity. The interactions between catalysts and plasma are commonly referred to as "synergy" [260]. It is the supernumerary effect of combining plasma and a catalyst (effect of catalyst plus plasma is greater than the sum of individual effects) [261, 262]. Fig. 8 and Fig. 9 illustrate the plasma catalysis synergetic effect, i.e. combining plasma with $\mathrm{Cu}-\mathrm{Ni} / \mathrm{Al}_{2} \mathrm{O}_{3}$ in DRM (Fig. 8).

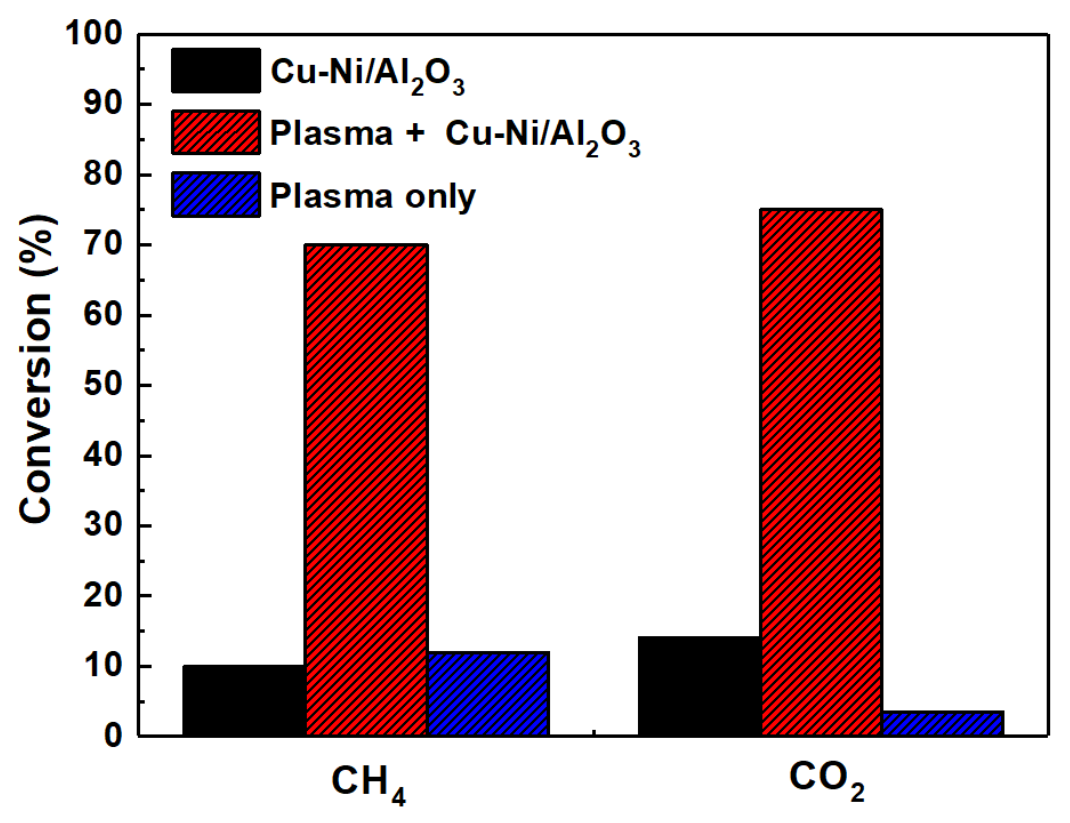

Figure 8. Maximum $\mathrm{CH}_{4}$ and $\mathrm{CO}_{2}$ conversion in DRM using plasma-only, thermal catalysis, and plasma catalysis. The improvement in the conversion of both gases due to the synergy of plasma catalysis is clearly illustrated.[263]. 


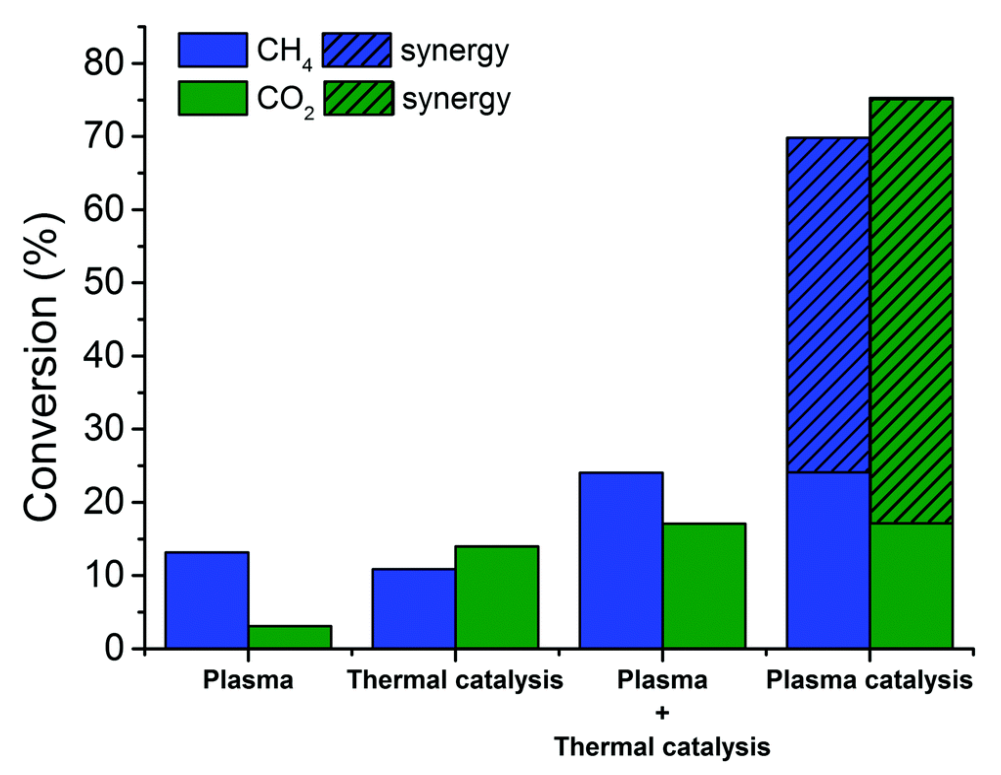

Figure 9. Demonstration of the improvement in $\mathrm{CH}_{4}$ and $\mathrm{CO}_{2}$ conversion due to the synergy of plasma-catalysis for the DRM $[158,263]$

It is substantial to differentiate the two main effects of combining catalysts with the plasma, including the physical and chemical effects. The chemical effects are responsible for the improved selectivity of the targeted products. At the same time, the physical effects are the foundation for improved energy efficiency. Meanwhile, for pure $\mathrm{CO}_{2}$ splitting, primarily $\mathrm{O}_{2}$ and $\mathrm{CO}$ are formed. Therefore, the main added value of the catalyst is for energy efficiency improvement. Notwithstanding, $\mathrm{CO}_{2}$ conversion can also be increased by chemical effects (e.g. enhanced dissociative chemisorption) as a result of catalyst acid/basic sites. For reactions involving $\mathrm{CO}_{2}$ and other reactants (e.g., $\mathrm{H}_{2} \mathrm{O}, \mathrm{H}_{2}$ ), such as in DRM reactions, the catalyst allows modifying selectivity to targeted products, although it needs to be realized that both effects are interdependent and cannot always be separated [255, 259]. These complex interactions/interdependence effects can be separated into two categories, namely: 1) the effects of plasma on the catalyst and 2) the effects of the catalyst on the plasma, as illustrated in Fig. 10.

It is worth noting that the induced changes and the effects due to plasma catalyst reactions are closely related. The modification of catalyst electronic properties is as a result of morphological changes, and these cause changes in chemical properties. The plasma effects on the catalysts are: (i) surface structure and morphological changes in the catalyst resulting in improved dispersion and larger active surface area [264, 265]. For example, Guo et al. [266] noted that the catalyst 
surface area increased as a result of plasma catalyst reactions and the number of corner atoms, vacancies, and edges of manganese oxide increased at the surface leading to improved plasma reactivity; (ii) modification of reaction pathways due to the availability of a wide range of active species; (iii) lower activation barriers and higher pre-exponential factors as a result of vibrationally excited plasma species, which may lead to non-adiabatic barrier crossings; (iv) formation of catalyst surface hot spots due to small micro-discharges; (v) collision-induced surface chemistry [267]; (vi) chemical and electronic changes on the catalyst surface that may change the catalyst oxidation state leading to a change in the catalyst work-function. This may be attributed to the presence of current or voltage altering the work-function of the catalyst [158, 255, 268, 269]. Khoja et al. [270] noted that surface chemistry is the most pertinent mechanism while discussing the synergetic effect in the DBD reactor since the plasma-catalytic effect depends on the DRM-DBD surface chemistry. This illustrates the delivery mechanism of the reactive species and the removal of unwanted molecules from the surface, which regulates the activity of the DRM process. DRMDBD surface chemistry can be divided into different categories, such as kinetic energy reactions or gas molecules with internal energy, photon-induced surface reactions, adsorption of charge carriers, collision-induced surface reactions, adsorption of natural species, and surface charging. Before the dissociation process, the gas molecules are organized according to their vibrational or translational energy. This occurrence is usually known as dissociative chemisorption and molecular physisorption.

Some effects of plasma on the catalyst are closely related to the effects of catalysts on plasma, e.g. improved electric field, the formation of catalyst hot spots due to micro discharges in the catalysts, and changes in discharge type [255]. Presumably, the most frequently researched effect of the catalyst on plasma is the electric field improvement near the surface of the catalyst using DBD. Another effect of the catalyst on the plasma is the alteration in the discharge type as a result of the development of surface discharge and vibrationally excited species. The influence of catalyst on plasma is particularly important for GAD and MW since the amount of energy that is deposited in vibrational excitations can be adjusted either on the catalyst-coated pellets/dielectric beads or on the catalyst surface. Generally, the discharge mode is filamentary discharge formation. Nevertheless, the discharge volume is decreased when fully packing the discharge zone of a DBD reactor, leading to a change in the discharge mode - generally from a filamentary discharge to a 
surface discharge — which in the long run leads to a decrease in $\mathrm{CO}_{2}$ and $\mathrm{CH}_{4}$ conversion in DRM $[271,272]$.

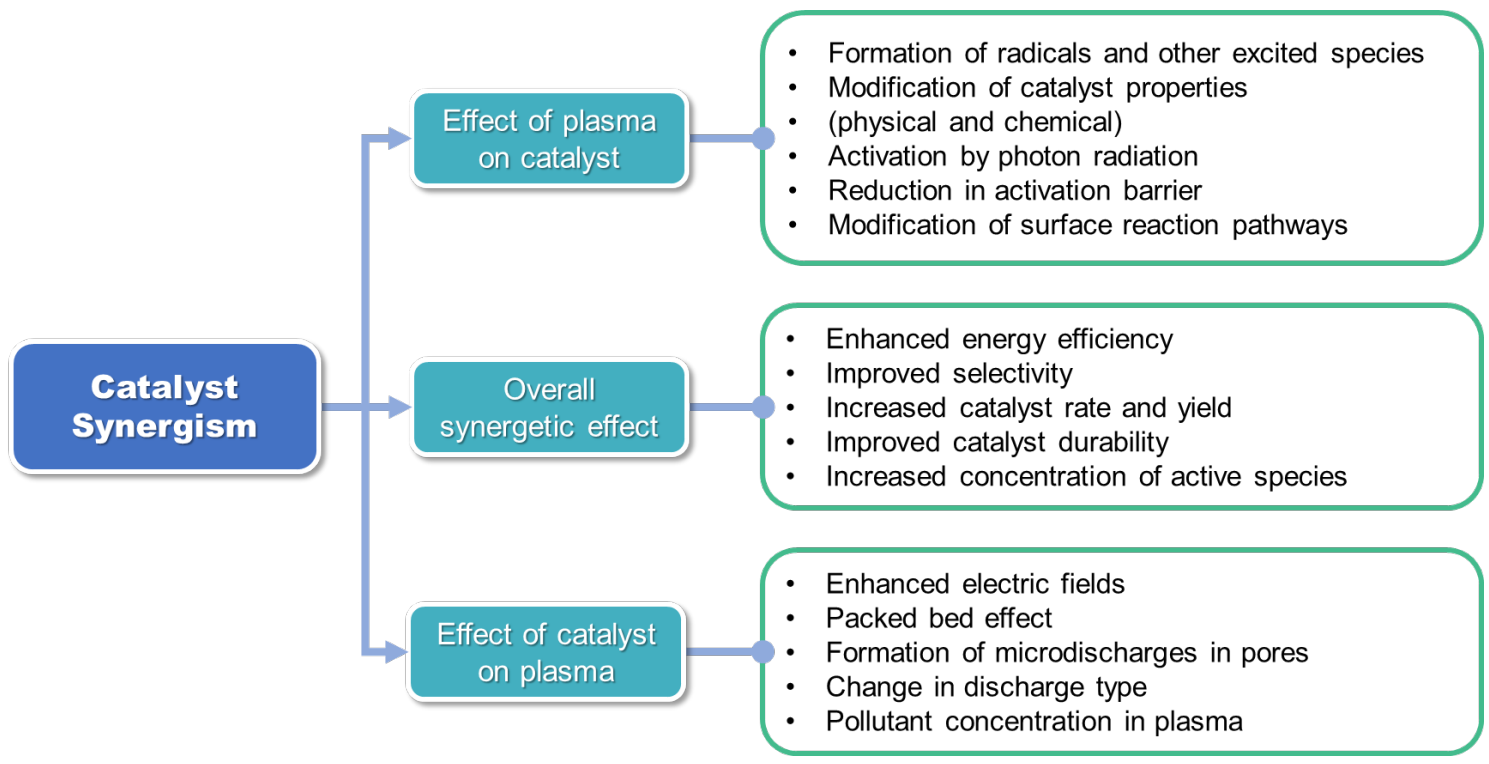

Figure 10. An overview of the possible effects of the catalyst on the plasma and vice versa, possibly leading to synergism in plasma-catalysis[255, 269, 272].

\section{Plasma $\mathrm{CO}_{2}$ conversion}

\subsection{Plasma $\mathrm{CO}_{2}$ conversion without catalyst}

Plasma has the potential to enable thermodynamically unfavorable chemical reactions to occur on the basis of its non-equilibrium properties, low-power requirement and its capacity to induce physical and chemical reactions at a relatively low temperature [273]. Numerous works have been conducted on the application of plasma technology in relation to $\mathrm{CO}_{2}$ conversion. Nunnally et al. [137] reported an energy efficiency and a conversion of $43 \%$ and $18 \%$, respectively, for $\mathrm{CO}_{2}$ splitting. The level of efficiency attained may be accredited to non-equilibrium $\mathrm{CO}_{2}$ excitation and the high-temperature gradient that exists between GAD and the surrounding gas, leading to fast quenching. Tu et al. [91] attained an energy efficiency of $60 \%$ and a conversion in the range of 8$16 \%$ was reported for DRM using a GAD. The result indicated that the energy efficiency of DRM using GAD is in an order of magnitude greater than that for DBD processing or CD. This is mainly because of the higher electron density (approximately 1023 per cubic meters) generated in the GAD. Lu et al. [274] studied $\mathrm{CO}_{2}$ conversion at low temperature and atmospheric pressure in a DBD reactor. The results obtained for the system at $600{ }^{\circ} \mathrm{C}$ without a catalyst were $41 \% \mathrm{CH}_{4}$ 
conversion and $55 \% \mathrm{CO}_{2}$ conversion. $\mathrm{CO}_{2}$ dissociation in an inductively coupled $\mathrm{RF}$ plasma and MW plasma was carried out at a low gas pressure with both systems exhibiting the features of NTP. The maximum energy efficiency attained was 59.3\% [275]. For $\mathrm{CO}_{2}$ reduction in pure $\mathrm{CO}_{2}$ and $\mathrm{CO}_{2}+\mathrm{O}_{2}$ with a flow rate of $100 \mathrm{ml} / \mathrm{min}$ using a wire to cylinder reactor operated in the range of $4.5-6.5 \mathrm{kV}$ at a negative polarity without catalyst, the conversion rate of $\mathrm{CO}_{2}$ to $\mathrm{CO}$ was very low [396]. However, increased $\mathrm{CO}$ production was observed when the $\mathrm{O}_{2}$ percentage was raised in the gas mixture. Similarly, when $\mathrm{CO}_{2}$ decomposition using direct current wire-plate $\mathrm{CD}$ was investigated, the maximum $\mathrm{CO}_{2}$ decomposition achieved was $10.91 \%$ for a flow rate of $30 \mathrm{ml} / \mathrm{min}$ [276]. This confirmed that direct current $\mathrm{CD}$ plasma can lead to higher conversion of $\mathrm{CO}_{2}$ into $\mathrm{O}_{2}$ and $\mathrm{CO}$. The low discharge power and higher flow rates are essential in transforming electric energy into chemical energy in $\mathrm{CO}_{2}$ molecules [276]. When $\mathrm{CO}_{2}$ conversion was conducted using a coplanar DBD without a catalyst, the highest $\mathrm{CO}_{2}$ conversion of $1 \%$ was attained at $0.190 \mathrm{~kJ} / \mathrm{L}$. In addition, the highest $\mathrm{CO}$ yield of $0.7 \%$ was obtained at a specific input energy of $0.210 \mathrm{~kJ} / \mathrm{L}$ : a clear indication that energy efficiency can be increased by the use of diluted $\mathrm{CO}_{2}$ in plasma operation [277]. The highest energy efficiency achieved so far for MW is $90 \%$ at a pressure range of 100 Torr-200 Torr [55]. Table 4 provides a summary of the results obtained by various works on plasma $\mathrm{CO}_{2}$ without a catalyst.

Table 4. Plasma $\mathrm{CO}_{2}$ conversion without a catalyst

\begin{tabular}{cccccc}
\hline Plasma Type & $\chi(\%)$ & $\eta(\%)$ & SIE $(\mathrm{eV} /$ molecule $)$ & SIE $\left(\mathrm{J} / \mathrm{cm}^{3}\right)$ & Ref. \\
\hline DBD & 30 & 1 & 87 & 375 & {$[46]$} \\
DBD & 18 & 3.8 & 13 & 45 & {$[278]$} \\
DBD & 14.3 & 8 & 5.2 & 22.4 & {$[279]$} \\
CD & 11 & 2 & 16 & 69 & {$[280]$} \\
GAD & 4.3 & 46 & 0.3 & 1.3 & {$[137]$} \\
GAD & 15 & 19 & 2.3 & 9.9 & {$[77]$} \\
RF & 20 & 3 & 19 & 82 & {$[244]$} \\
MW & 10 & 20 & 1.4 & 6 & {$[115]$} \\
MW & 10 & 90 & 0.3 & 1.3 & {$[281]$} \\
MW & 80 & 6 & 39 & 168.1 & {$[282]$} \\
MW & 20 & 20 & 2.9 & 12.5 & {$[283]$} \\
\hline
\end{tabular}




\begin{tabular}{lccccc}
\hline MW & 20 & 20 & 3 & - & {$[64]$} \\
MW & 83 & 24 & 10.3 & - & {$[284]$} \\
MW & 47 & 35 & 3.9 & - & {$[284]$} \\
MW & 11 & 51 & 0.6 & - & {$[284]$} \\
MW & 9 & 50 & 0.9 & - & {$[285]$} \\
MW & 3 & 82 & 0.1 & - & {$[285]$} \\
\hline
\end{tabular}

\subsection{Plasma-catalytic $\mathrm{CO}_{2}$ conversion}

The combination of NTP with a catalyst is a promising solution for $\mathrm{CO}_{2}$ conversion [286]. Integrating NTP with catalysts can improve the energy efficiency of the reaction by more than $60 \%$, generate UV emission, enhance the formation of both short-lived radicals and long-lived intermediate species $(100 \mu \mathrm{s})$ [256], and enable catalyst surface modification [107]. The incorporation of different catalysts in the plasma zone is frequently conducted with NTP for DRM in order to attain a high conversion rates and improved $\mathrm{H}_{2}$ selectivities, while reducing the amount of carbon deposition [287-289]. DRM using Pt-Ni/ZSM-5 prepared via the impregnation method was conducted and the results were compared with those attained from theoretical conversions without catalyst [290]. It was discovered that the amount of nickel precursor plays a crucial role in both the surface and catalytic properties, especially on bimetallic catalysts. The improved catalytic activity and stability achieved when using bimetallic catalysts was linked to the increased nickel dispersion.

In a study of $\mathrm{CO}_{2}$ conversion at low temperature and atmospheric pressure using a DBD reactor, the conversion obtained using a plasma $/ \mathrm{g}-\mathrm{C}_{3} \mathrm{~N}_{4}$ catalyst was twice that achieved when using the plasma without the $\mathrm{g}-\mathrm{C}_{3} \mathrm{~N}_{4}$ catalyst. In addition, incorporating the $\mathrm{g}-\mathrm{C}_{3} \mathrm{~N}_{4}$ catalyst into the plasma system improved the energy efficiency by $157 \%$ [274]. This was due to the injection of high energy electrons into the conduction band of $\mathrm{g}-\mathrm{C}_{2} \mathrm{~N}_{4}$ from the plasma that then participated in the conversion of $\mathrm{CO}_{2}$ adsorbed on the surface of the catalyst to $\mathrm{CO}_{a d}$ and $\mathrm{O}_{\mathrm{ad}}$. The high voltage was found to significantly enhance the separation of holes and photogenerated electrons on the catalyst surface, while the $\mathrm{g}-\mathrm{C}_{3} \mathrm{~N}_{4}$ catalyst modified the plasma discharge mode to produce a more uniform discharge. Michielsen et al. [291] showed the impact of catalyst materials and packing on $\mathrm{CO}_{2}$ 
conversion in a DBD plasma. The synergy created between the plasma and catalyst lowered the catalyst operating temperature, improved the catalytic activity, stability, the yield, selectivity, and energy efficiency of the process during $\mathrm{CO}_{2}$ conversion. The highest $\mathrm{CO}_{2}$ conversion and energy efficiency obtained was $25 \%$ and $4.5 \%$, respectively, using $\mathrm{BaTiO}_{3}$ as a catalyst. This work showed that altering the catalyst active sites and adjusting the support properties (e.g. packing and material) has huge potential to improve the performance of a packed bed plasma reactor for conversion of $\mathrm{CO}_{2}$. It was observed by Mei et al. that when $\mathrm{Ni} / \mathrm{Al}_{2} \mathrm{O}_{3}$ was used for DRM in a cylindrical DBD reactor, the yield of the targeted products $\left(\mathrm{CO}+\mathrm{H}_{2}\right)$ were notably improved compared to reactions using catalyst alone or NTP alone [49]. This was attributed to the great potential and synergy generated between the NTP and the catalyst, which lowered the catalyst operating temperature and improved the catalytic stability and activity. As a result, the conversion of reactants, the selectivity of products, and the energy efficiency were significantly improved, which also improved product yield. Table 5 provides a summary of various catalysts used in plasma-catalytic $\mathrm{CO}_{2}$ conversion.

Table 5. Summary of various catalysts used in plasma-catalytic $\mathrm{CO}_{2}$ conversion

\begin{tabular}{|c|c|c|c|c|c|}
\hline Catalyst & $\begin{array}{c}\text { Catalyst } \\
\text { weight } \\
(\mathrm{g})\end{array}$ & Power (W) & $\begin{array}{c}\mathrm{CH}_{4} \\
\text { conversion } \\
(\%)\end{array}$ & $\begin{array}{c}\mathrm{CO}_{2} \\
\text { conversion } \\
(\%)\end{array}$ & Ref. \\
\hline $\mathrm{g}-\mathrm{C}_{3} \mathrm{~N}_{4}$ & 0.2 & 40 & - & 12 & {$[274]$} \\
\hline $\mathrm{LaNiO}_{3} @ \mathrm{SiO}_{2}$ & 0.2 & 150 & 88 & 78 & {$[292]$} \\
\hline $\mathrm{Pt} 12 \mathrm{Ni}$ & 0.05 & 34.6 & 54 & 73 & {$[290]$} \\
\hline $\begin{array}{l}\mathrm{K}-\mathrm{Ni} / \mathrm{MgO}- \\
\mathrm{ZrO}_{2}\end{array}$ & 0.2 & - & 80 & 88 & {$[293]$} \\
\hline $\mathrm{BaZr}_{0.75} \mathrm{~T}_{0.25} \mathrm{O}_{3}$ & 4.2 & - & 58 & 43 & {$[294]$} \\
\hline $\mathrm{BaTiO}_{3}$ & 0.3 & 100 & - & 25 & {$[291]$} \\
\hline $\mathrm{Ni} / \mathrm{Al}_{2} \mathrm{O}_{3}$ & 0.25 & 50 & 18 & 13 & {$[295]$} \\
\hline Zeolite & 1 & 74 & 52 & 50 & {$[296]$} \\
\hline
\end{tabular}


The two major types of catalysis used in plasma catalytic process are noble metal-based catalysis (e.g. Rh- and $\mathrm{Ru}-$ based catalysis) and transition metal-based catalysis (Ni-based catalysis, $\mathrm{Cu}-$ and Fe- based catalysis). Noble metal-based catalysis is efficient for the formation of formates and formic acids, but is not suitable for industrial applications due to the high costs of noble metals [297]. Transition metal-based catalysts, however, are much cheaper, though they generally have problems with low selectivity and low yields. It is essential, therefore, that advancements are made to improve the catalytic systems in order for the plasma catalytic process to become economically feasible $[9,158]$.

\subsection{1 $\mathrm{CO}_{2}$ dissociation to $\mathrm{CO}$ and $\mathrm{O}_{2}$}

Much interest has been drawn to $\mathrm{CO}_{2}$ dissociation into $\mathrm{CO}$ and $\mathrm{O}_{2}$. It is worth noting that the reaction is unattainable at low temperatures with commercially available catalysis, although $\mathrm{CO}$ is a crucial chemical feedstock for fuel synthesis and production of other chemicals [30, 41, 257]. The direct decomposition of $\mathrm{CO}_{2}$ could be an interesting method to valorize $\mathrm{CO}_{2}$ and eliminate side product formation from hydrocarbons [1,298]. NTP enhances the highly endothermic reaction (R4). Experiments and modeling have been conducted by various researchers using different kinds of plasmas. DBDs (with coaxial DBD reactor being the most used reactor) [46, 299, 300], MW [169], and GAD [301] are the most commonly researched. The effects of NTP on the system can be related to the following reactions: electronic excitation of molecules, joule effect (gas heating) due to vibrational excitation, ionization, and direct dissociation of the $\mathrm{CO}_{2}$ molecules by electrons (R5 - R8).

$\mathrm{e}+\mathrm{CO}_{2} \rightarrow \mathrm{e}+\mathrm{CO}_{2}\left(v^{*}\right)$

$\mathrm{e}+\mathrm{CO}_{2}\left(v^{*}\right) \rightarrow \mathrm{e}+\mathrm{CO}+\mathrm{O}$

$\mathrm{e}+\mathrm{CO}_{2} \rightarrow \mathrm{CO}_{2}^{+}+\mathrm{e}+\mathrm{e}$

$\mathrm{e}+\mathrm{CO}_{2} \rightarrow \mathrm{CO}+\mathrm{O}+\mathrm{e}$

$v^{*}$ is the vibrationally excited state; approximately $97 \%$ of the total NTP energy can be transmitted to vibrationally excited state $\mathrm{CO}_{2}$ if the NTP discharge has an electron temperature range of 1-2 
$\mathrm{eV}$, or a reduced electric field $(\mathrm{E} / \mathrm{N})$ of 20-40 $\mathrm{Td}[302,303]$. For temporary and spatially transient DBD plasmas, E/N is greatly determined by the microdischarge (typically greater than $200 \mathrm{Td}$ ). Using DBD, the energy efficiency for $\mathrm{CO}_{2}$ conversion is usually in the range of 4-8\% [47].

$\mathrm{CO}_{2}$ dissociates by collision with energetic electrons, resulting in the formation of $\mathrm{CO}, \mathrm{O}_{2}$, and $\mathrm{C}$ via various reactions subject to the energy level of the electrons [1,291]. The most crucial parameter in $\mathrm{CO}_{2}$ dissociation is the specific input energy as it affects both the energy efficiency and the $\mathrm{CO}_{2}$ conversion [117]. When specific input energy was reduced, the energy efficiency improved to $9 \%$ and a corresponding drop in conversion to $8 \% . \mathrm{CO}_{2}$ dissociation has been conducted in packed bed DBD reactors using the following catalysts: $\mathrm{Pd}, \mathrm{Ag}, \mathrm{Ni}$, coated with $\mathrm{Al}_{2} \mathrm{O}_{3}$ support [291] or zeolite $3 \mathrm{~A}$. Zeolite $3 \mathrm{~A}$ enhanced selectivity towards hydrogen; the shape selectivity resulted in the formation of liquid hydrocarbons $\left(\mathrm{C}_{\mathrm{x}} \mathrm{H}_{\mathrm{y}}\right)$ [304]. The synergetic effects between the catalysts and plasma depend on the variation of plasma characteristics as a result of the catalyst material and packing. A possible negative or positive effect, therefore, hinges on the following: changes in produced plasma species, discharge type, discharge length, discharge power, sorption effects, electric fields, etc. [295]. It was realized that the main parameter that affects process energy efficiency was the flow rate when using a cylindrical DBD for $\mathrm{CO}_{2}$ conversion [117] . At the same time, an increase of discharge power and discharge length increased the $\mathrm{CO}_{2}$ conversion. Furthermore, the applied frequency had an insignificant effect on the energy efficiency and also on the conversion. Nonetheless, the plasma appears more filamentary at high frequency (75 kHz) in comparison to low frequency $(6 \mathrm{kHz})$. The effects of carrier gas $\left(\mathrm{N}_{2}, \mathrm{He}\right.$ and $\left.\mathrm{Ar}\right)$ in $\mathrm{CO}_{2}$ dissociation via NTP has also been investigated. When $\mathrm{Ar}$ and $\mathrm{He}$ were used, an increase in $\mathrm{CO}_{2}$ conversion was recorded. However, the effective conversion was reduced due to less $\mathrm{CO}_{2}$ in the mixture, hence inefficiency in counteracting the drop in $\mathrm{CO}_{2}$ fraction $[126,127,151,223]$. It has been noted that the addition of carrier gas resulted in increased costs. DBD has been shown to be successful in the absence of carrier gas [46]. It has been found that the most critical parameter is the gas flow rate as it affects $\mathrm{CO}$-yield and the conversion of $\mathrm{CO}_{2}$. Optimization of the dielectric material and reactor geometry are some of the ways of improving energy efficiency and $\mathrm{CO}_{2}$ conversion, in addition to the introduction of a catalyst bed to the discharge zone [46]. Electron impact dissociation has been singled out as the dominant pathway for $\mathrm{CO}_{2}$ decomposition in DBD plasma, whereas in GAD and MW discharges, a more energy-efficient vibrational excitation pathway plays a crucial role.[305]. Fig. 11 shows reaction pathways demonstrating the $\mathrm{CO}_{2}$ 
splitting formation and mechanisms. The predominant $\mathrm{CO}_{2}$ loss mechanism is dissociation upon collision with electrons (e), forming $\mathrm{CO}$ and $\mathrm{O}$. As shown from the thickest arrow line, no clear contrast is made between the ground state $\mathrm{CO}_{2}$ molecules and the vibrationally excited levels.

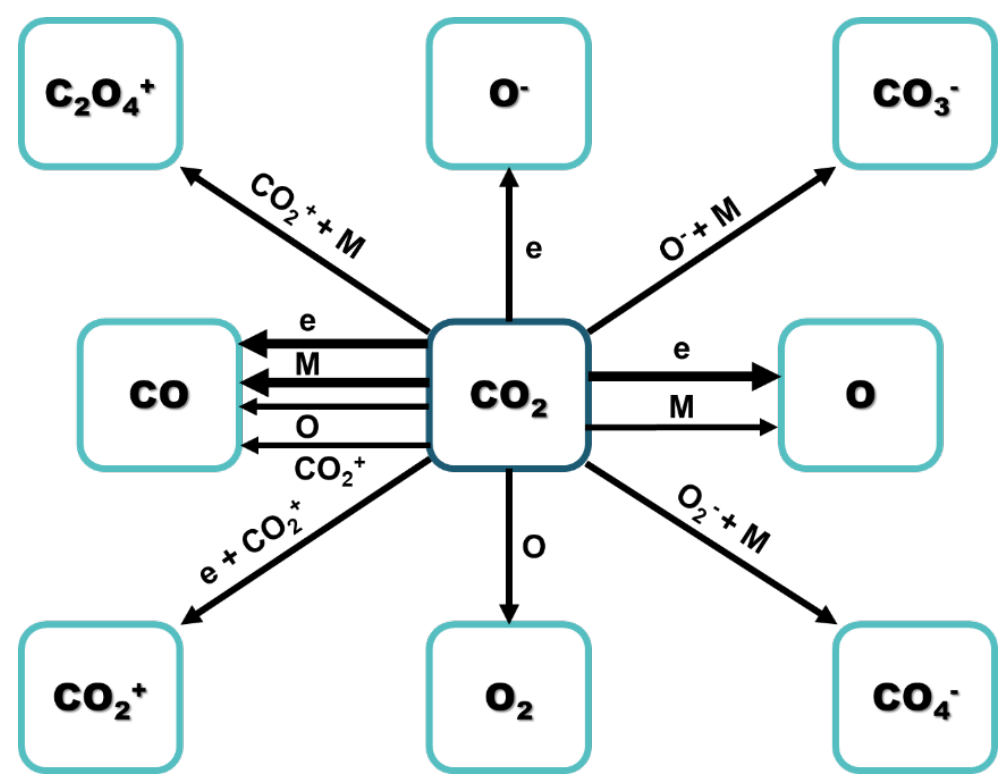

(a)

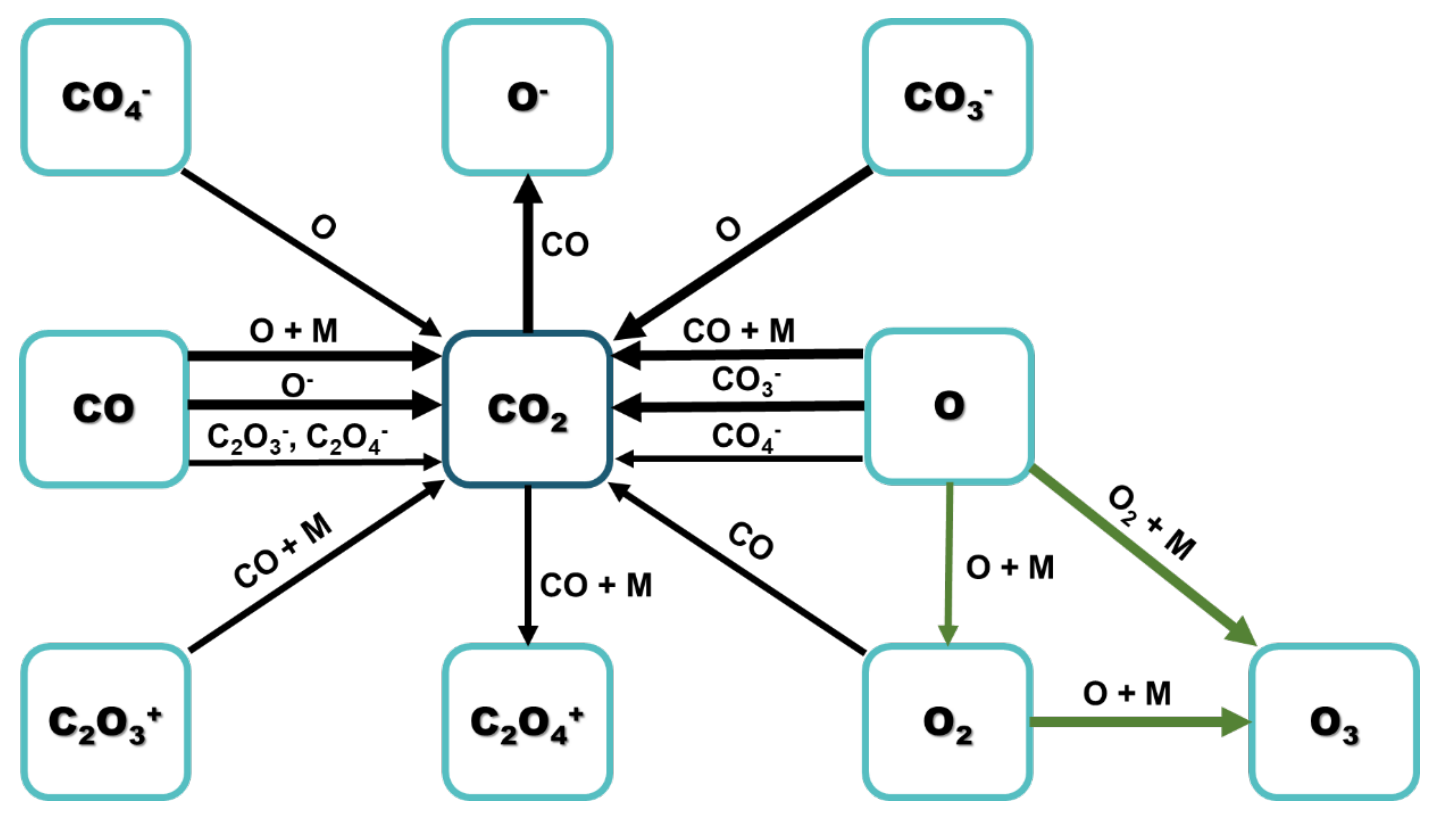

(b) 
Figure 11. Reaction pathways demonstrating the $\mathrm{CO}_{2}$ splitting (a) and formation (b) mechanisms. The thickness of the arrow lines corresponds to the importance of the reactions. The conversion reactions between $\mathrm{O}, \mathrm{O}_{2}$, and $\mathrm{O}_{3}$ are also indicated in (b), with green arrow lines [8]

When $\mathrm{CO}_{2}$ splitting using a DBD with $\mathrm{BaTiO}_{3}$ was carried out [8], the dielectric material improved the energy efficiency and $\mathrm{CO}_{2}$ decomposition. The $\mathrm{CO}_{2}$ conversion and the energy efficiency obtained were $13.5 \%$ and $7 \%$, respectively, at a $\mathrm{CO}_{2}$ feed of $50 \mathrm{sccm}$ and power of 20 W. It has been demonstrated that $\mathrm{CO}_{2}$ can be effectively decomposed by $\mathrm{MW}$ discharge of $\mathrm{Ar} / \mathrm{CO}_{2}$ or $\mathrm{He} / \mathrm{CO}_{2}$, with Ar being the most effective carrier gas for a low-temperature decomposition of $\mathrm{CO}_{2}$ into $\mathrm{O}_{2}$ [275] The most frequently used MW type for $\mathrm{CO}_{2}$ decomposition is surface guide (915 GHz and $2.45 \mathrm{GHz}$ ) [306]. This may be due to the high frequency of MW which in most cases is linked to the maximum absorption of applied power by the electrons, in addition to the slightly high excitation of the carbon dioxide asymmetric mode which is crucial for $\mathrm{CO}_{2}$ decomposition.

Wang et al. [307] carried out $\mathrm{CO}_{2}$ decomposition using a glow discharge with a $7 \mathrm{kV}$ input voltage and achieved a $\mathrm{CO}_{2}$ conversion of $30 \%$. It was realized that the reaction rates increased with an increase in input voltage. However, the highest energy efficiency was attained with $\mathrm{CO}_{2}$ containing gas at high flow rates, high $\mathrm{CO}_{2}$ concentration and reduced input voltage, at the expense of $\mathrm{CO}_{2}$ conversion. The amount of heat in the reactor is removed by the high flow rates, hence high flow rates are preferred in order to improve the reaction rate and the reactor efficiency. An investigation of $\mathrm{CO}_{2}$ dissociation efficiency using $\mathrm{RF}$ discharge at a plasma power of $1 \mathrm{~kW}$ and at a frequency of $13.56 \mathrm{MHz}$ was carried out and a 90\% conversion was achieved [244], which can be linked to the low-temperature plasma system. The system was capable of attaining high electron densities, hence improving the frequency of electron collisions that stimulate dissociation. The low gas temperature discharge also shields $\mathrm{O}_{2}$ and $\mathrm{CO}$ from reverse reactions by reducing the rate of reaction, which would otherwise lower the efficiency of the entire process. However, the maximum energy efficiency achieved was $3 \%$. The process of $\mathrm{CO}_{2}$ dissociation using plasma and a g- $\mathrm{C}_{3} \mathrm{~N}_{4}$ catalyst is illustrated in Fig. 12. NTP is generated in the high voltage electric field and $\mathrm{CO}_{2}$ is dissociated into $\mathrm{O}$ and $\mathrm{CO}$ radicals by gas-phase high energy electrons [308]. The g- $\mathrm{C}_{3} \mathrm{~N}_{4}$ catalyst has a broad pore distribution, containing mostly mesopores which increase the $\mathrm{g}-\mathrm{C}_{3} \mathrm{~N}_{4}$ catalyst specific surface area and, hence play a key role in the $\mathrm{CO}_{2}$ adsorption process [274]. The 
plasma-excited molecules of $\mathrm{CO}_{2}$ are adsorbed onto the catalyst surface to form $\mathrm{CO}_{2 \mathrm{ad}}$. The $\mathrm{O}$ radicals and $\mathrm{CO}$ radicals generated by the gas phase plasma are also adsorbed onto the catalyst surface, forming $\mathrm{O}_{\mathrm{ad}}$ and $\mathrm{CO}_{\mathrm{ad}}$, respectively. Furthermore, the $\mathrm{g}-\mathrm{C}_{3} \mathrm{~N}_{4}$ is excited by the high-energy active species produced in the discharge, which generates holes and electrons in the surface structure of the catalyst.. The holes and electrons are efficiently separated by the existing high voltage electric field.

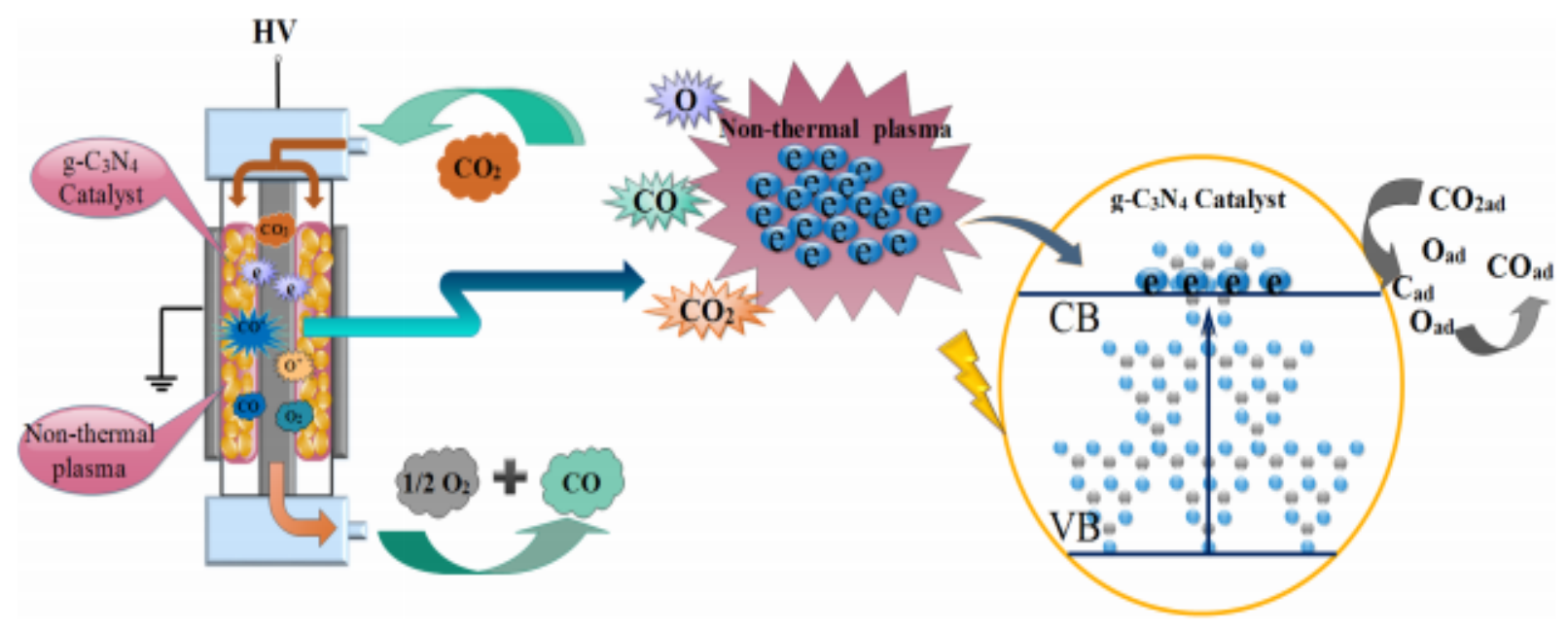

Figure 12. $\mathrm{CO}_{2}$ dissociation over a g- $\mathrm{C}_{3} \mathrm{~N}_{4}$ catalyst in a NTP [274]

Huang et al. [275] carried out $\mathrm{CO}_{2}$ dissociation in two different systems: one with an inductively coupled RF plasma at $2 \mathrm{~kW}$ and $27.12 \mathrm{MHz}$, and the other with a MW plasma at $2 \mathrm{~kW}$. Both the systems showed features of NTP and the maximum energy efficiency obtained was $59.3 \%$, surpassing a peak value of approximately $45 \%$ attained at thermodynamic equilibrium. This is a clear indication that electron-induced vibrational excitation plays a significant role in $\mathrm{CO}_{2}$ dissociation in the NTP. The addition of gases during the performance of $\mathrm{CO}_{2}$ dissociation using GAD at atmospheric pressure improved the conversion reaction due to the existence of excited $\mathrm{N}_{2}$ levels, which creates a positive impact. However, air and oxygen produced a negative effect, which may have been be due to $\mathrm{C}$ and $\mathrm{CO}$ reverse reaction to $\mathrm{CO}_{2}$ [135] [77]. Table 6 provides a summarized result for various NTP sources. Table 6 compares the energy efficiency, conversion efficiency and SIE of different non-thermal plasma types with different gas mixtures.

Table 6. Comparison of $\mathrm{CO}_{2}$ splitting and energy efficiency using different NTP sources 


\begin{tabular}{|c|c|c|c|c|c|c|c|}
\hline Plasma & Gas & Catalyst & $\begin{array}{l}\text { SIE } \\
(\mathrm{eV} / \\
\text { molecule) }\end{array}$ & $\begin{array}{l}\text { SIE } \\
\left(\mathrm{J} / \mathrm{cm}^{3}\right)\end{array}$ & $\chi(\%)$ & $\eta(\%)$ & Ref. \\
\hline$\overline{\text { DBD }}$ & $\mathrm{CO}_{2}$ & g- $\mathrm{C}_{3} \mathrm{~N}_{4}$ & - & 24 & 47.0 & - & [274] \\
\hline MW & $\mathrm{CO}_{2}$ & $\mathrm{NiO} / \mathrm{TiO}_{2}$ & 2.9 & 12.5 & 42.0 & 42.0 & [283] \\
\hline DBD & $\mathrm{CO}_{2}$ & - & - & 120.0 & 27.2 & 2.8 & {$[48]$} \\
\hline GAD & $\mathrm{CO}_{2}$ & - & 0.25 & - & 34.3 & 2.9 & [132] \\
\hline MW & $\mathrm{CO}_{2} / \mathrm{Ar} / \mathrm{O}_{2}$ & $\mathrm{NiO} / \mathrm{TiO}_{2}$ & - & 30.0 & 41.3 & 17.2 & {$[22]$} \\
\hline DBD & $\mathrm{CO}_{2}$ & $\mathrm{BaTiO}_{3}$ & 6.5 & 28.0 & 38.0 & 17.0 & [302] \\
\hline MW & $\begin{array}{l}\mathrm{CO}_{2}-\mathrm{H}_{2} \mathrm{O}- \\
\mathrm{Ar}\end{array}$ & - & 1.6 & - & - & 10.0 & {$[62]$} \\
\hline MW & $\mathrm{CO}_{2} / \mathrm{N}_{2}$ & - & 7.1 & - & 53.0 & 21.0 & [309] \\
\hline MW & $\mathrm{CO}_{2}-\mathrm{N}_{2}$ & - & 39.0 & 168.1 & 80.0 & 6.0 & [282] \\
\hline DBD & $\begin{array}{l}\mathrm{CO}_{2}-\mathrm{H}_{2} \mathrm{O}- \\
\mathrm{Ar}\end{array}$ & $\begin{array}{l}\mathrm{Ni} / \gamma- \\
\mathrm{Al}_{2} \mathrm{O}_{3}\end{array}$ & 4.5 & 19.4 & 36.0 & 23.0 & [287] \\
\hline DBD & $\mathrm{CO}_{2}$ & $\mathrm{CaTiO}_{3}$ & - & 52.9 & 20.5 & 4.8 & [310] \\
\hline $\mathrm{RF}$ & $\mathrm{CO}_{2}$ & - & 19.0 & 82.0 & 90.0 & 3.0 & {$[46]$} \\
\hline GAD & $\mathrm{CO}_{2} / \mathrm{H}_{2}$ & - & - & 15.4 & 17.4 & 14.1 & {$[77]$} \\
\hline Corona & $\mathrm{CO}_{2}$ & - & - & 80.0 & 10.9 & 1.7 & [276] \\
\hline
\end{tabular}

4.2.2 Dry reforming of methane

4.2.1. Dry reforming of methane for syngas production

As illustrated in reaction R1, DRM has the advantage of utilizing $\mathrm{CO}_{2}$ and $\mathrm{CH}_{4}$ (both greenhouse gases) in a single process to produce syngas along with other valuable chemicals, i.e. direct higher hydrocarbon formation. Syngas can be further processed into other chemicals and fuels i.e. valueadded oxygenated products namely; ethanol, dimethyl ether, formic acid, formaldehyde and methanol [81, 311-313]. Consequently, DRM is an effective method for environmental protection through effective energy resource utilization, hence acting as a means of sustainable development $[34,314,315]$. DRM is especially valuable in the production of oxygenated chemicals due to the low $\mathrm{H}_{2} / \mathrm{CO}$ molar ratio of the product gas $[91,316]$. However, the DRM process faces challenges, such as unfavorable thermodynamic limitations $\left(\Delta \mathrm{G}>0\right.$ at $\left.\mathrm{T}>700{ }^{\circ} \mathrm{C}\right)$. Indeed, DRM is more endothermic than steam reforming and demands more energy [70, 317]. This is because the reactant gases in DRM, $\mathrm{CO}_{2}(5.5 \mathrm{eV})$ and $\mathrm{CH}_{4}(4.45 \mathrm{eV})$, have dissociation energies that require considerable thermal energy to overcome $\left(\mathrm{CO}_{2}\right.$ is very stable and has the highest oxidized state of 
carbon [318]). It is, therefore, difficult to conduct the co-activation of both $\mathrm{C}-\mathrm{H}$ and $\mathrm{C}-\mathrm{O}$ bonds in $\mathrm{CH}_{4}$ and $\mathrm{CO}_{2}$, and so DRM is frequently carried out at high temperatures $\left(\sim 800^{\circ} \mathrm{C}\right)$ for thermal processes [319-321], although this can be significantly reduced through the use of catalysts [81, 322, 323]. NTP-based techniques also have great potential for converting $\mathrm{CO}_{2}$ into fuels and valueadded chemicals since NTPs possesses the capability of breaking the C-O bonds in a highly stable $\mathrm{CO}_{2}$ molecule at room temperature [30]. Investigations have been conducted on DRM using either pure or diluted $\mathrm{CO}_{2}$ with non-oxidative gases, such as $\mathrm{H}_{2}$, Ar or $\mathrm{He}$, to improve the conversion $[52,73,117,324]$, as illustrated in Fig. 13.

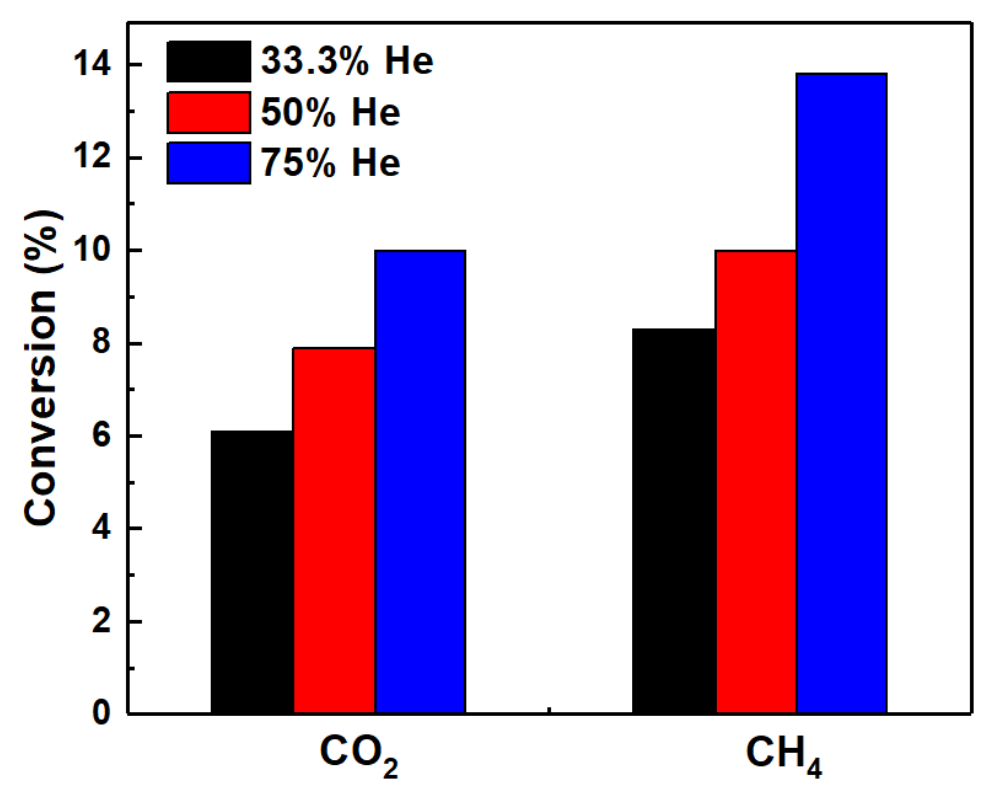

Figure 13. Effect of $\mathrm{He}$ addition on the conversion of $\mathrm{CH}_{4}$ and $\mathrm{CO}_{2}$ in the plasma packed with glass balls (discharge Power $8 \mathrm{~W}$, total flow $40 \mathrm{ml} / \mathrm{min}$, room temperature, $\mathrm{CO}_{2} / \mathrm{CH}_{4}$ molar ratio $1: 1)[47]$.

Diluent gases such as $\mathrm{N}_{2}, \mathrm{He}$, and Ar are mostly used in DBD plasma DRM to enhance the product distribution and minimize coke formation. However, this leads to additional, undesired cost. Diluent gas regulates the electron energy distribution function, which adjusts the reaction pathways, discharge characteristics, and $\mathrm{H}_{2} / \mathrm{CO}$ ratio. Noble gases, namely $\mathrm{He}$ and $\mathrm{Ar}$, are the preferred choice as a diluent, which can influence the plasma discharge owing to their lower breakdown voltages (compared with $\mathrm{CO}_{2}$ and $\mathrm{CH}_{4}$ ), resulting in the improved dissociation and ionization process [325]. He and Ar can be excited to metastable levels and ionized states, which are responsible for the energy transfer in DBD plasma DRM. Indeed, the addition of Ar or He 
results in greater electron energy distribution functions in the gas discharge state, leading to more opportunities for inelastic impact on $\mathrm{CO}_{2}$ and $\mathrm{CH}_{4}$ with the other species or co-reactants. Thus, the degree of ionization of the $\mathrm{CO}_{2}$ and $\mathrm{CH}_{4}$ molecules in the presence of $\mathrm{Ar}$ and He increases and $\mathrm{CO}_{2}$ and $\mathrm{CH}_{4}$ dissociation is faster [270].

The production of syngas by DRM using DBD has been investigated extensively under different experimental conditions, including flow rates, reactor designs, $\mathrm{CH}_{4} / \mathrm{CO}_{2}$ ratios, input powers, temperatures, and discharge lengths, etc. [263, 326]. Due to the complexity of plasma media, several hundred reactions can take place. The most probable reaction pathways for the formation and consumption of value added products and their intermediates from the conversion of a $\mathrm{CO}_{2} / \mathrm{CH}_{4}$ mixture are shown in Table 7. The $\mathrm{CO}$ production is closely correlated with $\mathrm{CO}_{2}$ dissociation as indicated in reactions R13, R20, R28, R31, R37, R39, R40, and R41. R29 is as a result of an electron impact on $\mathrm{CO}_{2}$, converting it into $\mathrm{CO}$ and $\mathrm{O}$; this is a very crucial process in $\mathrm{CO}_{2}$ splitting. In the presence of $\mathrm{CH}_{4}$, the $\mathrm{O}$ atoms are consumed by the following reactions: $\mathrm{R} 11$, $\mathrm{R} 13$, R31, and R25. According to R21 the recombination of two $\mathrm{CH}_{3} *$ results in the formation of ethane. R22 and R23 may also result in ethane formation, though with less probability than R21. $\mathrm{CH}_{2} \mathrm{O}$ can also be formed to some extent from R24 and R25. According to Ozkan et al. [150], the formation of oxygenated molecules, including methanol or acetic acid, also occurs in plasma. A two-step collisional mechanism may lead to $\mathrm{C}_{2} \mathrm{H}_{4}$ production, beginning with the dissociation of $\mathrm{C}_{2} \mathrm{H}_{6}$ into $\mathrm{H}$ radicals and $\mathrm{C}_{2} \mathrm{H}_{5}{ }^{*}$ (R35) followed by the collision of $\mathrm{C}_{2} \mathrm{H}_{5}{ }^{*}$ with the second electron, which then leads to the formation of $\mathrm{C}_{2} \mathrm{H}_{4}$ due to the abstraction of $\mathrm{H}$ radical (R35).

Table 7. Reaction pathways for formation and consumption of value added products in $\mathrm{CO}_{2} / \mathrm{CH}_{4}$ and their intermediates for plasma [313, 314,.315, 316, 317, 150, 323]

\begin{tabular}{lllllc}
\hline Reaction & & $\begin{array}{l}\text { Rate Constant } \\
\left(\mathbf{c m}^{3} / \mathbf{s}\right)\end{array}$ & $\begin{array}{l}\text { Reaction } \\
\text { No. }\end{array}$ & Ref. \\
\hline $\mathrm{CH}_{4}+\mathrm{CH}^{*} \rightarrow \mathrm{C}_{2} \mathrm{H}_{4}+\mathrm{H}^{*}$ & $9.74 \times 10^{-11}$ & $\mathrm{R} 9$ & {$[327,328]$} \\
$\mathrm{CH}_{3}{ }^{*}+\mathrm{CH}_{2}{ }^{*} \rightarrow \mathrm{C}_{2} \mathrm{H}_{4}+\mathrm{H}^{*}$ & $7.01 \times 10^{-11}$ & $\mathrm{R} 10$ & {$[327,328]$} \\
$\mathrm{C}_{2} \mathrm{H}_{5}{ }^{*}+\mathrm{O}^{*} \rightarrow \mathrm{C}_{2} \mathrm{H}_{4}+\mathrm{OH}^{*}$ & $4.40 \times 10^{-11}$ & $\mathrm{R} 11$ & {$[328,329]$} \\
$\mathrm{CH}_{4}+\mathrm{e}$ & $\rightarrow \mathrm{CH}_{3}^{*}+\mathrm{H}^{*}+\mathrm{e}$ & $\sigma 3$ & $\mathrm{R} 12$ & {$[328,330,331]$} \\
$\mathrm{CH}_{2}+\mathrm{O}^{*}$ & $\rightarrow \mathrm{CO}+\mathrm{H}_{2}$ & $5.53 \times 10^{-11}$ & $\mathrm{R} 13$ & {$[328,332]$} \\
\hline
\end{tabular}




\begin{tabular}{|c|c|c|c|c|c|c|}
\hline $\mathrm{CH}_{3} *$ & $\rightarrow$ & $\mathrm{CH}_{2}{ }^{*}+\mathrm{H}^{*}$ & 1.69 & $\times 10^{-8}$ & R14 & {$[150,327,333]$} \\
\hline $\mathrm{CH}_{3} *+\mathrm{e}$ & $\rightarrow$ & $\mathrm{CH}_{2} *+\mathrm{H}^{*}$ & 2.25 & $\times 10^{-8}$ & R15 & {$[331,332]$} \\
\hline $\mathrm{CH}_{3} *+\mathrm{e}$ & $\rightarrow$ & $\mathrm{CH}^{*}+\mathrm{H}_{2}$ & 7.88 & $\times 10^{-9}$ & R16 & {$[331,332]$} \\
\hline $\mathrm{CH}_{3}{ }^{*}+\mathrm{H}^{*}$ & $\rightarrow$ & $\mathrm{CH}_{2} *+\mathrm{H}_{2}$ & 1.00 & $\times 10^{-10}$ & R17 & {$[327,333]$} \\
\hline $\mathrm{CH}_{4}+\mathrm{H}^{*}$ & $\rightarrow$ & $\mathrm{CH}_{3} *+\mathrm{H}_{2}$ & 5.83 & $\times 10^{-13}$ & $\mathrm{R} 18$ & [327] \\
\hline $\mathrm{CH}_{4}^{+}+\mathrm{H}^{*}$ & $\rightarrow$ & $\mathrm{CH}_{3} *+\mathrm{H}_{2}$ & 1.00 & $\times 10^{11}$ & R19 & [333] \\
\hline $\mathrm{CH}^{*}+\mathrm{O}^{*}$ & $\rightarrow$ & $\mathrm{CO}+\mathrm{H}^{*}$ & 6.90 & $\times 10^{-11}$ & $\mathrm{R} 20$ & {$[327]$} \\
\hline $\mathrm{CH}_{3} *+\mathrm{CH}_{3} *$ & $\rightarrow$ & $\mathrm{C}_{2} \mathrm{H}_{6}$ & 4.20 & $\times 10^{11}$ & $\mathrm{R} 21$ & [334] \\
\hline $\mathrm{C}_{2} \mathrm{H}_{5} *+\mathrm{H}^{*}$ & $\rightarrow$ & $\mathrm{C}_{2} \mathrm{H}_{6}$ & 2.25 & $\times 10^{-10}$ & $\mathrm{R} 22$ & [329] \\
\hline $\mathrm{C}_{2} \mathrm{H}_{5} *+\mathrm{CH}_{4}$ & $\rightarrow$ & $\mathrm{C}_{2} \mathrm{H}_{6}+\mathrm{CH}_{3} *$ & 1.83 & $\times 10^{-24}$ & $\mathrm{R} 23$ & [335] \\
\hline $\mathrm{CH}_{2} *+\mathrm{O}_{2}$ & $\rightarrow$ & $\mathrm{H}_{2} \mathrm{CO}+\mathrm{O}^{*}$ & 5.93 & $\times 10^{-13}$ & R24 & {$[327,336]$} \\
\hline $\mathrm{CH}_{3} *+\mathrm{O}^{*}$ & $\rightarrow$ & $\mathrm{H}_{2} \mathrm{CO}+\mathrm{H}^{*}$ & 1.12 & $\times 10^{-10}$ & $\mathrm{R} 25$ & [337] \\
\hline $\mathrm{CH}^{*}+\mathrm{CO}_{2}$ & $\rightarrow$ & $2 \mathrm{CO}+\mathrm{H}^{*}$ & 9.68 & $\times 10^{-13}$ & R26 & [328] \\
\hline $\mathrm{H}^{*}+\mathrm{H}^{*}$ & $\rightarrow$ & $\mathrm{H}_{2}$ & 1.44 & $\times 10^{-14}$ & $\mathrm{R} 27$ & {$[300,338]$} \\
\hline $\mathrm{CO}_{2}+\mathrm{H}^{*}$ & $\rightarrow$ & $\mathrm{CO}+\mathrm{OH}^{*}$ & 1. 40 & $\times 10^{29}$ & $\mathrm{R} 28$ & {$[81,335]$} \\
\hline $\mathrm{CO}_{2}+\mathrm{e}$ & $\rightarrow$ & $\mathrm{CO}+\mathrm{O}^{*}+\mathrm{e}$ & $\sigma 23$ & & R29 & {$[81,330,338,339]$} \\
\hline $\mathrm{CO}_{2}+\mathrm{e}$ & $\rightarrow$ & $\mathrm{CO}_{2}^{+}+2 \mathrm{e}$ & 1.27 & $\times 10^{-10}$ & $\mathrm{R} 30$ & {$[339,340]$} \\
\hline $\mathrm{CO}_{2}+\mathrm{O}^{*}$ & $\rightarrow$ & $\mathrm{CO}+\mathrm{O}_{2}$ & 2.01 & $\times 10^{-10}$ & R31 & {$[339,341]$} \\
\hline $\mathrm{CO}_{2}^{+}+\mathrm{e}$ & $\rightarrow$ & $\mathrm{CO}+\mathrm{O}^{*}$ & 2.71 & $\times 10^{-07}$ & $\mathrm{R} 32$ & [332] \\
\hline $\begin{array}{l}\mathrm{CO}_{2}+\mathrm{e} \\
\mathrm{e}^{-}\end{array}$ & $\rightarrow$ & $\mathrm{CH}_{4} \mathrm{CO}+\mathrm{O}^{*}+$ & $\sigma 24$ & & R33 & [339] \\
\hline $\mathrm{C}_{2} \mathrm{H}_{6}+\mathrm{e}$ & $\rightarrow$ & $\mathrm{C}_{2} \mathrm{H}_{5}+\mathrm{H}^{*}+\mathrm{e}$ & $\sigma 18$ & & R34 & {$[330,342]$} \\
\hline $\mathrm{C}_{2} \mathrm{H}_{5} *+\mathrm{e}$ & $\rightarrow$ & $\mathrm{C}_{2} \mathrm{H}_{4}+\mathrm{H}^{*}+\mathrm{e}$ & $\sigma 19$ & & R35 & {$[342]$} \\
\hline $\mathrm{CH}+\mathrm{e}$ & $\rightarrow$ & $\mathrm{C}+\mathrm{H}+\mathrm{e}$ & $\sigma 20$ & & R36 & {$[330]$} \\
\hline $\mathrm{CO}_{2}+\mathrm{e}$ & $\rightarrow$ & $\mathrm{CO}+\mathrm{O}+\mathrm{e}$ & 5.4 & $\times 10^{-11}$ & R37 & [340] \\
\hline $\mathrm{CH}_{4}+\mathrm{e}^{*}$ & $\rightarrow$ & $\mathrm{CH}_{3} *+\mathrm{H}^{*}$ & $\sigma 21$ & & R38 & [340] \\
\hline $\mathrm{C}+\mathrm{O}+\mathrm{e}^{*}$ & $\rightarrow$ & $\mathrm{CO}$ & $\sigma 22$ & & R39 & {$[150,340]$} \\
\hline $\mathrm{CO}_{2}+\mathrm{e}$ & $\rightarrow$ & $\mathrm{CO}+\mathrm{O}^{-}$ & 5.94 & $\times 10^{-13}$ & $\mathrm{R} 40$ & {$[150]$} \\
\hline $\mathrm{CO}_{2}^{+}+\mathrm{e}$ & $\rightarrow$ & $\mathrm{CO}+\mathrm{O}$ & 6.6 & $\times 10^{-31}$ & R41 & [340] \\
\hline
\end{tabular}

*The adsorption sites. 
The combination of NTP with heterogeneous catalysts has attracted much attention in order to improve the selectivity to target products and the conversion of $\mathrm{CO}_{2}$ [213]. Various catalysts have been investigated for DRM, including those reported by Yap et al. [52], Ozkan [300], Wang et al. [311], Snoeckx et al. [158] and Sentek et al. [324]. For a full summary of different catalysts used for $\mathrm{CO}_{2} \mathrm{DRM}$, refer to [343, 344].

Zhang et al. [329] studied the conversion of $\mathrm{CH}_{4}$ and $\mathrm{CO}_{2}$ for higher hydrocarbons and synthesis gas by the combination of catalysts and DBD. It was noted that, in addition to the dissociation of $\mathrm{CO}_{2}$ to $\mathrm{O}$ and $\mathrm{CO}$ radicals in a gas phase plasma, $\mathrm{CO}_{2}$ and plasma-excited $\mathrm{CO}_{2}$ molecules can also be adsorbed on the surface of the $\mathrm{Ni} / \mathrm{SiO}_{2}$ catalyst forming adsorbed $\mathrm{CO}_{2 \text { ad. }}$ In NTP, the energetic electrons can dissociate these $\mathrm{CO}_{2 \mathrm{ad}}$ molecules to form adsorbed $\mathrm{O}_{\mathrm{ad}}$ and $\mathrm{CO}_{\mathrm{ad}}$ species on the surface of $\mathrm{Ni} / \mathrm{SiO}_{2}$. The desorption of $\mathrm{CO}_{a d}$ can produce $\mathrm{CO}$. Meanwhile, the recombination of $\mathrm{O}_{\mathrm{ad}}$ can form $\mathrm{O}_{2 a d}$ and the desorption of $\mathrm{O}_{2 a d}$ can produce $\mathrm{O}_{2}$. At the same time, the $\mathrm{O}_{\mathrm{ad}}$ species may oxidize $\mathrm{Ni}$ catalyst to form $\mathrm{NiO}$ which can then be reduced to $\mathrm{Ni}$ by $\mathrm{CO}_{\mathrm{ad}}$ or $\mathrm{CO}$ in the reaction. There is a likelihood that the $\mathrm{CO}$ and $\mathrm{O}$ radicals produced by plasma in the gas phase can be adsorbed on the $\mathrm{Ni} / \mathrm{SiO}_{2}$ forming $\mathrm{CO}_{a d}$ and $\mathrm{O}_{\mathrm{ad}}$. The combination of $\mathrm{O}_{\mathrm{ad}}$ and $\mathrm{CO}_{\mathrm{ad}}$ on the $\mathrm{Ni}$ catalyst could lead to $\mathrm{CO}_{2}$ formation. The other reactions, including the reaction between $\mathrm{CO}$ and $\mathrm{O}_{\mathrm{ad}}$, and the reaction between $\mathrm{CO}_{\mathrm{ad}}$ and $\mathrm{O}$, may lead to the formation of $\mathrm{CO}_{2}$ [330]. Spencer et al. [244] reported that the recombination of $\mathrm{O}$ radicals to $\mathrm{O}_{2}$ prevails over the combination of $\mathrm{CO}$ with $\mathrm{O}$ radicals on various solid surfaces at low temperatures.

Zeng et al. [51] and Sentek et al. [324] carried out DRM using a DBD reactor. The molar ratio of $\mathrm{CO}_{2} / \mathrm{CH}_{4}$ affects the $\mathrm{CO} / \mathrm{H}_{2}$ molar ratio, conversion of the reactants, the yield, and the selectivities of the main products. Variation of the total flow rate of the reactants has an effect on neither the selectivity to syngas nor $\mathrm{CO} / \mathrm{H}_{2}$ molar ratio [51]. The parameters that affect the $\mathrm{CO}_{2}$ and $\mathrm{CH}_{4}$ conversion were confirmed when Nguyen et al converted them to $\mathrm{CO}+\mathrm{H}_{2}$ using a $\mathrm{CD}$ [88]. Applied peak voltage, pulse frequency, $\mathrm{CH}_{4} / \mathrm{CO}_{2}$ ratio, and the total flow rate were key variables for DRM. Rahemi et al. [345] conducted $\mathrm{CO}_{2}$ reforming of $\mathrm{CH}_{4}$ using a glow discharge (GD) to investigate the influence of applied voltage on catalytic properties using a $\mathrm{Ni}-\mathrm{Co} / \mathrm{Al}_{2} \mathrm{O}_{3}-\mathrm{ZrO}_{2}$ catalyst. The results obtained are further confirmation that enhanced voltages lead to increased production of energetic plasma species, resulting in increased surface defects which are important for catalytic reactivity. Long et al. [346] carried out DRM using a $\mathrm{Ni} / \gamma-\mathrm{Al}_{2} \mathrm{O}_{3}$ catalyst and cold plasma jet, and 
realized that cold plasma was a better option to convert $\mathrm{CO}_{2}$ and $\mathrm{CH}_{4}$ to $\mathrm{CO}+\mathrm{H}_{2}$. The combination of cold plasma jet and $\mathrm{Ni} / \gamma-\mathrm{Al}_{2} \mathrm{O}_{3}$ enhanced the production yields, energy efficiency and the reactant conversions. The activity of the catalyst, which was placed outside the discharge zone, was improved as it was automatically heated by the plasma jet. Li et al. [347] investigated the HZSM-5 zeolite effect on the $\mathrm{CO}_{2}$ reforming of $\mathrm{CH}_{4}$ using a corona discharge. The composition and $\mathrm{CO} / \mathrm{H}_{2}$ ratio changed as a result of the high voltage applied to initiate $\mathrm{CD}$.

4.2.2.2. Dry reforming of methane for the synthesis of oxygenates

Direct conversion of methane and carbon dioxide into liquid fuels and chemicals through a singlestep catalytic process that bypasses the formation of syngas remains a major challenge. The direct conversion of $\mathrm{CO}_{2}$ with $\mathrm{CH}_{4}$ represents a promising process (Fig. 14) for not only $\mathrm{CH}_{4}$ activation but also $\mathrm{CO}_{2}$ valorization. $\mathrm{CH}_{4}$ can replace $\mathrm{H}_{2}$ as an ideal $\mathrm{H}$ supplier in $\mathrm{CO}_{2}$ hydrogenation as $\mathrm{CH}_{4}$ contains a high hydrogen density and is available from various sources, such as biogas, flared gas, natural gas, and shale gas [348].

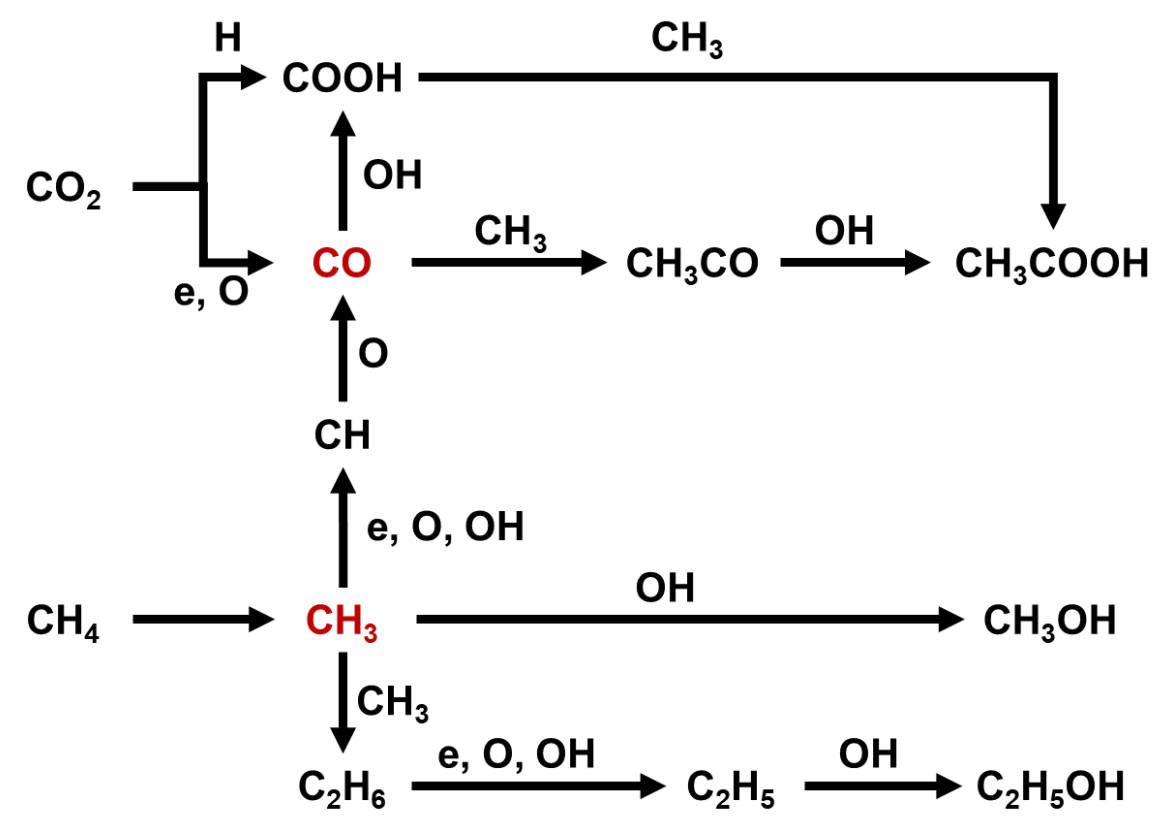

Figure 14. Possible reaction routes for the formation of $\mathrm{CH}_{3} \mathrm{COOH}, \mathrm{CH}_{3} \mathrm{OH}$, and $\mathrm{C}_{2} \mathrm{H}_{5} \mathrm{OH}$ in the direct reforming of $\mathrm{CH}_{4}$ and $\mathrm{CO}_{2}$ using a $\mathrm{DBD}$ [348].

Wang et al. [348] developed a unique and groundbreaking plasma synthesis process for the direct and one-step activation of carbon dioxide and methane into higher value liquid fuels and chemicals (e.g., acetic acid, methanol, ethanol, acetone and formaldehyde) at room temperature and 
atmospheric pressure using a novel DBD plasma reactor with a water electrode. The total selectivity of oxygenates was $50-60 \%$, with acetic acid being the main liquid product with $40.2 \%$ selectivity. This is the highest value obtained for acetic acid so far and is a clear indication that NTPs can be used in overcoming the existing thermodynamic barrier for the direct conversion of $\mathrm{CO}_{2}$ and $\mathrm{CH}_{4}$ into a range of platform chemicals and synthetic fuels. This major breakthrough technology has great potential to deliver a step-change in future $\mathrm{CH}_{4}$ activation and $\mathrm{CO}_{2}$ conversion for chemical energy storage.

Zou et al. [349] carried out a starch-enhanced synthesis of oxygenates directly from $\mathrm{CH}_{4}$ and $\mathrm{CO}_{2}$ using a DBD. The use of starch was found to inhibit the production of liquid $\mathrm{C}_{\mathrm{x}} \mathrm{H}_{\mathrm{y}}$ and significantly improve the selectivity to oxygenates $\left(\mathrm{CH}_{2} \mathrm{O}, \mathrm{CH}_{3} \mathrm{OH}, \mathrm{C}_{2} \mathrm{H}_{6} \mathrm{O}, \mathrm{CH}_{2} \mathrm{O}_{2}, \mathrm{CH}_{3} \mathrm{COOH}\right)$. The total selectivity obtained was about $10-40 \%$ with a $\mathrm{CH}_{4}$ and $\mathrm{CO}_{2}$ conversion of approximately $20 \%$. Lower $\mathrm{CH}_{4}$ feed favored the formation of $\mathrm{CH}_{2} \mathrm{O}, \mathrm{CH}_{3} \mathrm{OH}, \mathrm{C}_{2} \mathrm{H}_{6} \mathrm{O}, \mathrm{CH}_{2} \mathrm{O}_{2}$, and $\mathrm{CH}_{3} \mathrm{COOH}$, and increased flow rate of $\mathrm{CH}_{4}$ resulted in improved selectivity of oxygenates. Starch was used as a coating in order to modify the dielectric surface, thereby improving the production of oxygenates from $\mathrm{CO}_{2}$ and $\mathrm{CH}_{4}$. In this case, starch is a co-reactant, even though its conversion is much lower compared to $\mathrm{CO}_{2}$ and $\mathrm{CH}_{4}$. Scapinello et al. [350] investigated the catalytic effect of the electrode surface and discharge power in a DBD reactor on $\mathrm{CH}_{4}$ and $\mathrm{CO}_{2}$ conversion to $\mathrm{C}_{\mathrm{n}} \mathrm{H}_{2 \mathrm{n}+1} \mathrm{COOH}$ and $\mathrm{CH}_{2} \mathrm{O}_{2}$ at atmospheric pressure using $\mathrm{Cu}$ and $\mathrm{Ni}$ electrodes. It was suggested that $\mathrm{CO}_{2}$ hydrogenation on the metal surface, plasma synthesis of $\mathrm{CH}_{2} \mathrm{O}, \mathrm{CH}_{3} \mathrm{OH}, \mathrm{C}_{2} \mathrm{H}_{6} \mathrm{O}, \mathrm{CH}_{2} \mathrm{O}_{2}$, and $\mathrm{CH}_{3} \mathrm{COOH}$ was enhanced by increasing the discharge power. Aldehydes $\left(-\mathrm{CHO}\right.$, including $\mathrm{C}_{2} \mathrm{H}_{4} \mathrm{O}$ and $\mathrm{CH}_{2} \mathrm{O}$, could be easily produced, even at room temperature. The selectivity of the end products was related to the $\mathrm{CO}_{2}: \mathrm{CH}_{4}$ ratio. In addition, the formation of $\mathrm{CH}_{2} \mathrm{O}$ was proposed to be from a methyl radical $\left(\mathrm{CH}_{3}+\mathrm{O} \rightarrow \mathrm{HCHO}+\mathrm{H}\right)[68,342]$. Dey et al. [351] reported the selective reduction of $\mathrm{CO}_{2}$ with $\mathrm{Ar}$ as a carrier gas using a $\mathrm{DBD}$ in the presence of organic $\mathrm{C}_{\mathrm{x}} \mathrm{H}_{\mathrm{y}}$. The addition of hydrocarbons $\left(\mathrm{C}_{n} \mathrm{H}_{2 n+x} ; n=6-12 ; \mathrm{x}=0\right.$ or 2$)$ led to the formation of $\mathrm{HCHO}$, with the highest $\mathrm{H}$ atom utilization efficiency being approximately $15 \%$ of the total present.

Evidently, $\mathrm{CO}_{2}$ conversion with $\mathrm{H}_{2}$-containing co-reactant is a promising technique for the formation of aldehydes, acids, esters, and alcohols, especially because this method offers direct oxidative route can bypass the intermediate formation of syngas. However, more research is required in this area to improve the selectivity of these value-added products over the currently produced syngas. 
4.2.2.3. Dry reforming of methane for synthesis of higher hydrocarbons $\left(\mathrm{C}_{\mathrm{x}} \mathrm{H}_{\mathrm{y}}\right)$

$\mathrm{CO}_{2}$ oxidative coupling is a very attractive technique as it obviates the intermediate steps, like reforming, to directly form valuable products. $\mathrm{CO}_{2}$ can be a better oxidant than $\mathrm{O}_{2}$ for oxidative $\mathrm{CH}_{4}$ conversion, notwithstanding, $\mathrm{C}_{2}$-hydrocarbon yields are still fairly low [352, 353]. Further research is needed, therefore, especially on high-performance catalysis, the behavior of the catalysts, and the design of the reactors. Production of $\mathrm{C}_{2+}$ hydrocarbons, especially $\mathrm{C}_{2} \mathrm{H}_{4}$, from $\mathrm{CH}_{4}$ oxidative coupling is a promising pathway for the utilization of extremely large reservoirs of natural gas, converting it into products like petrochemical feedstock, liquid fuels and chemicals [354, 355]. Co-feeding $\mathrm{CO}_{2}$ with a $\mathrm{CH}_{4}$ feed stream improves $\mathrm{CH}_{4}$ conversion and reduces coking [213]. Coking formation results in carbon deposition on the electrode surface, catalyst and dielectric surface due to $\mathrm{CH}_{4}$ decomposition, which is the main problem in DBD plasma reactors used specifically for pure $\mathrm{CH}_{4}$ as a feed. The coke limits both the number of discharge streamers and energetic electrons that interact with feed gases in the reaction zone, hence reducing $\mathrm{CH}_{4}$ conversion.

Liu [356] conducted an investigation on $\mathrm{C}_{2} \mathrm{H}_{4}$ and $\mathrm{C}_{2} \mathrm{H}_{6}$ oxidative synthesis from $\mathrm{CH}_{4}$ by using $\mathrm{CO}_{2}$ as oxidant, initiated by an $\mathrm{AC}$ electric field. By streaming discharge reactions, the gas discharge improved $\mathrm{CH}_{4}$ conversion, attaining a $20-45 \%$ yield of $\mathrm{C}_{2}$ hydrocarbons. $\mathrm{The} \mathrm{CH}_{4}$ and $\mathrm{CO}_{2}$ conversions were $25 \%-80 \%$ and $8-40 \%$, respectively. The reactions were as shown in R42 and R43. The gas discharges, such as glow, arc, silent, and corona discharges, were an abundant resource for the formation of free radicals [357]. The streamer discharge induced decomposition of $\mathrm{CO}_{2}\left(\mathrm{e}+\mathrm{CO}_{2} \rightarrow \mathrm{CO}+\mathrm{O}^{-}\right.$or e $\left.+\mathrm{CO}_{2} \rightarrow \mathrm{CO}+\mathrm{O}+\mathrm{e}\right)$. O species $\left(\mathrm{O}^{-}\right.$and $\left.\mathrm{O}\right)$ are actively involved during coupling reactions, leading to the formation of $\mathrm{C}_{2} \mathrm{H}_{4}$ and $\mathrm{C}_{2} \mathrm{H}_{6}$. Khoja et al. [71] noted that the selectivity of $\mathrm{CO}$ and $\mathrm{H}_{2}$ increased with improved SIE; however, the selectivity of $\mathrm{C}_{2} \mathrm{H}_{6}$ decreased. This indicates that the increase in SIE leads to a change in the reaction pathways and enhances the yield of $\mathrm{H}_{2}$ by the recombination of $\mathrm{CH}_{3}$ and $\mathrm{H}$, or may help in the methyl radicals' breakdown. A detailed description of the main reactions have been reported by Fotouh and Liu [357]. The conversion of $\mathrm{CH}_{4}$ and $\mathrm{CO}_{2}$ and the yield of $\mathrm{C}_{2} \mathrm{H}_{4}$ were improved with the increase of feed $\mathrm{CO}_{2}$ and input voltage, but the increase of $\mathrm{CO}_{2}$ composition resulted in the reduction of the yield of $\mathrm{C}_{1}$ hydrocarbons [356, 357].

$2 \mathrm{CH}_{4}+\mathrm{CO}_{2} \rightarrow \mathrm{C}_{2} \mathrm{H}_{6}+\mathrm{CO}+\mathrm{H}_{2} \mathrm{O}$ 
$2 \mathrm{CH}_{4}+2 \mathrm{CO}_{2} \rightarrow \mathrm{C}_{2} \mathrm{H}_{4}+2 \mathrm{CO}+2 \mathrm{H}_{2} \mathrm{O}$

Recent advances have been achieved in the direct production of higher hydrocarbons using $\mathrm{CO}_{2}$ as an oxidant. The use of silent plasma discharge has increased the energy yield significantly. Biloen and Sachtler [358] conducted an experimental investigation into the mechanism of $\mathrm{C}_{x} \mathrm{H}_{y}$ synthesis over Fischer-Tropsch catalysts. In addition to $\mathrm{C}_{\mathrm{x}} \mathrm{H}_{\mathrm{y}}(\mathrm{x}=2$ and $\mathrm{x}=3)$, heavy oil, syngas, plasma polymers, liquid fuel and a small percentage of oxygenates were also produced with varying energy yields, as follows: light higher hydrocarbon $6 \mathrm{~g} / \mathrm{kWh}$, syngas $14.4 \mathrm{~g} / \mathrm{kWh}$, and liquid fuel $5.8 \mathrm{~g} / \mathrm{kWh}$. Chain reactions led to the production of higher hydrocarbons initiated by $\left[\mathrm{CH}_{3}{ }^{*}\right]$ methyl radical $[81,213]$. When $\mathrm{CO}_{2}$ was reacted with $\mathrm{CH}_{4}, \mathrm{H}_{2}$ or $\mathrm{H}_{2} \mathrm{O}$, the following end products were formed: $\mathrm{CH}_{3} \mathrm{OH}, \mathrm{C}_{2} \mathrm{H}_{6} \mathrm{O}, \mathrm{CH}_{2} \mathrm{O}, \mathrm{C}_{2} \mathrm{H}_{4} \mathrm{O}, \mathrm{C}_{\mathrm{n}} \mathrm{H}_{2 \mathrm{n}+1} \mathrm{COOH}$, higher hydrocarbons $\left(\mathrm{C}_{2} \mathrm{H}_{\mathrm{x}}, \mathrm{C}_{3} \mathrm{H}_{\mathrm{y}}, \mathrm{C}_{4} \mathrm{H}_{\mathrm{z}}\right)$ and syngas. Thus, the combination of plasma technology with catalysis is advisable when selective synthesis of specific compounds is required. Table 8 shows a summary of various catalysts used for DRM in NTP-assisted $\mathrm{CO}_{2}$ conversion, comparing the conversion and selectivity. Various studies have been carried out on oxidative coupling of $\mathrm{CH}_{4}$ to $\mathrm{C}_{2} \mathrm{H}_{6}$ and $\mathrm{C}_{2} \mathrm{H}_{4}$ over $\mathrm{SrO}-\mathrm{Cr}_{2} \mathrm{O}_{3}, \mathrm{SrO}-\mathrm{ZnO}, \mathrm{SrO}-\mathrm{CeO}_{2}, \mathrm{SrO}-\mathrm{MnO}_{2}, \mathrm{BaO}-\mathrm{ZnO}, \mathrm{BaO}-\mathrm{Cr}_{2} \mathrm{O}_{3}, \mathrm{BaO}-\mathrm{CeO}_{2}$ [359], $\mathrm{CaO}-\mathrm{CeO}_{2}$ [360], $\mathrm{La}_{2} \mathrm{O}_{3}-\mathrm{ZnO}$ [361], $\mathrm{CaO}-\mathrm{MnO}_{2}, \mathrm{CaO}-\mathrm{Cr}_{2} \mathrm{O}_{3}$ [362], $\mathrm{MnO}_{2}-\mathrm{SrCO}_{3}$ [363], and $\mathrm{La}_{2} \mathrm{O}_{3} / \gamma-\mathrm{Al}_{2} \mathrm{O}_{3}$. Zhang et al. [364] investigated the effect of $\mathrm{La}_{2} \mathrm{O}_{3} / \gamma-\mathrm{Al}_{2} \mathrm{O}_{3}$ catalysts on $\mathrm{CO}_{2}$ and $\mathrm{CH}_{4}$ reactions via corona pulse discharge. $\mathrm{A} \mathrm{C}_{2}$ selectivity $72.8 \%$ was achieved with a $7 \% \mathrm{La}_{2} \mathrm{O}_{3} /$ $\gamma-\mathrm{Al}_{2} \mathrm{O}_{3}$ catalyst, which is higher than when no catalyst was used. The conversion of $\mathrm{CH}_{4}$ attained was $24.9 \%$. The highest $\mathrm{C}_{2}$ product selectivity achieved using the catalyst was $54.5 \%$ for $\mathrm{C}_{2} \mathrm{H}_{2}$, followed by $\mathrm{C}_{2} \mathrm{H}_{4}(9.3 \%)$ and $\mathrm{C}_{2} \mathrm{H}_{6}(9.1 \%)$. The $\mathrm{CO}_{2}$ concentration influences $\mathrm{C}_{2}$ selectivity and $\mathrm{CH}_{4}$ conversion as the $\mathrm{CO}_{2}$ feed concentration is directly proportional to $\mathrm{CH}_{4}$ conversion.

Table 8. Summarized list of catalysts used for DRM to higher hydrocarbons.

\begin{tabular}{|c|c|c|c|c|c|c|c|c|c|c|}
\hline italyst & Plasma & $\begin{array}{l}\text { Power } \\
(\mathrm{W})\end{array}$ & $\mathrm{T}\left({ }^{\circ} \mathrm{C}\right)$ & $\begin{array}{c}\mathrm{CO}_{2} / \mathrm{CH}_{4} \\
\text { molar } \\
\text { ratio }\end{array}$ & $\begin{array}{l}\text { SIE } \\
(k J / L)\end{array}$ & $\begin{array}{l}\mathrm{CO}_{2} \\
\text { conversion } \\
(\%)\end{array}$ & $\begin{array}{l}\mathrm{CH}_{4} \\
\text { Conversion } \\
(\%)\end{array}$ & $\begin{array}{l}\text { Highest } \mathrm{H}_{2} \\
\text { selectivity (\%) }\end{array}$ & $\begin{array}{l}\text { Highest CO } \\
\text { selectivity } \\
(\%)\end{array}$ & Ref. \\
\hline $\begin{array}{l}\% \mathrm{Ni}^{-} / \mathrm{La}_{2} \mathrm{O}_{3^{-}} \\
\mathrm{gAl}_{2} \mathrm{O}_{4}\end{array}$ & DBD & 125.6 & - & $1: 1$ & - & 84.0 & 79.9 & 41.4 & 40.5 & [365] \\
\hline
\end{tabular}




\begin{tabular}{|c|c|c|c|c|c|c|c|c|c|c|}
\hline$\overline{/ \gamma-\mathrm{Al}_{2} \mathrm{O}_{3}-\mathrm{MgO}}$ & DBD & 100 & - & $1: 1$ & 300 & 74.5 & 73 & 47.0 & 48.0 & [71] \\
\hline - 10 wt. $\%$ & DBD & 260 & - & $1: 1$ & 130 & 33.5 & 55.7 & 53.5 & 63.9 & {$[366]$} \\
\hline \multicolumn{11}{|l|}{$/ \gamma-\mathrm{Al}_{2} \mathrm{O}_{3}$} \\
\hline :olite $\mathrm{NaX}$ & DBD & 500 & 150 & $1: 1$ & 200 & $18.0^{\mathrm{a}}$ & $22.0^{\mathrm{a}}$ & - & 44.9 & [367] \\
\hline :olite A & DBD & $100-500$ & 150 & $1: 1$ & 150 & 39.4 & 63.6 & 50.0 & $50.0^{\mathrm{a}}$ & [287] \\
\hline olite $\mathrm{NaY}$ & DBD & 500 & 150 & $1: 1$ & 150 & 39.9 & 66.6 & 38.6 & 42.7 & [368] \\
\hline :olite HY & DBD & $100-500$ & 150 & - & 150 & 37.0 & 63.0 & - & 46.1 & [369] \\
\hline$\%$ & DBD & 8 & $\mathrm{RT}$ & $2.3: 1$ & - & 12.9 & 21.9 & 30.0 & 66.9 & {$[52]$} \\
\hline \multicolumn{11}{|l|}{${ }_{2} \mathrm{O}_{3} / \mathrm{Al}_{2} \mathrm{O}_{3}$} \\
\hline$/ \mathrm{Al}_{2} \mathrm{O}_{3}-\mathrm{ZrO}_{2}$ & LPGD & - & 850 & $2: 1$ & - & 77.8 & 80.7 & - & - & [370] \\
\hline$/ \mathrm{Al}_{2} \mathrm{O}_{3}$ & APGD & - & 750 & - & - & 78.8 & 73.3 & - & - & [371] \\
\hline$/ \mathrm{MgO}$ & DBD & - & 700 & & - & 30.7 & 20.0 & - & - & {$[372]$} \\
\hline $\mathrm{Fe} / \gamma-\mathrm{Al}_{2} \mathrm{O}_{3}$ & DBD & 160 & & $1: 1$ & - & 60.5 & 68.7 & 74.4 & 86.7 & [369] \\
\hline $\mathrm{Fe}_{2} \mathrm{O}_{4} \# \mathrm{SiO}_{2}$ & DBD & 160 & & $1: 1$ & - & 70.3 & 80.0 & 80.5 & 89.9 & [369] \\
\hline
\end{tabular}

RT- Room temperature; LPGD-Low pressure glow discharge; a- indicates that the values were taken from the graph

The oxidative synthesis of high-value $\mathrm{C}_{\mathrm{x}} \mathrm{H}_{\mathrm{y}}$ using $\mathrm{CH}_{4}$ and $\mathrm{CO}_{2}$ as oxidants, together with the removal of $\mathrm{NO}_{\mathrm{x}}$ and $\mathrm{SO}_{\mathrm{x}}$, has great potential for industrial applications for the removal of $\mathrm{CO}_{2}$ emissions by conversion, which is very economically attractive. In order to commercialize this technique, there is a need for further investigation and improvement in the following areas: obtaining a usable production rate of useful products, optimization of NTP discharge reactor, and sourcing a low cost and sustainable power supply.

\subsection{3 $\mathrm{CO}_{2}$ hydrogenation}

4.2.3.1 Reverse water gas shift reaction

$\mathrm{CO}_{2}+\mathrm{H}_{2} \rightarrow \mathrm{CO}+\mathrm{H}_{2} \mathrm{O}, \quad \Delta \mathrm{H}^{0}, 298 \mathrm{~K}=-49.8 \mathrm{~kJ} / \mathrm{mol}$ 
This is one of the main ways of converting $\mathrm{CO}_{2}$ into fuel and chemical energy. Reaction R44 is commonly known as the reverse water gas shift (RWGS) reaction. It occurs when $\mathrm{H}_{2}$ is reacted with $\mathrm{CO}_{2}$ in a plasma process and is used when products other than $\mathrm{CH}_{4}$ are needed. The $\mathrm{H}_{2} / \mathrm{CO}_{2}$ ratio can be altered appropriately as various products attain the maximum selectivity at varying reagent ratios [30]. The production of liquid fuels can also be achieved through Fischer-Tropsch synthesis, whereby $\mathrm{CO}_{2}$ is at least partly converted using $\mathrm{H}_{2}$ at high temperatures to form $\mathrm{CO}$ via the RWGS to form the syngas required for Fischer-Tropsch synthesis. The RWGS leads to extra consumption of $\mathrm{H}_{2}$ and inhibits the formation of $\mathrm{CH}_{3} \mathrm{OH}$ [373]. According to Inui \& Takeguchi [374], the large amount of $\mathrm{H}_{2} \mathrm{O}$ produced as a byproduct from both $\mathrm{CH}_{3} \mathrm{OH}$ synthesis and the RWGS side reaction had a negative effect on the active metal in the reaction process, thus resulting in catalyst deactivation. Consequently, $\mathrm{CH}_{3} \mathrm{OH}$ synthesis from the hydrogenation of $\mathrm{CO}_{2}$ requires more selective catalysts to avoid the formation of unwanted byproducts [375].

\subsubsection{Hydrogenation of $\mathrm{CO}_{2}$ to $\mathrm{CH}_{3} \mathrm{OH}$}

$$
\begin{array}{ll}
\mathrm{CO}+2 \mathrm{H}_{2} \rightarrow \mathrm{CH}_{3} \mathrm{OH} & \Delta \mathrm{H}^{0}, 298 \mathrm{~K}=-90.8 \mathrm{~kJ} / \mathrm{mol} \\
\mathrm{CO}_{2}+3 \mathrm{H}_{2} \rightarrow \mathrm{CH}_{3} \mathrm{OH}+\mathrm{H}_{2} \mathrm{O} & \Delta \mathrm{H}^{0}, 298 \mathrm{~K}=-40.9 \mathrm{~kJ} / \mathrm{mol}
\end{array}
$$

The main reactions for hydrogenation of carbon dioxide to $\mathrm{CH}_{3} \mathrm{OH}$ synthesis are shown in R44R46. There is a high likelihood that $\mathrm{CO}$ produced from reaction R44 may undergo further hydrogenation to form $\mathrm{CH}_{3} \mathrm{OH}$ (reaction R45). Reactions $\mathrm{R} 45$ and $\mathrm{R} 46$ show the selective hydrogenation of $\mathrm{CO}$ and $\mathrm{CO}_{2}$ to $\mathrm{CH}_{3} \mathrm{OH}$ (methanol), respectively. The major disadvantage of selective hydrogenation of $\mathrm{CO}_{2}$ is the formation of $\mathrm{H}_{2} \mathrm{O}$ as a product as this can deactivate catalysts and has to be separated from the methanol to isolate the pure product [158, 311]. Reactions R45 and $\mathrm{R} 46$ are currently employed on an industrial scale for $\mathrm{CH}_{3} \mathrm{OH}$ production. $\mathrm{CO}_{2}$ hydrogenation to $\mathrm{CH}_{3} \mathrm{OH}$ is a promising process for $\mathrm{CO}_{2}$ conversion and utilization. Despite a well-developed route for $\mathrm{CO}$ hydrogenation to $\mathrm{CH}_{3} \mathrm{OH}$, the use of $\mathrm{CO}_{2}$ as a feedstock for $\mathrm{CH}_{3} \mathrm{OH}$ synthesis remains underexplored, and one of its major drawbacks is high reaction pressure (usually 30-300 atm) [376]. Current research on $\mathrm{CO}_{2}$ hydrogenation to $\mathrm{CH}_{3} \mathrm{OH}$ mostly focuses on the use of heterogeneous catalysis at high pressures. Cu-based catalysts have attracted great interest for 
catalytic $\mathrm{CO}_{2}$ hydrogenation for $\mathrm{CH}_{3} \mathrm{OH}$ synthesis, attributable to the excellent activity of metallic $\mathrm{Cu}$ for this reaction [376].

4.2.3.3 Hydrogenation of $\mathrm{CO}_{2}$ to $\mathrm{CH}_{4}$

$\mathrm{CO}_{2}+4 \mathrm{H}_{2} \rightarrow \mathrm{CH}_{4}+2 \mathrm{H}_{2} \mathrm{O} \quad \Delta \mathrm{H}^{0}, 298 \mathrm{~K}=-165 \mathrm{~kJ} / \mathrm{mol}$

For reaction $\mathrm{R} 47$ (methane production), a higher $\mathrm{H}_{2}$ feed content is favorable for $\mathrm{CO}_{2}$ conversion. A typical $\mathrm{H}_{2} / \mathrm{CO}_{2}$ ratio of $4: 1$ is used to give the best $\mathrm{CH}_{4}$ selectivity and $\mathrm{CO}_{2}$ conversion [66]. $\mathrm{CO}_{2}$, being a stable molecule, requires a very active catalyst and/ or high energy input for the chemical transformation, but the addition of $\mathrm{H}_{2}$ provides room for methanation ( $\left.\mathrm{R} 47\right)$, which is exothermic and highly thermodynamically favorable at low temperatures. Therefore, lower temperatures and high pressures promote the reaction. Nakagawa et al. [377] used a pulse power discharge in the reduction of $\mathrm{CO}_{2}$ both in the presence and absence of $\mathrm{H}_{2} . \mathrm{CO}_{2}$ reduction using $\mathrm{H}_{2}$ was found to be independent of gas pressure. At a pressure $<450$ Torr the reduction efficiency recorded was approximately twice that when $\mathrm{H}_{2}$ was a presence in $\mathrm{CO}_{2}$ feed. $\mathrm{H}_{2} \mathrm{O}$ can be used for syngas production and in methanation [62], though further reports indicated that the addition of $\mathrm{H}_{2} \mathrm{O}$ may result in a reduced $\mathrm{CO}_{2}$ conversion [378]. Table 9 provides a simplified scheme for the reaction of $\mathrm{H}+\mathrm{CO}_{2}$ in the presence of microwave plasma. It should be highlighted that some of the recorded rate constants are out of the temperature range of less than $2000 \mathrm{~K}$ [379]. The reverse shift water gas reaction mechanism considers the proposed scheme and starts with R57, where $\mathrm{O}$ and $\mathrm{CO}$ are released [62]. The generation of $\mathrm{O}$ atoms generally results in the production of $\mathrm{H}$ atoms and $\mathrm{OH}$ radicals, as indicated in $\mathrm{R} 60$. Therefore, the large concentration of $\mathrm{H}$ atoms renders $\mathrm{R} 48$ the predominant path for $\mathrm{CO}$ production, whereas $\mathrm{R} 61$ dominates the $\mathrm{H}_{2} \mathrm{O}$ formation path (as shown in R48, R65 and $\mathrm{R} 66$ for $\mathrm{OH}$ radical generation).

Table 9. Summary of chemical reactions scheme for the reaction of $\mathrm{H}_{2}$ and $\mathrm{CO}_{2}$

\begin{tabular}{llll}
\hline Reaction & $\left.\begin{array}{l}\text { Rate Constant } \\
\left(\mathrm{cm}^{3} \text { molecule }\right.\end{array} \mathrm{s}^{-1}\right)$ & Reaction & Ref. \\
& $2.5 \times 10^{-10} \exp (-13300 / \mathrm{T})$ & $\mathrm{R} 48$ & {$[379]$} \\
\hline $\mathrm{CO}_{2}+\mathrm{H} \rightarrow \mathrm{CO}+\mathrm{OH}$ & $2 \times 10^{-8} \exp (-57900 / \mathrm{T})$ & $\mathrm{R} 49$ & {$[380]$} \\
$\mathrm{O}_{2}+\mathrm{O} \rightarrow \mathrm{O}+\mathrm{O}+\mathrm{O}$ & $8.14 \times 10^{-9} \exp (-59700 / \mathrm{T})$ & $\mathrm{R} 50$ & {$[380]$} \\
$\mathrm{O}_{2}+\mathrm{O}_{2} \rightarrow \mathrm{O}+\mathrm{O}+\mathrm{O}_{2}$ & $2.40 \times 10^{-9} \exp (-59500 / \mathrm{T})$ & $\mathrm{R} 51$ & {$[380]$} \\
$\mathrm{O}_{2}+\mathrm{CO} \rightarrow \mathrm{O}+\mathrm{O}+\mathrm{CO}$ & & & \\
\hline
\end{tabular}




\begin{tabular}{llll}
\hline $\mathrm{O}_{2}+\mathrm{CO}_{2} \rightarrow \mathrm{O}+\mathrm{O}+\mathrm{CO}_{2}$ & $2.57 \times 10^{-9} \exp (-56150 / \mathrm{T})$ & $\mathrm{R} 52$ & {$[380]$} \\
$\mathrm{CO}+\mathrm{O}_{2} \rightarrow \mathrm{CO}_{2}+\mathrm{O}$ & $1.23 \times 10^{-12} \exp (-12800 / \mathrm{T})$ & $\mathrm{R} 53$ & {$[328]$} \\
$\mathrm{CO}_{2}+\mathrm{O} \rightarrow \mathrm{CO}+\mathrm{O}_{2}$ & $7.77 \times 10^{-12} \exp (-16600 / \mathrm{T})$ & $\mathrm{R} 54$ & {$[328]$} \\
$\mathrm{CO}_{2}+\mathrm{O}_{2} \rightarrow \mathrm{CO}+\mathrm{O}+\mathrm{O}_{2}$ & $3.72 \times 10^{-10} \exp (-60200 / \mathrm{T})$ & $\mathrm{R} 55$ & {$[380]$} \\
$\mathrm{CO}_{2}+\mathrm{CO} \rightarrow \mathrm{CO}+\mathrm{O}+\mathrm{CO}$ & $4.39 \times 10^{-7} \exp (-65000 / \mathrm{T})$ & $\mathrm{R} 56$ & {$[380,381]$} \\
$\mathrm{CO}_{2}+\mathrm{CO}_{2} \rightarrow \mathrm{CO}+\mathrm{O}+$ & $4.39 \times 10^{-7} \exp (-65000 / \mathrm{T})$ & $\mathrm{R} 57$ & {$[380,381]$} \\
$\mathrm{CO}_{2}$ & & & \\
$\mathrm{CO}+\mathrm{OH} \rightarrow \mathrm{CO}_{2}+\mathrm{H}$ & $1.12 \times 10^{-13} \exp (0.00091 / \mathrm{T})$ & $\mathrm{R} 58$ & {$[379]$} \\
$\mathrm{H}_{2}+\mathrm{H}_{2} \rightarrow \mathrm{H}+\mathrm{H}+\mathrm{H}_{2}$ & $1.43 \times 10-12 \mathrm{~T}^{-0.7} \exp (-52530 / \mathrm{T})$ & $\mathrm{R} 59$ & {$[379]$} \\
$\mathrm{O}+\mathrm{H}_{2} \rightarrow \mathrm{OH}+\mathrm{H}$ & $1.80 \times 10^{-20} \mathrm{~T}^{2.8} \exp (-2980 / \mathrm{T})$ & $\mathrm{R} 60$ & {$[379]$} \\
$\mathrm{OH}+\mathrm{H}_{2} \rightarrow \mathrm{H}_{2} \mathrm{O}+\mathrm{H}$ & $1.06 \times 10^{-17} \mathrm{~T}^{2} \exp (-1490 / \mathrm{T})$ & $\mathrm{R} 61$ & {$[379]$} \\
$\mathrm{OH}+\mathrm{H} \rightarrow \mathrm{O}+\mathrm{H}_{2}$ & $8.10 \times 10^{-21} \mathrm{~T}^{2.8} \exp (-1950 / \mathrm{T})$ & $\mathrm{R} 62$ & {$[379]$} \\
$\mathrm{OH}+\mathrm{O} \rightarrow \mathrm{H}+\mathrm{O}_{2}$ & $7.50 \times 10^{-10} \mathrm{~T}^{-0.5} \exp (-30 / \mathrm{T})$ & $\mathrm{R} 63$ & {$[379]$} \\
$\mathrm{OH}+\mathrm{OH} \rightarrow \mathrm{H}_{2} \mathrm{O}+\mathrm{O}$ & $3.50 \times 10^{-16} \mathrm{~T}^{1.4} \exp (200 / \mathrm{T})$ & $\mathrm{R} 64$ & {$[379]$} \\
$\mathrm{H}_{2} \mathrm{O}+\mathrm{O} \rightarrow \mathrm{OH}+\mathrm{OH}$ & $7.60 \times 10^{-15} \mathrm{~T}^{1.3} \exp (-8605 / \mathrm{T})$ & $\mathrm{R} 65$ & {$[379]$} \\
$\mathrm{H}_{2} \mathrm{O}+\mathrm{H} \rightarrow \mathrm{H}_{2}+\mathrm{OH}$ & $1.03 \times 10^{-16} \mathrm{~T}^{1.9} \exp (-9265 / \mathrm{T})$ & $\mathrm{R} 66$ & {$[379]$} \\
\hline
\end{tabular}

Currently, there are increasing interests in the development of improved sustainable industrial processes for the direct hydrogenation of $\mathrm{CO}_{2}$ to $\mathrm{CH}_{3} \mathrm{OH}$ due to the promising significance of $\mathrm{CH}_{3} \mathrm{OH}$ in an expanding hydrogen economy. $\mathrm{CH}_{3} \mathrm{OH}$ is a primary liquid petrochemical which is of high significance in both the energy and chemical industries. $\mathrm{CH}_{3} \mathrm{OH}$ can be easily stored and transported $[382,383]$. During the non-thermal discharge process, both $\mathrm{H}_{2}$ and $\mathrm{CO}_{2}$ are excited, whereby they possess sufficient energy to counter the limitation of high activation energy of direct hydrogenation of $\mathrm{CO}_{2}$ without the use of catalyst [81]. Activation energy is defined as the minimum input energy required to initiate a reaction.

$\mathrm{CO}_{2}+\mathrm{e} \rightarrow \mathrm{CO}_{2}{ }^{*}+\mathrm{e}$

$\mathrm{H}_{2}+\mathrm{e} \rightarrow \mathrm{H}_{2} *+e$

Direct production of $\mathrm{CH}_{3} \mathrm{OH}$ from the hydrogenation of $\mathrm{CO}_{2}$ is environmentally sustainable and efficient as it becomes increasingly attainable to make hydrogen gas in an economically efficient way using renewable energy [383]. Eliasson et al. [384] investigated $\mathrm{CO}_{2}$ hydrogenation into 
$\mathrm{CH}_{3} \mathrm{OH}$ using a DBD with and without a catalyst. The numerical simulation and experimental results indicated that $\mathrm{CH}_{4}$ formation was the main competitive reaction for the formation of $\mathrm{CH}_{3} \mathrm{OH}$. Furthermore, the effects of pressure, gas temperature, the flow rate of the feed gas, the mixing ratio of inlet gas and electric power were also investigated. It was shown that at high pressure and low electric power the formation of $\mathrm{CH}_{3} \mathrm{OH}$ can exceed the methanation process. De Bie et al. [383] carried out 1D fluid modeling for $\mathrm{CO}_{2}$ hydrogenation in a DBD plasma at varying $\mathrm{CO}_{2} / \mathrm{H}_{2}$ ratios, residence time, and plasma species. The most common reaction products obtained were $\mathrm{H}_{2} \mathrm{O}, \mathrm{CH}_{4}$ and $\mathrm{CO}$, while $\mathrm{CH}_{3} \mathrm{OH}, \mathrm{C}_{2} \mathrm{H}_{6}, \mathrm{O}_{2}$, and $\mathrm{CH}_{2} \mathrm{O}$ were also formed to a lower extent. Varying the $\mathrm{CO}_{2} / \mathrm{H}_{2}$ molar ratios did not greatly affect the densities of oxygenates and hydrocarbon formed as the $\mathrm{CO}_{2}$ conversion was found to be low, irrespective of the gas mixing ratios. Very recently, Wang et al. have developed a novel and specially designed DBD reactor using water as both the ground electrode and cooling for the direct $\mathrm{CO}_{2}$ hydrogenation to methanol at room temperature and atmospheric pressure. They found that the reactor structure greatly affects the production of methanol in this process. The highest methanol selectivity of $54 \%$ was achieved in the plasma hydrogenation of $\mathrm{CO}_{2}$ without a catalyst at ambient conditions [376].

Liu et al. [81] provided the radical reaction mechanism for the hydrogenation of $\mathrm{CO}_{2}$ [384] in a review on NTP approaches in $\mathrm{CO}_{2}$ utilization. Bill et al. [385] carried out the hydrogenation of $\mathrm{CO}_{2}$ to $\mathrm{CH}_{3} \mathrm{OH}$ in a tubular packed bed reactor using $\mathrm{Cu}$-based catalysts and a comparative approach was also investigated using a DBD reactor. It was realized that the simultaneous presence of plasma discharge and a catalyst led to a considerable decrease in the optimum temperature range from $220{ }^{\circ} \mathrm{C}$ (packed bed reactor) to approximately $100{ }^{\circ} \mathrm{C}$ inside the discharge. A considerable increase in $\mathrm{CH}_{3} \mathrm{OH}$ yield was obtained when $\mathrm{CuO} / \mathrm{ZnO} / \mathrm{Al}_{2} \mathrm{O}_{3}$ catalysts were introduced in the discharge zone, with the yield of $\mathrm{CH}_{3} \mathrm{OH}$ improved by a factor of approximately $10 . \mathrm{CO}_{2}$ reduction and recycling were conducted using NTP at atmospheric pressure by surface discharge. Valuable hydrocarbons (dimethyl ether and $\mathrm{CH}_{4}$ ) were produced at $11 \mathrm{kV}$ discharge voltage, a $\mathrm{CO}_{2} / \mathrm{H}_{2}$ ratio of $1: 2$, and a flow rate of $0.2 \mathrm{l} / \mathrm{min}$. $\mathrm{CO}_{2}$ conversion to $\mathrm{C}_{\mathrm{x}} \mathrm{H}_{\mathrm{y}}$ plus water vapor (deoxidizing agent) of $50 \%$ needed a higher voltage of $12 \mathrm{kV}$ [386]. In $\mathrm{CH}_{3} \mathrm{OH}$ formation using NTPs plasma, methyl formation plays an important role [387]. Bhatnagar et al. [388] confirmed that the methyl radical could promote the parallel formation of $\mathrm{C}_{2} \mathrm{H}_{6}$. Apart from $\mathrm{CH}_{4}, \mathrm{H}_{2}$, and $\mathrm{H}_{2} \mathrm{O}$ commonly being used as hydrogen sources, glycerol has been suggested as a hydrogen source. It has been investigated 
and implemented as a $\mathrm{H}_{2}$ donor in the formation of $\mathrm{CH}_{3} \mathrm{OH}$ from $\mathrm{CO}_{2}$ in a hybrid photocatalyticenzymatic system [389].

\subsubsection{Reduction with $\mathrm{H}_{2} \mathrm{O}$}

$\mathrm{CO}_{2}+\mathrm{H}_{2} \mathrm{O} \rightarrow \mathrm{CO}+\mathrm{H}_{2}+\frac{1}{2} \mathrm{O}_{2}, \Delta \mathrm{H}^{0}, 298 \mathrm{~K}=525 \mathrm{~kJ} / \mathrm{mol}$

$\mathrm{CO}_{2}+2 \mathrm{H}_{2} \mathrm{O} \rightarrow \mathrm{CH}_{3} \mathrm{OH}+\frac{3}{2} \mathrm{O}_{2}, \quad \Delta \mathrm{H}^{0}, 298 \mathrm{~K}=676 \mathrm{~kJ} / \mathrm{mol}$

There is no known traditional reforming approach for the conversion of $\mathrm{CO}_{2}$ with $\mathrm{H}_{2} \mathrm{O}$, hence R69 and R70 are presented for the purpose of interest. R69 and R70 are endothermic reactions, partially explaining why there is no thermocatalytic approach. High temperatures are required for R69 and R70 as they are for the splitting of pure $\mathrm{CO}_{2}$, but with lower energy efficiency.

5. Technology development of plasma $\mathrm{CO}_{2}$ conversion and utilization

\section{1. $\mathrm{CO}_{2}$ capture}

Recently, numerous technologies on $\mathrm{CO}_{2}$ capture and storage (CCS) have been reported. The process involves three main steps: capturing $\mathrm{CO}_{2}$ emissions (pre-combustion, oxy-fuel combustion, post-combustion), transportation, and $\mathrm{CO}_{2}$ storage. The $\mathrm{CO}_{2}$ storage methods currently under consideration include $\mathrm{CO}_{2}$ disposal in deep oceans, aquifers, and minerals storage [390-392]. CCS and $\mathrm{CO}_{2}$ utilization are two effective approaches for mitigating or limiting $\mathrm{CO}_{2}$ emissions. One of the major criteria that have to be attained is that a sufficient quantity of $\mathrm{CO}_{2}$ must be converted, stored or otherwise prevented from release into the atmosphere [393]. Generally, $\mathrm{CO}_{2}$ is captured from large industrial plants and other non-atmospheric $\mathrm{CO}_{2}$ sources like geothermal vents (releasing stored $\mathrm{CO}_{2}$ ). Some methods used to capture $\mathrm{CO}_{2}$ from the atmosphere include using carbonate and hydroxide absorbents, producing $\mathrm{H}_{2}$ by $\mathrm{H}_{2} \mathrm{O}$ hydrolysis, and synthesizing $\mathrm{CH}_{3} \mathrm{OH}$ by the reaction of $\mathrm{H}_{2}$ and $\mathrm{CO}$ using heat and electricity supplied by nuclear fusion or fission. $\mathrm{CO}_{2}$ stripping from seawater is another method that is being considered to reduce the environmental impact of $\mathrm{CO}_{2}$ emissions [394-396]. The major problem of $\mathrm{CO}_{2}$ disposal can be avoided, and even turned into an advantage, by converting $\mathrm{CO}_{2}$ into valuable products and alternative fuels using NTP. 
Lee et al. [397] reviewed various techniques for $\mathrm{CO}_{2}$ capture and utilization. These include: $\mathrm{CO}_{2}$ capture, electrolysis of $\mathrm{CO}_{2}$ and $\mathrm{H}_{2} \mathrm{O}$, and fuel synthesis. The electrolysis of $\mathrm{CO}_{2}$ and $\mathrm{H}_{2} \mathrm{O}$ has been carried out in solid oxide cells to produce a $\mathrm{CO}$ and $\mathrm{H}_{2}$ mixture [398-402]. However, the process also disadvantageously produced $\mathrm{CO}_{2}$ and $\mathrm{O}_{2}$ together in the anode compartment of the electrolysis cell, hence the need for subsequent gas-phase separation [403, 404]. Different options for $\mathrm{CO}_{2}$ capture are illustrated in Fig. 15, with the primary focus on both atmospheric air and stationary air.

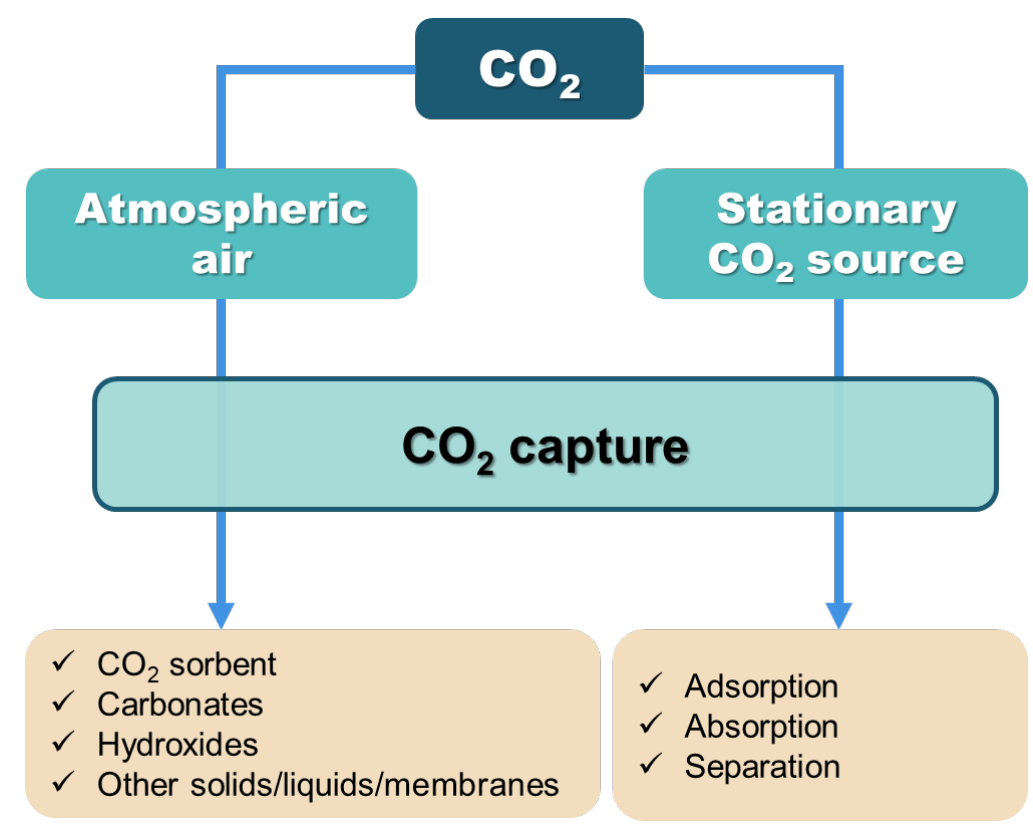

Figure 15. Various options for $\mathrm{CO}_{2}$ capture

The use of alkaline chemicals has dominated other methods for scrubbing the air to achieve stores of concentrated $\mathrm{CO}_{2}$. Indeed, various methods for removing $\mathrm{CO}_{2}$ from the atmosphere using alkaline absorbents have been investigated since the 1940s. Different metal hydroxides, including $\mathrm{Ca}(\mathrm{OH})_{2}, \mathrm{NaOH}$ and $\mathrm{KOH}$, have been used since they readily react with $\mathrm{CO}_{2}$ to form carbonates $\left(\mathrm{CO}_{2}+2 \mathrm{OH} \rightarrow \mathrm{CO}_{3}{ }^{2-}+\mathrm{H}_{2} \mathrm{O}\right)$. The adsorbents are regenerated using heat or electrical energy to release the bound $\mathrm{CO}_{2}$, or a carbonate solution is used that dissolves the $\mathrm{CO}_{2}$ to form bicarbonate $\left(\mathrm{CO}_{2}+\mathrm{CO}_{3}{ }^{2-}+\mathrm{H}_{2} \mathrm{O} \rightarrow 2 \mathrm{HCO}_{3}{ }^{-}\right)$. Fig. 16 illustrates some of the different $\mathrm{CO}_{2}$ capture technologies, including adsorption, absorption, membrane, cryogenic, chemical looping combustion, and hydrate. The major challenges of these technologies are presented in Table 10. 


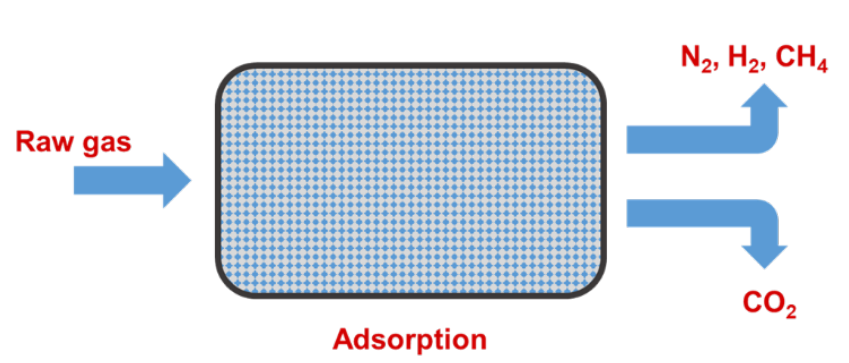

a. Adsorption

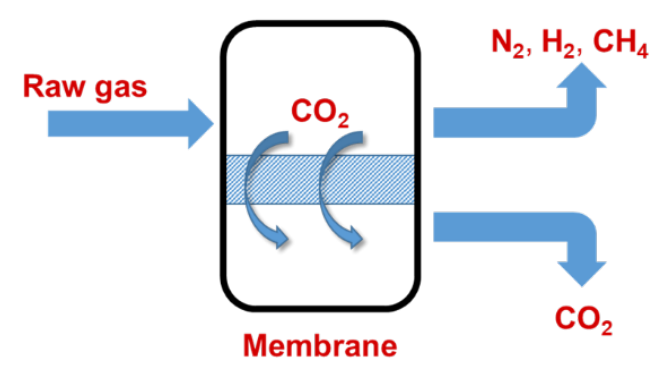

b. Membrane

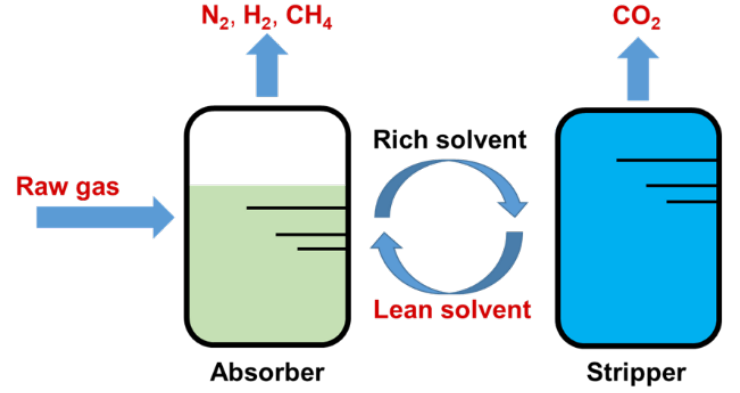

c. Absorption

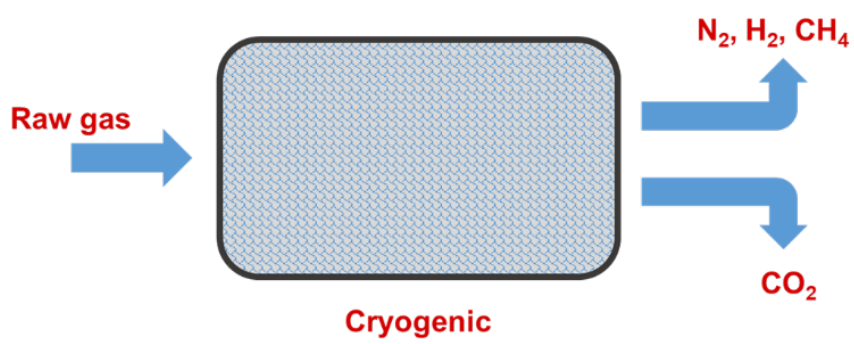

d. Cryogenic

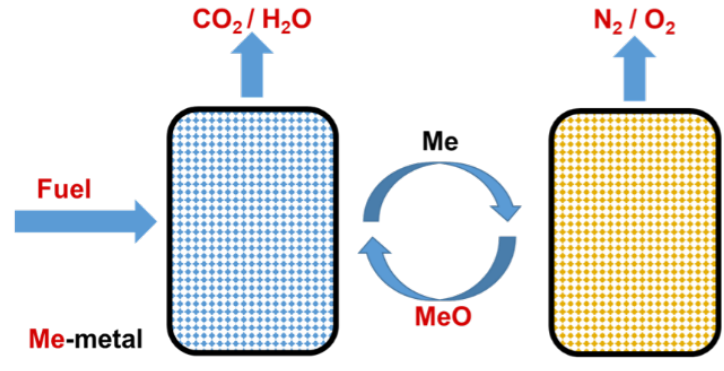

e. Chemical looping combustion

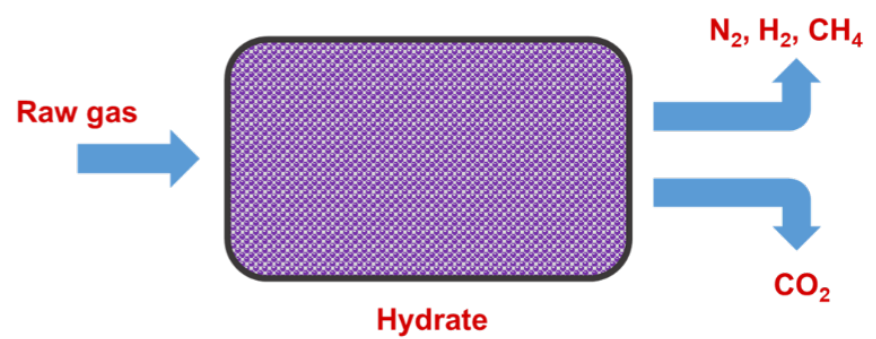

f. hydrate

Fig. 16. The schematic diagrams of various $\mathrm{CO}_{2}$ capture technologies

Table 10. Major challenges of different $\mathrm{CO}_{2}$ capture technologies [397, 405-408].

\section{Technology}

Major challenges 


\begin{tabular}{|c|c|}
\hline Adsorption & $\begin{array}{l}\mathrm{CO}_{2} \text { selectivity is relatively low. } \\
\text { Adsorption rate is generally low. } \\
\text { Difficulties in handling solid. } \\
\text { Large pressure drop in the flue gas. } \\
\text { operation. } \\
\text { It requires periodic regeneration of adsorbents. }\end{array}$ \\
\hline Membrane & $\begin{array}{l}\text { High cost due to membrane manufacturing. } \\
\text { * } \text { Requires a compression work for driving force. } \\
\text { Requires high selectivity as a result of low-pressure } \\
\text { ratio and } \mathrm{CO}_{2} \text { concentration. } \\
\text { Fouling effect. } \\
\text { * Needs high surface area membrane due to the } \\
\text { increased flow rate of the industrial flue gas. } \\
\text { The permeability of the polymeric membrane is } \\
\text { negatively affected by moisture. } \\
\text { pemperature, pressure and other operating }\end{array}$ \\
\hline Absorption & $\begin{array}{l}\text { Solvent degeneration e.g. amine. } \\
\text { Extra compression work needed for captured } \mathrm{CO}_{2} \\
\text { transportation and storage. } \\
\text { * Large energy penalty for regeneration. } \\
\text { High corrosion rate on the equipment. } \\
\text { Solvent emissions cause a negative environmental } \\
\text { impact. }\end{array}$ \\
\hline
\end{tabular}




\begin{tabular}{ll}
\hline Cryogenic & Not suitable for low $\mathrm{CO}_{2}$ concentration, generally \\
& below $50 \%$. \\
& Requires high energy to cater for adequate \\
& refrigeration. \\
& Requires removal of moisture from the gas mixture to \\
prevent blockage as a result of ice particles. & \\
& A constant build-up of solidified $\mathrm{CO}_{2}$ on heat- \\
& exchanger surfaces unfavorably affect heat transfer \\
& and lowers the process efficiency. \\
$*$ & Requires high installation cost. \\
& During capture/regeneration cycles there is sorbent \\
& decay. \\
$*$ & High vulnerability and attrition rate. \\
& Air separation unit is required to attain pure $\mathrm{O}_{2}$ for \\
& calcination. \\
&
\end{tabular}

Typical $\mathrm{CO}_{2}$ separation processes, like membrane-based separation and cryogenic distillation, are not feasible economically. Numerous techniques have been developed for $\mathrm{CO}_{2}$ capture from ambient air. Table 11 shows a selection using amine-grafted oxides, traditional solids, alkaline solutions and Metal-Organic Frameworks [409]. 
Table 11. Selection of technologies for $\mathrm{CO}_{2}$ capture from ambient air and relevant advantages and disadvantages

\begin{tabular}{|c|c|c|}
\hline Material & Advantages & Disadvantages \\
\hline Solid supported amine & $\begin{array}{l}\text { low energy requirement for regeneration; } \\
\text { high tolerance to moisture }\end{array}$ & $\begin{array}{l}\text { require hours to achieve } \\
\text { saturation }\end{array}$ \\
\hline Amine-grafted MOF & high $\mathrm{CO}_{2}$ capacity; fast kinetics & $\begin{array}{c}\text { sensitivity to moisture; } \\
\text { expensive synthesis routes; } \\
\text { unclear stability }\end{array}$ \\
\hline Alkaline solution & high $\mathrm{CO}_{2}$ selectivity; cheap material & energy-intensive regeneration \\
\hline $\begin{array}{l}\text { Traditional solid } \\
\text { (physisorbent) }\end{array}$ & high thermal stability & negative impact of moisture \\
\hline Chemisorbent & $\begin{array}{l}\text { high adsorption capacity under high } \\
\text { temperature }\end{array}$ & $\begin{array}{l}\text { huge heat requirements for } \\
\text { desorption }\end{array}$ \\
\hline
\end{tabular}

\subsection{Integration of $\mathrm{CO}_{2}$ capture with plasma $\mathrm{CO}_{2}$ conversion}

On an industrial scale, the integration of $\mathrm{CO}_{2}$ capture and conversion using NTP seems more feasible since NTP possesses the ability to break highly stable $\mathrm{CO}_{2}$ molecule at room temperature and pressure $[4,30,42] . \mathrm{CO}_{2}$ capture and utilization by NTP is a technique which relies on $\mathrm{CO}_{2}$ conversion to liquid fuels such as $\mathrm{CH}_{3} \mathrm{OH}$, carbonate, $\mathrm{C}_{2} \mathrm{H}_{6} \mathrm{O}, \mathrm{C}_{2} \mathrm{H}_{4}$, etc. In particular, $\mathrm{CH}_{3} \mathrm{OH}$ is the main feed for chemicals that can be further converted to alternative high molecular liquid fuels $[373,395]$. Various energy sources can be used in generating NTP for splitting $\mathrm{CO}_{2}$ and $\mathrm{H}_{2} \mathrm{O}$ to reverse the combustion process and produce fuels [399]. Chemical conversion of $\mathrm{CO}_{2}$ into fuels and value-added platform chemicals has been viewed as a vital aspect for developing low-carbon economic sustainability in the energy and chemical sector. A notably significant pathway that is presently being developed for $\mathrm{CO}_{2}$ utilization is catalytic $\mathrm{CO}_{2}$ hydrogenation. This technique can produce various fuels and chemicals, such as $\mathrm{CO}, \mathrm{CH}_{2} \mathrm{O}_{2}, \mathrm{CH}_{3} \mathrm{OH}$, alcohols, and hydrocarbons. Nevertheless, high $\mathrm{H}_{2}$ consumptions $\left(\mathrm{CO}_{2}+3 \mathrm{H}_{2} \rightarrow \mathrm{CH}_{3} \mathrm{OH}+\mathrm{H}_{2} \mathrm{O}\right)$ and high operating pressures (ca. 30- 300 bar) are the main disadvantages related to this technique [348]. 
$\mathrm{CO}_{2}$ capture, conversion, and utilization are the most up and coming techniques for stabilizing the amount of greenhouse gas pollution in the atmosphere. Using wasteful $\mathrm{CO}_{2}$ emissions as a portion of energy carriers for the synthesis of fuels and high value-added chemicals is an attractive chemical pathway. However, considering the chemical stability of $\mathrm{CO}_{2}$, it is very challenging to discover an energy efficient thermal process for $\mathrm{CO}_{2}$ conversion. NTP technology provides an attractive alternative to thermal processes for converting inert $\mathrm{CO}_{2}$ emissions into value-added chemicals and fuels due to its low power requirements and non-equilibrium characteristics $[115$, 283].

In this section, two pathways are proposed for $\mathrm{CO}_{2}$ capture and utilization that use NTP as an activator for either direct or indirect $\mathrm{CO}_{2}$ conversion. The first system (Fig. 17) directly converts the captured $\mathrm{CO}_{2}$ (here via reduction) to useful fuels and value-added chemicals (e.g. alcohols) using NTP. The second system (Fig. 18) first converts the captured $\mathrm{CO}_{2}$ to syngas $\left(\mathrm{CO}+\mathrm{H}_{2}\right)$, e.g. by DRM, using NTP, which is then used as a feedstock for Fischer-Tropsch synthesis to produce fuels and liquid chemicals (e.g. hydrocarbons).

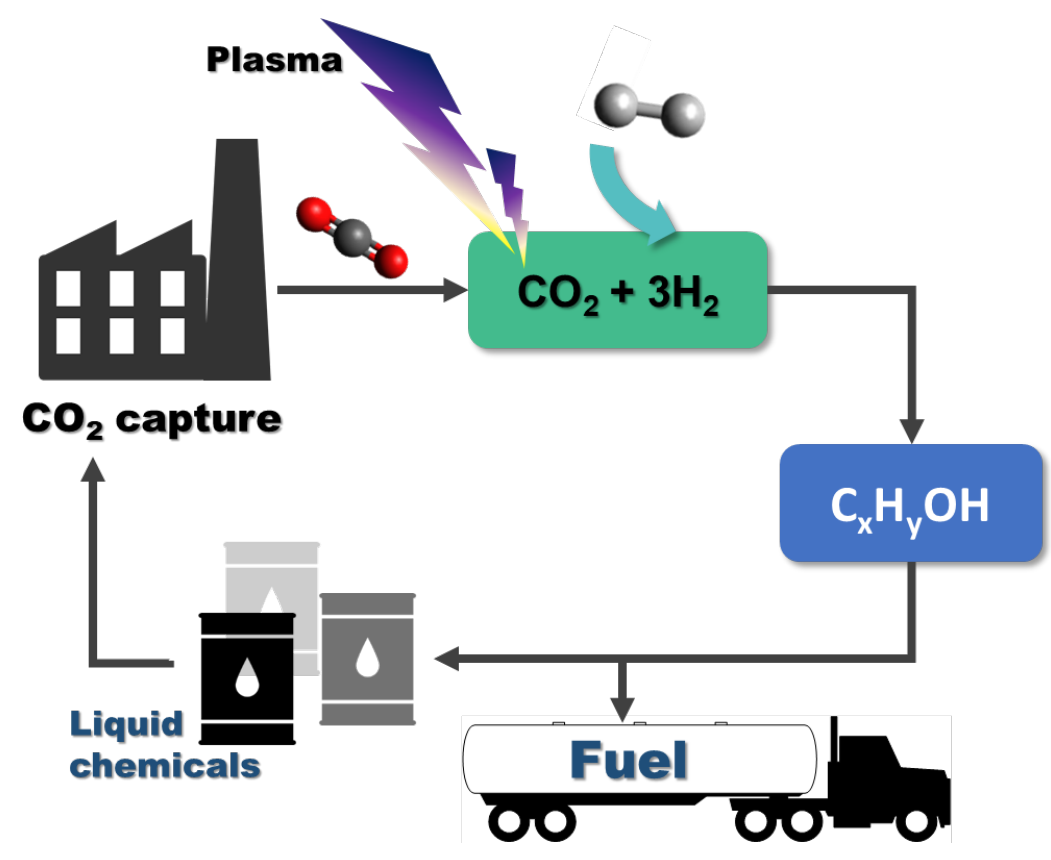

Figure 17. $\mathrm{CO}_{2}$ capture, direct $\mathrm{CO}_{2}$ conversion, and utilization. 


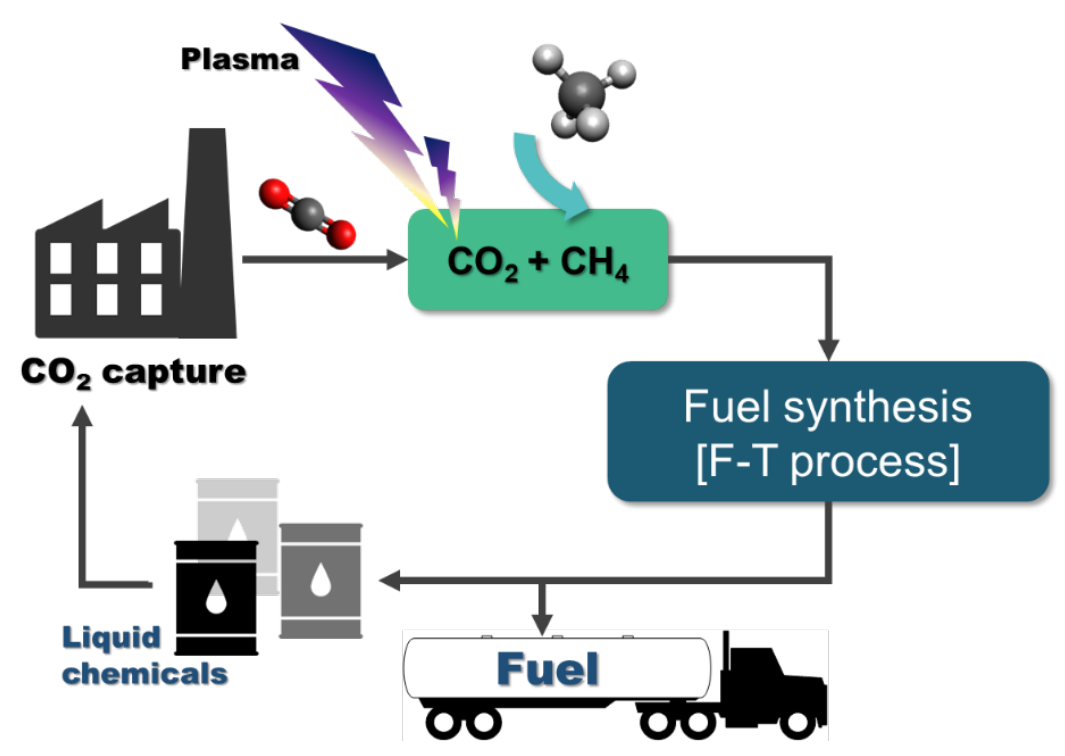

Fig. 18. $\mathrm{CO}_{2}$ capture, indirect $\mathrm{CO}_{2}$ conversion and utilization

Moss et al. [410] demonstrated that $\mathrm{CO}_{2}$ capture by pressure swing absorption (PSA) and conversion by NTP is a feasible process for the production of $\mathrm{CO}$, although on a small scale. $\mathrm{CO}$ is a useful precursor to many chemicals and major feedstocks for the chemical industries. $\mathrm{CO}_{2}$ capture was first carried out using a high PSA technique, then the flue gas composition was upgraded to high purity $\mathrm{CO}_{2}$. The captured $\mathrm{CO}_{2}$ was passed through a pulse corona discharge reactor where $\mathrm{CO}_{2}$ was converted to $\mathrm{CO}$ and other products through electron-initiated dissociation. The aim was to produce non-fossil fuels derived from carbon for chemical feedstocks using NTP technology. The advantages of this technique are that it has flexible operating conditions, the flexibility of carrier gases, and the allowance for variable gas streams to be captured and upgraded to achieve a higher concentration of $\mathrm{CO}_{2}$ with some conversion to a useful product. It was concluded that high selectivity can be attained with swift adsorption/desorption while utilizing a cheap and durable sorbent that displays zero sorbent losses and can be regenerated freely by simple pressure drops.

Nakajima et al. [411] investigated $\mathrm{CO}_{2}$ reduction using adsorption followed by NTP treatment. The technique consisted of the physical adsorption process followed by an $\mathrm{N}_{2}$ plasma reduction treatment. During the physical adsorption stage, $\mathrm{CO}_{2}$ was adsorbed by molecular sieve zeolite $13 \mathrm{X}$ (APG-III). The second stage involves the $\mathrm{N}_{2}$ plasma reduction process in which the adsorbed $\mathrm{CO}_{2}$ was reduced to $\mathrm{CO}$ using NTP flow that was generated by a circulating $\mathrm{N}_{2}$ plasma reactor. The $\mathrm{CO}$ 
produced is then used as a fuel. The $\mathrm{CO}_{2}$ conversion to $\mathrm{CO}$ was less than $5.3 \%$ with a $\mathrm{CO}$ concentration of approximately $1 \%$.

Thermal catalytic techniques are presently applied to produce liquid hydrocarbons, such as methoxymethane $\left(\mathrm{CH}_{3} \mathrm{OCH}_{3}\right)$ from $\mathrm{CO}_{2}$ and $\mathrm{H}_{2}$. For the production of $\mathrm{CH}_{3} \mathrm{OCH}_{3}$, the following conditions are required: high temperatures in the range of $240-270^{\circ} \mathrm{C}$ and pressures of $3 \mathrm{MPa}$. If NTP processes can be used as an alternative, the energy input can be remarkably reduced as NTP is at room temperature and pressure. Therefore, to produce hydrocarbons directly from $\mathrm{CO}_{2}$, hybrid catalysts are essential. New reactor setups and novel catalysts may aid in offsetting the required high pressures in a plasma reactor. Progressive research is required to develop plasma processes that produce liquid hydrocarbons, which are presently only produced by other (non-plasma) methods. However, if successful, these NTP assisted catalysis processes could completely change the energy and chemical industries [30, 412-414].

\subsection{Demonstrations of NTP- $\mathrm{CO}_{2}$ conversion}

Many laboratory-based investigations and a few large-scale demonstrations have been carried out in relation to the conversion of $\mathrm{CO}_{2}$ into valuable chemicals and fuels. There have been various practical commercialization attempts. However, none of these have been able to adequately meet the environmental and economic market requirements as a result of various challenges. Some of the most noticeable challenges include i) $\mathrm{CO}_{2}$ conversion requires higher energy input, ii) insufficient socio-economical driving forces i.e. inadequate investment-incentives and restricted market size, iii) lack of industrial commitments to promote $\mathrm{CO}_{2}$-based chemicals, iv) insufficient maturity of the technology. Considering these issues, the industrial-scale implementation of $\mathrm{CO}_{2}$ conversion to valuable products is not feasible economically [415]. The US Department of Energy is investigating various NTP technologies for their catalytic properties related to $\mathrm{CO}_{2}$ decomposition and fossil energy conversion. In addition to evaluating the effectiveness of DBD plasma for both $\mathrm{CO}_{2}$ decomposition and conversion into valuable fuels and chemicals, they have partnered with the Department of Physics at West Virginia University (WVU) to develop a Versatile Atmospheric Dielectric Barrier Discharge Experimental Reactor (VADER) to probe plasma-assisted $\mathrm{CO}_{2}$ decomposition. The VADER system has the following characteristics: variable plasma frequency range $(0-10 \mathrm{kHz})$, a flexible operating pressure range of $10^{-3}-2 \mathrm{~atm}$, optical access ports for plasma diagnostics, and flexible electrode gap of approximately $2 \mathrm{~cm}$. 
Currently, there are ongoing investigations to quantify $\mathrm{CO}_{2}$ decomposition and the application of optical diagnostics to determine plasma parameters, such as the temperatures of electrons and neutral species [396]. The US Department of Energy is also investigating the performance of a GAD plasma technology for the logistic fuel conversion into $\mathrm{H}_{2}$ - rich synthesis gas.

A prototype solution has been developed for $\mathrm{CH}_{3} \mathrm{OH}$ production from renewable feeds $\left(\mathrm{CO}_{2}\right.$ and biomass) based on a novel MW plasma technology (an NTP generated by high-intensity MW fields). A bench-scale reactor based on solid-state MW generator MiniFlow 200SS manufactured by SAIREM has been conceptualized, designed and constructed. Furthermore, a scalable containerized MW plasma gasifier of $10-20 \mathrm{~kW}$ th using a $6 \mathrm{~kW}$ power input was built for biomass gasification through the funding of the Bill and Melinda Gates Foundation. The results showed a super equilibrium conversion process [397]. The United States patented technology [416] for heavy hydrocarbon and natural gas co-conversion using DBD plasma at moderately elevated temperatures $\left(<300{ }^{\circ} \mathrm{C}\right)$ to activate $\mathrm{CH}_{4}$ to produce a high concentration of reactive light hydrocarbons and $\mathrm{H}_{2}$ radicals.

In the process of development and evaluation of a new technique, the production capacity depicts the fundamental design guideline, hence determining the equipment requirements. Generally, bulk chemicals are produced on a very large scale, consequently, reactions need to operate at significantly high throughput. As a result, high energy input is needed; for instance, a typical $\mathrm{CH}_{3} \mathrm{OH}$ production plant [417] with a $100 \mathrm{kton} /$ year rate of production and electricity consumption rate of $550 \mathrm{kWh} /$ ton is considered herein. The largest microwave plasma system developed so far has an output capacity of $3.3 \mathrm{kton}$ biomass/year and produces $1.5 \mathrm{kton}$ ethanol/year [418]. Therefore, to achieve the required capacity for bulk chemical manufacturing, the current MW plasma reactors should be scaled up by a factor of 66 for this specific process, which is challenging. In order to accelerate the industrial application of NTP technology, there is a need for the development of a low cost and reliable power supply with large output.

\section{Concluding remarks and future perspectives}

In this review, NTP-assisted $\mathrm{CO}_{2}$ conversion into value added-chemicals and fuels has been demonstrated to be a technology with considerable potential for reducing $\mathrm{CO}_{2}$ emissions, since NTP has a great ability to break $\mathrm{CO}_{2}$ bonds at room temperature and pressure. The selectivity and

efficiency for these reactions can often be improved by introducing a catalyst to the system. In 
order to make NTP-catalytic $\mathrm{CO}_{2}$ capture and conversion technology feasible and economically attractive, an advanced investigation into the reactor technology and the unusual plasma-catalyst chemistry is essential. Indeed, plasma and catalysts operate via different mechanisms, but their combination in plasma catalysis can generate synergetic effects that improve their performances during reactions. Thus, combining NTP and catalysts is an option for integrating the benefits of both plasma and catalysts into systems used for $\mathrm{CO}_{2}$ conversion and utilization. The presently available $\mathrm{CO}_{2}$ capture technology needs improvement in relation to cycle durability and increasing adsorption capacity to achieve economic feasibility. In addition, the use of efficient $\mathrm{CO}_{2}$ adsorbents is imperative. Therefore, it is important to acquire further knowledge of these technologies in order to design and develop efficient processes that successfully integrate systems for $\mathrm{CO}_{2}$ capture and conversion using NTP.

Furthermore, it was realized that $\mathrm{CO}_{2}$ conversion using NTP is a promising technology for upscaling and commercialization to produce more complex carbon-based chemicals and fuels. Some of the carbon-based liquids presently produced in small amounts include $\mathrm{CH}_{3} \mathrm{OH}, \mathrm{C}_{2} \mathrm{H}_{4}$, and $\mathrm{C}_{4}$ hydrocarbons. Notwithstanding, the viability of this technology is affected by the low selectivity of these products. Developing a suitable catalyst can enhance the selectivity of these carbon-based liquid chemicals. Moreover, detailed research is required on the catalyst sensitivities to admixtures and the performance of plasma-catalysts under intricate conditions as the catalyst plays a crucial role in reducing kinetic barriers and improving activities. In the presence of the catalyst, electron density can be improved and micro discharges can be induced, leading to higher energy efficiency, high-value products, and high reaction rates. However, this may not be attained simultaneously by a single method. An in-depth understanding of the intrinsic structurecomposition-activities link, morphologies, shapes, sizes, and recipes can be a major boost in designing cost-effective catalysis and improving plasma-catalytic performance.

Various reactions can occur in NTP-activated $\mathrm{CO}_{2}$ conversion that operate through the formation of different intermediates, which then follow different mechanistic steps along pathways to make different products. Some of these reactions can aid the conversion to useful products, whereas others can hinder it. For example, electron transfer reactions that produce $\mathrm{CO}_{2}$ anion radicals hinder further conversion of $\mathrm{CO}_{2}$, yet electron impact reactions that break $\mathrm{C}-\mathrm{O}$ bonds are crucial to produce $\mathrm{CO}$ - an important precursor in the production of liquid fuels and value-added 
chemicals. Therefore, in order to increase the yield and selectivity of desired products, the identification of exact steps in the activation of $\mathrm{CO}_{2}$ will be essential, especially when designing modified catalysts for the process.

Finally, in order to realize a successful $\mathrm{CO}_{2}$ conversion and utilization project with integrated $\mathrm{CO}_{2}$ capture technology, many commercial and technical challenges must be overcome. Examples of some of the most important issues are: that the plasma produces a complex mixture of chemicals, including higher hydrocarbons (HCs); the separation of syngas needs advanced technological and energy requirements, forecasting additional energy consumption; and the interaction between the catalyst and plasma is only on the external surface of the particles, which means that the active sites of the catalyst are not fully explored by the plasma-excited species. However, structured methods to incorporate the catalyst into the reactor may help to strengthen the synergy between the plasma and catalyst. Future research in this area could be related to the general design of product flow diagrams, feasibility studies, economic analysis, catalyst modification, and in using combinations of hybrid processes for $\mathrm{CO}_{2}$ emissions control.

\section{Acknowledgement}

Adwek George would like to thank the following scientists for their valuable discussions during the preparation of this manuscript: Dr. Arowo Moses and Prof. Zachary Siagi at the School of Engineering at Moi University, Kenya. The authors are grateful for the financial support of the Key Project of National Science Foundation of Tianjin (18JCZDJC39800), The project science and technology of Tianjin (18ZXSZSF00040,18KPXMSF00080, 18PTZWHZ00010). CW and XT thank the funding from the European Union's Horizon 2020 research and innovation programme under the Marie Skłodowska-Curie grant agreement No 823745. XT, MC and YW thank the financial support from the the State Key Laboratory of Electrical Insulation and Power Equipment at Xi'an Jiaotong University (No. EIPE19207), China. 


\section{References}

[1] Yap D, Tatibouët J-M, Batiot-Dupeyrat C. Carbon dioxide dissociation to carbon monoxide by nonthermal plasma. Journal of $\mathrm{CO}_{2}$ Utilization 2015;12 54-61.

[2] Uhm HS, Kwak HS, Hong YC. Carbon dioxide elimination and regeneration of resources in a microwave plasma torch. Environmental Pollution. 2016;211:191-7.

[3] IPCC. Climate Change 2014 : Mitigation of Climate Change. Contribution of Working Group III to the Fifth Assessment Report of the Intergovernmental Panel on Climate Change. New York, 2014; 2014.

[4] Kerry YKM, Igor C, Joseph G, Edman TSC. Recent advances in $\mathrm{CO}_{2}$ capture and utilization. ChemSusChem: Chemistry Sustainability Energy Materials. 2008;1:893-9.

[5] Friedlingstein P, Houghton RA, Marland G, Hackler J, Boden TA, Conway TJ, et al. Update on $\mathrm{CO}_{2}$ emissions. Nat Geosci. 2010;3:811-2.

[6] Shi J, Jiang $Y$, Jiang Z, Wang X, Wang X, Zhang S, et al. Enzymatic conversion of carbon dioxide. Chem Soc Rev 2015;44:5981-6000.

[7] Qiao J, Liu Y, Hong F, Zhang J. A review of catalysts for the electro reduction of carbon dioxide to produce low-carbon fuels. Chem Soc Rev. 2014;43:631-75.

[8] Sun SR, Wang $\mathrm{HX}$, Mei DH, Tu X, Bogaerts A. $\mathrm{CO}_{2}$ conversion in a gliding arc plasma: Performance improvement based on chemical reaction modeling. Journal of $\mathrm{CO}_{2}$ Utilization. 2017;17:220-34.

[9] Wang W, Wang S, Ma X, Gong J. Recent advances on catalytic hydrogenation of carbon dioxide. Chem Soc Rev. 2011;40 3703-27.

[10] Gallardo-Fuentes S, Contreras R, Isaacs M, Honores J, Quezada D, Landaeta E, et al. On the mechanism of $\mathrm{CO}_{2}$ electro-cycloaddition to propylene oxides. Journal of $\mathrm{CO}_{2}$ Utilization 2016;16:114-20.

[11] Ganesh I. Electrochemical conversion of carbon dioxide into renewable fuel chemicals - The role of nanomaterials and the commercialization. Renewable and Sustainable Energy Reviews. 2016;59 (2016) 1269-97.

[12] Pletcher D. The cathodic reduction of carbon dioxide-What can it realistically achieve? A mini review. Electrochemistry Communications. 2015;61:97-101.

[13] Ganesh I. Conversion of carbon dioxide into methanol - a potential liquid fuel: Fundamental challenges and opportunities (a review). . Renewable and Sustainable Energy Reviews. 2014;31:221-57.

[14] Rao H, Schmidt LC, Bonin J, Robert M. Visible-light-driven methane formation from $\mathrm{CO}_{2}$ with a molecular iron catalyst. NATURE 2017;548:3.

[15] Yun LY, Sol JH, Tae KY. A review: Effect of nanostructures on photocatalytic $\mathrm{CO}_{2}$ conversion over metal oxides and compound semiconductors. Journal of $\mathrm{CO}_{2}$ Utilization. 2017;20:163-77.

[16] Kim HR, Razzaq A, A.Grimes C, In S-I. Heterojunction p-n-p $\mathrm{Cu}_{2} \mathrm{O} / \mathrm{S}-\mathrm{TiO}_{2} / \mathrm{CuO}$ : Synthesis and application to photocatalytic conversion of $\mathrm{CO}_{2}$ to methane. Journal of $\mathrm{CO}_{2}$ Utilization. 2017;20:91-6.

[17] Jingjie W, Xiao-Dong Z. Catalytic conversion of $\mathrm{CO}_{2}$ to value added fuels: Current status, challenges, and future directions. . Chinese Journal of Catalysis 2016;37 999-1015.

[18] Xudong C, Peimei D, Zhengfeng H, Yanzhao Z, Yi C, Xiaoxiao N, et al. Green synthesis of plasmonic Ag nanoparticles anchored $\mathrm{TiO}_{2}$ nanorod arrays using cold plasma for visible-light-driven photocatalytic reduction of $\mathrm{CO}_{2}$. Journal of $\mathrm{CO}_{2}$ Utilization. 2017;20:200-7.

[19] Xue-Ting F, Mei J, Ming-Hsien L, Jun C. Water effect on band alignment of GaP: A theoretical insight into pyridinium catalyzed $\mathrm{CO}_{2}$ reduction. Journal of Energy Chemistry. 2017;26:724-9.

[20] Hu B, Guild C, L.Suib S. Thermal, electrochemical, and photochemical conversion of $\mathrm{CO}_{2}$ to fuels and value-added products. Journal of $\mathrm{CO}_{2}$ utilization. 2013;1:18-27. 
[21] Nader R, Mohammad H, Ali AB, Mahdi FJ, Sirous K. Conversion of $\mathrm{CH}_{4} / \mathrm{CO}_{2}$ to syngas over Ni-Co/Al $\mathrm{O}_{3}{ }^{-}$ $\mathrm{ZrO}_{2}$ nanocatalyst synthesized via plasma assisted co-impregnation method: Surface properties and catalytic performance. Journal of Applied Physics. 2013;114:094301.

[22] Chen G, Georgieva V, Godfroid T, R. Snyders, Ogletree. MPD. Plasma assisted catalytic decomposition of $\mathrm{CO}_{2}$. Applied Catalysis B: Environmental 2016;190:115-24.

[23] Ashford B, Wang Y, Wang L, Tu X. Plasma-Catalytic Conversion of Carbon Dioxide. Plasma Catalysis: Springer; 2019. p. 271-307.

[24] Ferreira A, Ribeiro B, Marques PASS, Ferreira AF, Dias AP, Pinheiro HM, et al. Scenedesmus obliquus mediated brewery wastewater remediation and $\mathrm{CO}_{2}$ biofixation for green energy purposes. Journal of Cleaner Production 2017;165:1316-27.

[25] Cheng J, Lu H, He X, Yang W, J. Zhou KC. Mutation of Spirulina sp. by nuclear irradiation to improve growth rate under $15 \%$ carbon dioxide in flue gas. Bioresource Technology. 2017; 238:650-6.

[26] Duarte JH, Morais EG, Radmann EM, Costa JAV. Biological $\mathrm{CO}_{2}$ mitigation from coal power plant by Chlorella fusca and Spirulina sp. . Bioresource Technology. 2017;234 472-5.

[27] Kassim MA, Meng TK. Carbon dioxide $\left(\mathrm{CO}_{2}\right)$ biofixation by microalgae and its potential for biorefinery and biofuel production. . Science of the Total Environment. 2017;584:1121-9.

[28] Spinner NS, Vega JA, Mustain WE. Recent progress in the electrochemical conversion and utilization of $\mathrm{CO}_{2}$. Catal Sci Technol. 2012;2:19-28

[29] Zheng Y, Zhang W, Li Y, Chen J, Yu B, Wang J, et al. Energy related $\mathrm{CO}_{2}$ conversion and utilization: Advanced materials/ nanomaterials, reaction mechanisms and technologies. . Nano Energy. 2017;40:51239.

[30] Ashford B, Tu X. Non-thermal plasma technology for the conversion of $\mathrm{CO}_{2}$. Current Opinion in Green and Sustainable Chemistry. 2017;3: 45-9.

[31] Kim HH, Ogata A. Interaction of Non-thermal Plasma with Catalyst for the Air Pollution Control International J of Plasma Environmental Sci and Technol 2011;6:43-8.

[32] Jim VD, Jo D, Christophe L, Herman VL. Combining non-thermal plasma with heterogeneous catalysis in waste gas treatment: a review. Applied Catalysis B: Environmental. 2008;78:324-33.

[33] Xu S, Whitehead JC, A.Martin P. $\mathrm{CO}_{2}$ conversion in a non-thermal, barium titanate packed bed plasma reactor: The effect of dilution by Ar, $N_{2}$. Chem Eng Journal. 2017;327:764-73.

[34] Ray D, Nepak D, Janampelli S, Goshal P, Subrahmanyam CJET. Dry reforming of Methane in DBD plasma over $\mathrm{Ni}$ - based catalysts: Influence of process conditions and support on performance and durability. 2019;7:1801008.

[35] Zhao G, Huang $X$, Wang $X$, Wang $X$. Progress in catalyst exploration for heterogeneous $\mathrm{CO}_{2}$ reduction and utilization: A Critical Review. Journal of Materials Chemistry A. 2017;5:21625-49.

[36] Zhuxing $S$, Haiqiang $W$, Zhongbiao $W$, Lianzhou W. $g-C_{3} N_{4}$ based composite photocatalysts for photocatalytic $\mathrm{CO}_{2}$ reduction. Catalysis Today 2018;300:160-72.

[37] Fauziah M, Manuel P, S MA. Enzymatic conversion of $\mathrm{CO}_{2}$ to $\mathrm{CH}_{3} \mathrm{OH}$ via reverse dehydrogenase cascade biocatalysis: Quantitative comparison of efficiencies of immobilized enzyme systems. Biochem Eng Journal. 2017;127:217-28.

[38] Jianquan L, S MA, Valentina MR, Manuel P. Cascade catalysis in membranes with enzyme immobilization for multi-enzymatic conversion of $\mathrm{CO}_{2}$ to methanol. New biotechnology. 2015;32:319-27. [39] Hyanjoo P, Jihui C, Hoyoung K, Eunkyoung H, Don-Hyung $H$, Hyun AS, et al. AgIn dendrite catalysts for electrochemical reduction of $\mathrm{CO}_{2}$ to $\mathrm{CO}$. Applied Catalysis B: Environmental. 2017;219:123-31.

[40] Lee $\mathrm{H}, \mathrm{Kim} \mathrm{SK}$, Ahn SH. Electrochemical preparation of $\mathrm{Ag} / \mathrm{Cu}$ and $\mathrm{Au} / \mathrm{Cu}$ foams for electrochemical conversion of $\mathrm{CO}_{2}$ to CO. . Journal of Industrial and Eng Chem. 2017;54:218-25.

[41] Xiaobing Z, Jian-Hao L, Xiao-Song L, Jing-Lin L, Xin Q, Ai-Min Z. Enhanced effect of plasma on catalytic reduction of $\mathrm{CO}_{2}$ to $\mathrm{CO}$ with hydrogen over $\mathrm{AU} / \mathrm{CeO}_{2}$ low temperature Journal of energy chemistry. 2017;26:488-93. 
[42] Kim J-C, Getoff N, Jun J. Catalytic conversion of $\mathrm{CO}_{2}-\mathrm{CH}_{4}$ mixture into synthetic gas-Effect of electron beam radiation. Radiation Phys and Chem. 2006;75:243-6.

[43] Li K, Tang X, Yi H, Ning P, Song J, Wang J. Mechanism of Catalytic oxidation of NO over Mn-Co-Ce- ${ }_{x}$ Catalysts with the Aid of Non-Thermal Plasma at Low Temperature. Ind Eng Chem Res. 2011;50:11023-8.

[44] Babaie M, Davari P, PouyanTalebizadeh, Zare F, Rahimzadeh H, Ristovski Z, et al. Performance evaluation of non-thermal plasma on particulate matter, ozone, and $\mathrm{CO}_{2}$ coleration for diesel exhaust emission reduction. Chem Eng Journal. 2015;276 240-8.

[45] Duan X, Hu Z, Li Y, Wang B. Effects of dielectric materials on the decomposition of carbon dioxide using DBD microplasma reactor. AIChE J. 2014; 61:898-903.

[46] Sabine P, Bert V, Xin T, Christophe DB, Tom M, Dragana P, et al. Conversion of carbon dioxide to valueadded chemicals in atmospheric pressure dielectric barrier discharges. Plasma Sources Sci Technol. 2010;19:6pp.

[47] Snoeckx R, Zeng YX, Tu X, Bogaerts A. Plasma-based dry reforming: improving the conversion and energy efficiency in a dielectric barrier discharge RSC advances. 2015;5:29799-808

[48] Danhua $\mathrm{M}$, Xin T. Conversion of $\mathrm{CO}_{2}$ in a cylindrical dielectric barrier discharge reactor: Effects of plasma processing parameters and reactor design. Journal of $\mathrm{CO}_{2}$ Utilization. 2017;19:68-78.

[49] Mei DH, Liu SY, Tu X. $\mathrm{CO}_{2}$ reforming with methane for syngas production using a dielectric barrier discharge plasma coupled with $\mathrm{Ni} / \mathrm{Y}^{-} \mathrm{Al}_{2} \mathrm{O}_{3}$ catalysts: Process optimization through response surface methodology. Journal of $\mathrm{CO}_{2}$ Utilization 2017;21:14-326.

[50] Ray D, Reddy PMK, Ch.Subrahmanyam. Ni-Mn/ $\mathrm{Y}-\mathrm{Al}_{2} \mathrm{O}_{3}$ assisted plasma dry reforming of methane. Catalysis Today. 2018;309:212-8.

[51] Zeng Y, Zhu X, Mei D, Ashford B, Tu X. Plasma-catalytic dry reforming of methane over $\gamma-\mathrm{Al}_{2} \mathrm{O}_{3}$ supported metal catalysts. Catalysis Today 2015;256 80-7.

[52] Yap D, Tatibouët JM, Dupeyrat CB. Catalyst assisted by non-thermal plasma in dry reforming of methane at low temperature. Catalysis Today 2018;299 263-71.

[53] Valentin G, Jean-Michel T, Catherine B-D. Use of a non-thermal plasma for the production of synthesis gas from biogas. Applied Catalysis A: General. 2009;353 228-35.

[54] Lu N, Bao X, Jiang N, Shang K, Li J, Wu Y. Non-Thermal Plasma-Assisted Catalytic Dry Reforming of Methane and Carbon Dioxide Over G- $\mathrm{C}_{3} \mathrm{~N}_{4}$-Based Catalyst. Topics in Catal. 2017;60:855-68.

[55] Fridman A. Plasma chemistry in energy systems and environmental control. In: Press CU, editor.2008.

[56] Goula MA, Charisiou ND, Siakavelas G, Tzounisc L, I.Tsiaoussis, P.Panagiotopoulou, et al. Syngas production via the biogas dry reforming reaction over $\mathrm{Ni}$ supported on zirconia modified with $\mathrm{CeO}_{2}$ or $\mathrm{La}_{2} \mathrm{O}_{3}$ catalysts. International journal of hydrogen energy 2017;42 13724 -40.

[57] Tanios C, Bsaibes S, Gennequin C, Labaki M, Cazier F, Billet S, et al. Syngas production by the $\mathrm{CO}_{2}$ reforming of $\mathrm{CH}_{4}$ over Ni-Co-Mg-Al catalysts obtained from hydrotalcite precursors. International journal of hydrogen energy. 2017;42 12818-28.

[58] Han J, Zhan Y, Street J, To F, Yu F. Natural gas reforming of carbon dioxide for syngas over Ni-Ce-Al catalysts. International journal of hydrogen energy. 2017;42 18364 -74.

[59] Rodemerck $U$, Schneider $\mathrm{M}$, Linke $\mathrm{D}$. Improved stability of $\mathrm{Ni} / \mathrm{SiO}_{2}$ catalysts in $\mathrm{CO}_{2}$ and steam reforming of methane by preparation via a polymer-assisted route. Catalysis Communications 2017;102 98-102.

[60] Zahra T, Mardali Y, Mohammad T, Behnam K. Promotional effect of samarium on the activity and stability of Ni-SBA- 15 catalysts in dry reforming of methane. Microporous and Mesoporous Materials 2017;251 9-18.

[61] Zeng YX, Wang L, Wu CF, Wang JQ, Shen BX, Tu X. Low temperature reforming of biogas over K-, Mgand Ce-promoted $\mathrm{Ni} / \mathrm{Al}_{2} \mathrm{O}_{3}$ catalysts for the production of hydrogen rich syngas: Understanding plasmacatalytic synergy. Applied Catalysis B: Environmental. 2018;224:469-78. 
[62] Guoxing C, Tiago S, Violeta G, Thomas G, Nikolay B, Rony S, et al. Simultaneous dissociation of $\mathrm{CO}_{2}$ and $\mathrm{H}_{2} \mathrm{O}$ to syngas in a surface-wave microwave discharge. International Journal of Hydrogen Energy. 2015;40:3789 -96.

[63] Hoeben WFIMW, Heesch EJMBV, Beckers FJCMF. Plasma driven water assisted $\mathrm{CO}_{2}$ methanation. IEEE Trans Plasma Sci. 2015;43:1954-8.

[64] Fuente JFdl, Moreno SH, Stankiewicz Al, Stefanidis GD. Reduction of $\mathrm{CO}_{2}$ with hydrogen in a nonequilibrium microwave plasma reactor. International Journal of Hydrogen Energy 2016;41:21067 - 77.

[65] Fuente JFdl, Moreno SH, Stankiewicz Al, Stefanidis GD. On the improvement of chemical conversion in a surface-wave microwave plasma reactor for $\mathrm{CO}_{2}$ reduction with hydrogen (The Reverse Water-Gas Shift reaction). International Journal of Hydrogen Energy. 2017;42 12943 -55.

[66] Zeng $\mathrm{Y}$, Tu X. Plasma catalytic $\mathrm{CO}_{2}$ hydrogenation at low temperatures. IEEE Trans Plasma Sci. 2016;44:405-11.

[67] Horvath G, Skalny JD, Mason NJ. FTIR study of decomposition of carbon dioxide in dc corona discharges. J Phys D: Appl Phys 2008;41:(8pp).

[68] Tiago S, Nikolay $B$, Thomas $G$, Rony $S$. Understanding $\mathrm{CO}_{2}$ decomposition in microwave plasma by means of optical diagnostics. Plasma Processes and Polymers. 2017;14:1600103.

[69] Arita $\mathrm{K}$, lizuka S. Hydrogenation of $\mathrm{CO}_{2}$ to $\mathrm{CH}_{4}$ using a low-pressure cross-field pulse discharge with hydrogen 22nd International Symposium on Plasma Chemistry: Antwerp, Belgium; 2015.

[70] Debjyoti R, Kumar RPM, Subrahmanyam C. Glass beads packed DBD-plasma assisted dry reforming of methane. Topics in Catalysis. 2017;60:869-78.

[71] Khoja AH, Tahir M, Amin NAS. Cold plasma dielectric barrier discharge reactor for dry reforming of methane over $\mathrm{Ni} / \mathrm{\gamma}-\mathrm{Al}_{2} \mathrm{O}_{3}-\mathrm{MgO}$ nanocomposite. Fuel Processing Technology. 2018;178:166-79.

[72] Alp O, Thierry D, Gregory A, Philippe DK, Annemie B, François R. $\mathrm{CO}_{2}-\mathrm{CH}_{4}$ conversion and syngas formation at atmospheric pressure using a multi-electrode dielectric barrier discharge. Journal of $\mathrm{CO}_{2}$ utilization. 2015;9:74-81.

[73] Bogaerts A, Berthelot A, Heijkers S, Kolev S, Snoeckx R, Sun S, et al. $\mathrm{CO}_{2}$ conversion by plasma technology: insights from modeling the plasma chemistry and plasma reactor design. Plasma Sources Sci Technol. 2017;26:063001-34.

[74] Snoeckx R, Heijkers S, Wesenbeeck KV, Lenaerts S, Bogaerts $A . \mathrm{CO}_{2}$ conversion in a dielectric barrier discharge plasma: $\mathrm{N}_{2}$ in the mix as a helping hand or problematic impurity? . Energy Environ Sci. 2016;9:999-1011.

[75] Ozkan A, Bogaerts A, Reniers F. Routes to increase the conversion and the energy efficiency in the splitting of $\mathrm{CO}_{2}$ by a dielectric barrier discharge. J Phys D: Appl Phys 2017;50:11pp.

[76] Odeyemi F, Rabinovich A, Fridman A. Gliding Arc Plasma-Stimulated Conversion of Pyrogas into Synthesis Gas. IEEE Trans Plasma Sci. 2012;40:1124-30.

[77] Indarto A, Yang DR, Choi J-W, Lee $\mathrm{H}$, Song HK. Gliding arc plasma processing of $\mathrm{CO}_{2}$ conversion. J of Hazardous Materials. 2007;146:309-15.

[78] Song HK, Choi JW, Lee H. Methane conversion in a gliding arc discharge. The 5th International Symposium on Pulsed Power and Plasma Applications2004. p. 375-8.

[79] Eliasson B, Kogelschatz U. Non equilibrium volume plasma chemical processing. IEEE Trans Plasma Sci 1991;19:1063-77.

[80] Grill A. Cold plasma in materials fabrication: from fundamentals to applications. In: Press I, editor. New York1994.

[81] Chang-jun L, Gen-hui X, Timing W. Non-thermal approaches in $\mathrm{CO}_{2}$ utilization. Fuel Proc Tech 1999;58:119-34.

[82] Venugopalan M, Veprek S. Kinematics and catalysis in plasma chemistry. New York: Springer-Verlag; 1983. 
[83] Li D, Li X, Bai M, Tao X, Shang S, Dai $\mathrm{X}$, et al. $\mathrm{CO}_{2}$ reforming of $\mathrm{CH}_{4}$ by atmospheric pressure glow discharge plasma: A high conversion ability. Int J of Hydrogen Energy. 2009;34:308-13.

[84] Chen Q, Dai W, Tao XM, Yu H, Dai XY, Yin YX. $\mathrm{CO}_{2}$ reforming of $\mathrm{CH}_{4}$ by atmospheric pressure abnormal glow plasma. Plasma Science and Technology. 2006;8:181-4.

[85] Huang A, Xia GG, Wang JY, Suib SL, Hayashi Y, Matsumoto $\mathrm{H} . \mathrm{CO}_{2}$ reforming of $\mathrm{CH}_{4}$ by atmospheric pressure ac discharge plasmas. Journal of Catalysis 2000;189:349- 59.

[86] Li Y, Liu CJ, Eliasson B, Wang Y. Synthesis of oxygenates and higher hydrocarbons directly from methane and carbon dioxide using dielectric-barrier discharges: product distribution. Energy Fuels. 2002;16:864-70.

[87] Shang S, Liu G, Chai X, Tao X, Li X, Bai M, et al. Research on Ni/ $y-\mathrm{Al}_{2} \mathrm{O}_{3}$ catalyst for $\mathrm{CO}_{2}$ reforming of $\mathrm{CH}_{4}$ prepared by atmospheric pressure glow discharge plasma jet. Catalysis Today2009.

[88] Nguyen $\mathrm{HH}$, Nasonova A, Nah IW, Kim KS. Analysis on $\mathrm{CO}_{2}$ reforming of $\mathrm{CH}_{4}$ by corona discharge process for various process variables J of Ind and Eng Chem 2015;32:58-62.

[89] Patino P, Perez Y, Caetano M. Coupling and reforming of methane by means of low pressure radiofrequency plasmas. Fuel 2005;84:2008-14.

[90] Ghorbanzadeh AM. Carbon dioxide reforming of methane by pulsed glow discharge at atmospheric pressure: The effect of pulse compression. J of Applied Physics. 2007;101.

[91] Tu X, Whitehead JC. Plasma dry reforming of methane in an atmospheric pressure AC gliding arc discharge: Cogeneration of syngas and carbon nanomaterials. Int J of Hydrogen Energy. 2014;39:9658-69.

[92] Scapinello M, Martini LM, Dilecce G, Tosi P. Conversion of $\mathrm{CH}_{4} / \mathrm{CO}_{2}$ by a nanosecond repetitively pulsed discharge. J Phys D: Appl Phys. 2016;49:(8pp).

[93] Schiavon M, Torretta V, Casazza A, Ragazzi M. Non-thermal Plasma as an Innovative Option for the Abatement of Volatile Organic Compounds: a Review. Water Air Soil Pollution. 2017.

[94] Ye Z, Veerapandian SKP, Onyshchenko I, Nikiforov A, Geyter ND, Giraudon JM, et al. An in-Depth Investigation of Toluene Decomposition with a Glass Beads-Packed Bed Dielectric Barrier Discharge Reactor. Ind Eng Chem Res. 2017 56:10215-26.

[95] Deynse AV, Morent R, Leys C, Geyter ND. Influence of ethanol vapor addition on the surface modification of polyethylene in a dielectric barrier discharge. Applied Surface Science. 2017;419 847-59.

[96] Peng M, Li L, Xiong J, Hua K, Wang S, Tao Shao. Study on Surface Properties of Polyamide 66 Using Atmospheric Glow-Like Discharge Plasma Treatment. Coatings. 2017;7:123.

[97] Tanino M, Xilu W, Takashima K, Katsura S, Mizuno A. Sterilization using dielectric barrier discharge at atmospheric pressure. Int J Plas Env Sci \& Tech. 2007;1:102-7.

[98] Wang Y, Craven M, Yu X, Ding J, Bryant P, Huang J, et al. Plasma-Enhanced Catalytic Synthesis of Ammonia over a Ni/Al2O3 Catalyst at Near-Room Temperature: Insights into the Importance of the Catalyst Surface on the Reaction Mechanism. ACS Catalysis. 2019;9:10780-93.

[99] Konelschatz U, Eliasson B, Egli W. Dielectric barrier discharges, principles and applications. J Phys IV France. 1997;7:47-66.

[100] Cal MP, Schluep M. Destruction of benzene with non-thermal plasma in dielectric barrier discharge reactors. Env Prog. 2014;20:151-6.

[101] Kostov KG, Honda Ry, Alves LMS, Kayama ME. characteristics of dielectric barrier discharge reactor for material treatment. Brazilian Journal of Physics. 2009;39:2322-5.

[102] Pekárek S. Experimental Study of Nitrogen Oxides and Ozone Generation by Corona-Like Dielectric Barrier Discharge with Airflow in a Magnetic Field. Plasma Chem Plasma Process 2017;37:1313.

[103] Portugal S, Roy S, Lin J. Functional relationship between material property, applied frequency and ozone generation for surface dielectric barrier discharges in atmospheric air. In: Reports $\mathrm{S}$, editor.

[104] Gallon HJ, Kim HH, Tu X, Whitehead JC. Microscope-ICCD imaging of an atmospheric pressure $\mathrm{CH}_{4}$ and $\mathrm{CO}_{2}$ dielectric barrier discharge. IEEE Transactions on Plasma Science. 2011;39:2176-7. 
[105] Xiaozhen S, Yong Z, Fuyang Q, Xiangrong W. Effect of glass additions on Ca0.8 Sr0.2 $\mathrm{TiO}_{3}$ ceramics for a cylindrical dielectric barrier discharge reactor in $\mathrm{CO}_{2}$ plasma. Rare Materials and Eng. 2016;45:303742.

[106] Alliati $\mathrm{M}$, Mei D, Tu X. Plasma activation of $\mathrm{CO}_{2}$ in a dielectric barrier discharge reactor: A chemical kinetic model from the microdischarge to the reactor scale. Journal of $\mathrm{CO}_{2}$ Utilization. 2018;27:308-19.

[107] Talebizadeh P, Babaie M, Brown R, Rahimzadeh H, Ristovski Z, Arai M. The role of non-thermal plasma technique in $\mathrm{NO}_{x}$ treatment: A review. Renewable and Sustainable Energy Reviews. 2014;40:886901.

[108] Cao X, Zhao W, Zhang R, Hou H, Chen S, Zhang R. Conversion of NO with a catalytic packed bed dielectric barrier discharge reactor. Plasma Sci Technol 2017;19:115504-8.

[109] Matsumoto T, Wang D, Namihira T, Akiyama H. Non thermal plasma technic for air pollution control, Air Pollution-A comprehensive perspective, Vol 3,. p. 215-34.

[110] Wang X, Yang Q, Yao C, Zhang X, Sun C. Dielectric Barrier Discharge Characteristics of Multineedleto-Cylinder Configuration. Energies. 2011;4:2133-50.

[111] Mei D, Zhu X, He YL, Yan JD, Tu X. Plasma-assisted conversion of $\mathrm{CO}_{2}$ in a dielectric barrier discharge reactor: understanding the effect of packing materials Plasma Sources Science and Technology. 2015;24:015011.

[112] Wang C, Zhang G, X. Wang. Comparisons of discharge characteristics of a dielectric barrier discharge with different electrode structures. Vacuum 2011;86:960-4.

[113] Pridman A, Chirokov A, Gutsol A. Non thermal atmospheric pressure discharges. J Phys D Appl Phys. 2001;34:2810.

[114] Fang Z, Qui Y, Zhang C, Kuffel E. Factors influencing the existence of the homogeneous dielectric barrier discharge in air at atmospheric pressure. Phys D Appl Phys 2007;40:1401.

[115] Spencer LF, Gallimore AD. $\mathrm{CO}_{2}$ Dissociation in atmospheric pressure plasma/ catalyst system: a study of efficiency. Plasma Sources Sci Technol. 2013;22:015019.

[116] Wang S, Zhang Y, Liu X, Wang X. Enhancement of $\mathrm{CO}_{2}$ conversion rate and conversion efficiency by homogeneous discharges. Chem Proc and Plasma Chem. 2012;32:979-89.

[117] Aerts R, Somers W, Bogaerts A. Carbon Dioxide Splitting in a Dielectric Barrier Discharge Plasma: A Combined Experimental and Computational Study. ChemSusChem. 2015;8:702-16.

[118] Butterworth T, Elder R, Allen R. Effects of particle size on $\mathrm{CO}_{2}$ reduction and discharge characteristics in a packed bed plasma reactor. J Chem Eng 2016;293 55-67.

[119] Meiners A, Leck M, Abel B. Efficiency enhancement of a dielectric barrier plasma discharge by dielectric barrier optimization. Review of Scientific Instruments 2010;81:113507

[120] Meiners A, Leck M, Abel B, Erratum. Efficiency enhancement of a dielectric barrier plasma discharge by dielectric barrier optimization. Review of Scientific Instruments. 2011;82:039903

[121] Rusanov VD, Fridman AA, G. V. Sholin. $\mathrm{CO}_{2}$ dissociation in a nonequilibrium plasma Sov Phys - Tech Phys. 1979;24:1195-8

[122] Iza F, Walsh JL, Kong MG. From Submicrosecond- to Nanosecond-Pulsed Atmospheric-Pressure Plasmas. IEEE Trans Plasma Sci. 2009;37:1289-96.

[123] Laroussi M. Nanoseconds pulsed non-equilibrium plasma discharges and applications in Proc. Int Symp Plasma Chem. Kyoto, Japan2007.

[124] Pai DZ, Lacoste DA, Laux CO. Nanosecond repetitively pulsed discharges in air at atmospheric pressure-The spark regime. Plasma Sour Sci Technol. 2010;19:1-10.

[125] Bazelyan EM, Raizer YP. Spark Discharge Boca Raton, FL: CRC Press; 1998.

[126] Leiweke RJ, Ganguly BN. Effects of pulsed-excitation applied voltage rise time on argon metastable production efficiency in a high pressure dielectric barrier discharge. Appl Phys Lett. 2007;90:241. 
[127] Moss MS, Yanallah K, Allen RWK, Pontiga F. An investigation of $\mathrm{CO}_{2}$ splitting using nanosecond pulsed corona discharge: effect of argon addition on $\mathrm{CO}_{2}$ conversion and energy efficiency. Plasma Sources Sci Technol. 2017;26:18pp.

[128] Pilla G, Galley D, Lacoste DA, Lacas F, Veynante D, Laux CO. Stabilization of a turbulent premixed flame using a nanosecond repetitively pulsed plasma. IEEE Trans Plasma Sci. 2006;34:2471-7.

[129] Bak MS, Do H, Mungal MG, Cappelli MA. Plasma-assisted stabilization of laminar premixed methane/air flames around the lean flammability limit. Combustion Flame. 2012;159: 3128-37,.

[130] Bak MS, Im S-K, Cappelli M. Nanosecond-Pulsed Discharge Plasma Splitting of Carbon Dioxide. IEEE Trans on Plasma Sci. 2015;43:1002-7.

[131] Scapinello $M$, Martini $L M$, Dilecce G, Tosi P. Reforming of $\mathrm{CH}_{4}$ and $\mathrm{CO}_{2}$ by a nanosecond-pulsed discharge at atmospheric pressure. 22nd International Symposium on Plasma Chemistry. Antwerp, Belgium2015.

[132] Wang W, Mei D, Tu X, Bogaerts A. Gliding arc plasma for $\mathrm{CO}_{2}$ conversion: Better insights by a combined experimental and modelling approach. Chem Eng Journal 2017;330:11-25.

[133] Fridman AA, Nester S, Kennedy LA, Saveliev A, O. Mutaf-Yardimci. Gliding arc gas discharge. Prog Energy Combust Sci. 1999;25:211-31.

[134] Burlica R, Kirkpatrick MJ, Locke BR. Formation of reactive species in gliding arc discharges with liquid water. J Electrostatics. 2016;64:35-43.

[135] Indarto A, Choi JW, Lee $\mathrm{H}$, Song HK. Conversion of $\mathrm{CO}_{2}$ by gliding arc plasma. Environ Eng Sci 2006;23:1033-43.

[136] Chun YN, Song HO. Syngas production using gliding arc plasma. Energy Sources A: Recov Util Environ Eff. 2008;30: 1202-12.

[137] Nunnally T, Gutsol K, Rabinovich A, Fridman A, Gutsol A, Kemoun A. Dissociation of $\mathrm{CO}_{2}$ in a low current gliding arc plasmatron. J Phys D Appl Phys. 2011;44:274009.

[138] Czernichowski A. Gliding arc, Applications to engineering and environment control. Pure Appl Chem. 1994;66:1301-10.

[139] Mei D, Wang Y, Liu S, Alliati M, Yang H, Tu X. Plasma reforming of biomass gasification tars using mixed naphthalene and toluene as model compounds. Energy Conversion and Management. 2019;195:409-19.

[140] Wang Y, Yang H, Tu X. Plasma reforming of naphthalene as a tar model compound of biomass gasification. Energy Conversion and Management. 2019;187:593-604.

[141] Zhang H, Li L, Li X, Wang W, Yan J, Tu X. Warm plasma activation of CO2 in a rotating gliding arc discharge reactor. Journal of $\mathrm{CO}_{2}$ Utilization. 2018;27:472-9.

[142] Kozak T, Bogaerts A. Splitting of $\mathrm{CO}_{2}$ By Vibrational Excitation In Non-Equilibrium Plasmas: A Reaction Kinetics Model. Plasma Sources Sci Technol 2014;23:045004.

[143] Sreethawong T, Thakonpatthanakun P, Chavadej S. Partial oxidation of methane with air for synthesis gas production in a multistage gliding arc discharge system. Int J Hydrogen Energy 2007;32:1067-79.

[144] Burlica R, Kirkpatrick MJ, Locke BR. Formation of reactive species in gliding arc discharges with liquid water. J Electrostatics 2016;64:35-43.

[145] Petitpas G, Rollier JD, Darmon A, Gonzalez-Aguilar J, Metkemeijer R, Fulcheri L. A comparative study of non-thermal plasma assisted reforming technologies Int J Hydrogen Energy 2007;32 2848-67.

[146] Patil BS, Palau JR, Hessel V, Lang J, Wang Q. Plasma nitrogen oxides synthesis in a milli-scale gliding arc reactor: investigating the electrical and process parameters. Plasma Chem Plasma Process. 2016;36:241-57.

[147] Kalra CS, Gutsol AF, Fridman AA. Gliding arc discharges as a source of intermediate plasma for methane partial oxidation. IEEE Trans Plasma Sci. 2005;33:32-41. 
[148] Ramakers M, Medrano JA, Trenchev G, Gallucci F, Bogaerts A. Revealing the arc dynamics in a gliding arc plasmatron: a better insight to improve $\mathrm{CO}_{2}$ conversion. Plasma Sources Sci Technol 2017;26 12pp.

[149] Zhu F, Zhang H, Yan X, Yan J, Ni M, Li X, et al. Plasma-catalytic reforming of CO2-rich biogas over $\mathrm{Ni} / \mathrm{Y}$-Al2O3 catalysts in a rotating gliding arc reactor. Fuel. 2017;199 430-7.

[150] Tan Z, Ai P. CO $\mathrm{CO}_{2}$ reforming of biogas to obtain synthesis gas using non-thermal plasma. Journal of the Energy Institute. 2017;90:864-74.

[151] Tu X, Gallon HJ, Whitehead JC. Dynamic behavior of an atmospheric argon gliding arc plasma. IEEE Trans Plasma Sci. 2011;39:2900-1.

[152] Pellerin S, Cormier J-M, Richard F, Musiol K, Chapelle J. Determination of the electrical parameters of a bi-dimensional d.c. Glidarc. J Phys D: Appl Phys. 1999;32:891-7.

[153] Kozák T, Bogaerts A. Splitting of $\mathrm{CO}_{2}$ by vibrational excitation in non-equilibrium plasmas: a reaction kinetics model. Plasma Sources Sci Technol. 2014;23:45004.

[154] Trenchev G, Kolev S, Bogaerts A. A 3D model of a reverse vortex flow gliding arc reactor. Plasma Sources SciTechnol. 2016; 2535014.

[155] Zhu J, Gao J, Ehn A, Aldén M, Marcus, Li Z, et al. Measurements of 3D slip velocities and plasma column lengths of a gliding arc discharge. Appl Phys Lett. 2015;106.

[156] Heijkers S, A. Bogaerts. $\mathrm{CO}_{2}$ Conversion in a Gliding Arc Plasmatron: Elucidating the Chemistry through Kinetic Modeling J Phys Chem C. 2017;121:22644-55.

[157] Zhang H, Zhu F, Li X, XU R, Li L, Yan J, et al. Steam reforming of toluene and naphthalene as tar surrogate in a gliding arc discharge reactor. Journal of hazardous materials. 2019;369:244-53.

[158] Snoeckx R, Bogaerts A. Plasma technology - a novel solution for $\mathrm{CO}_{2}$ conversion? . Chem Soc Rev. 2017;46.

[159] Kolev S, Bogaerts A. A 2D model for a gliding arc discharge. Plasma Sources Sci Technol. 2015;24.

[160] Czernichowski A, Nassar H, A. Ranaivosoloarimanana. Spectral and electrical diagnostics of gliding arc. Acta Physic a Polonica A. 1996;89:595-6.

[161] Kuznetsova IV, Kalashnikov NY, Gutsol AF, Fridman AA, Kennedy LA. Effect of 'overshooting' in the transitional regimes of the low-current gliding arc discharge. J Appl Phys. 2002;92:4231-7.

[162] Mutaf-Yardimci O, Saveliev AV, Fridman AA, Kennedy LA. Thermal and nonthermal regimes of gliding arc discharge in air flow. J Appl Phys. 1998;84:1062-641.

[163] Kozák T, Bogaerts A. Splitting of $\mathrm{CO}_{2}$ by vibrational excitation in non-equilibrium plasmas: a reaction kinetics model. Plasma Sources Sci Technol. 2014;23.

[164] Zhang H, Wang W, Li X, Han L, Yan M, Zhong Y, et al. Plasma activation of methane for hydrogen production in a N2 rotating gliding arc warm plasma: A chemical kinetics study. Chemical Engineering Journal. 2018;345:67-78.

[165] Li K, Liu JL, Li XS, Zhu X, Zhu AM. Warm plasma catalytic reforming of biogas in a heat-insulated reactor: Dramatic energy efficiency and catalyst auto-reduction. Chem Eng J. 2016;288: 671-9.

[166] Lebedev YA. Microwave discharges: generation and diagnostics. Journal of Physics; 2010.

[167] Berthelot A, Bogaerts A. Modeling of $\mathrm{CO}_{2}$ Splitting in a Microwave Plasma: How to Improve the Conversion and Energy Efficiency. J Phys Chem C. 2017;121: 8236-51.

[168] Gold SH, Nusinovich GS. Review of high-power microwave source research Review of Scientific Instruments. 1997;68

[169] Chen G, Godfroid T, Britun N, Georgieva V, Ogletree MPD, Snyders R. Plasma-catalytic conversion of $\mathrm{CO}_{2}$ and $\mathrm{CO}_{2} / \mathrm{H}_{2} \mathrm{O}$ in a surface-wave sustained microwave discharge. Applied Catalysis $\mathrm{B}$ : Environmental. 2017;214:114-25.

[170] Lebedev YA. Microwave Discharges: Fundamentals and Applications Proc. . 4th Int Workshop. Zvenigorod, Russia2000.

[171] Litvak AG. Strong Microwaves: Sources and Applications Nizhny Novgorod: Institute of Applied Physics RAS; 2008. 
[172] Moisan M, Pelletier J. Microwave Excited Plasmas. Amsterdam: : Elsevier; 1992.

[173] Ferreira C, Moisan M. Microwave Discharges: Fundamentals and Applications Proc. NATO ARW Vimeiro, Portugal: NATO ASI, Series B: Physics; 1992.

[174] Baddour RF, Timmins RS. The Applications of Plasmas to Chemical Processing In: Press M, editor. 1967 ed: Cambridge, Mass.

[175] Okress E. Microwave Power Engineering New York: Acad. Press; 1968.

[176] Demidov VI, Kolokolov NB, Kudryavtsev AA. Probe Method of Diagnostics of Low Temperature Plasma Moscow: Energoatomizdat1996

[177] Swift JD, Schwar MJR. Electrical probes for plasma diagnostics. London: Iliffe books; 1970.

[178] Scapinello M, Delikonstantis E, Stefanidis GD. The panorama of plasma-assisted non-oxidative methane reforming, Chemical Engineering \& Processing: Process Intensification Chem Eng Processing and Proc Intensification. 2017;117:120-40.

[179] Jasinski M, Czylkowski D, Hrycak B, Dors M, Mizeraczyk J. Atmospheric pressure microwave plasma source for hydrogen production. Int J of Hydrogen Energy 2013;38 11473-83.

[180] Jiang W, Masugata K, Yatsui K. Mechanism of microwave generation by virtual cathode oscillation. Phys Plasmas 1995;2.

[181] Chun SM, Hong YC, Choi DH. Reforming of methane to syngas in a microwave plasma torch at atmospheric pressure. Journal of $\mathrm{CO}_{2}$ Utilization 2017;19:221-9.

[182] Fukuda S. Proceedings of the Third Workshop on Pulsed RF Sources for Linear Colliders (RF 96). Pulsed RF Sources for Linear Colliders (RF 96). Tsukuba, Japan: High Energy Accelerator Research Organization (KEK); 1997.

[183] Mennicken L, Janz A, Roth S. The German R\&D program for $\mathrm{CO}_{2}$ utilization-innovations for a green economy. Environ Sci Pollut R. 2016;23:11386-92.

[184] Kranenburg KV, Schols E, Gelevert H, Kler RD, Delft YV, Weeda M. Empowering the chemical industry: opportunities for electrification. 2016. p. 1-32.

[185] Belmonte T, Noel C, Gries T, Martin J, Henrion. G. Theoretical background of optical emission spectroscopy for analysis of atmospheric pressure plasmas. Plasma Sources Sci Technol. 2015;24.

[186] Konoplev IV, Cross AW, Maclnnes P, He W, Whyte CG, Phelps ADR, et al. High-current oversized annular electron beam formation for high-power microwave research. Appl Phys Letters 2006;89:171503. [187] Speckmann FW, Muller D, Kohler J, Birke KP. Low pressure glow-discharge methanation with an ancillary oxygen ion conductor. Journal of $\mathrm{CO}_{2}$ Utilization 2017;19:130-6.

[188] Mesyats GA. Pulse Power. 1 ed: Springer; 2007.

[189] Schutze A, Jeong JY, Babayan SE, Park J, Selwyn GS, Hicks RF. The atmospheric pressure plasma jet: A review and comparison to other plasma sources. IEEE Trans on Plasma Sci. 1998;26:1685-94.

[190] Generalov NA, Zimakov VP, Kosynkin VD, Raizer YP, Solov'ev NG. Fast flow technical combinedaction $\mathrm{CO}_{2}$ laser. Sov J Quant Electron. 1982;9:1549-57.

[191] Hill AE. Continuous uniform excitation of medium pressure $\mathrm{CO}_{2}$ laser plasmas by means of controlled avalanche ionization. Appl Phys Lett 1973;22 670-3.

[192] Generalov NA, Zimakov VP, Kosynkin VD, Raizer YP, Roitenburg DI. Method for significantly increasing the stability limit of the discharge in fast flow large volume lasers. Sov J Tech Phys Lett. 1975;1:201-2.

[193] Yuan XH, Wei C, Min CZ. Effect of Glow Discharge Plasma on Copper based Catalysts for Methanol Synthesis. Acta Phys Chim Sin. 2007;23:1042-6.

[194] R. H. Stark, Schoenbach KH. Direct current high-pressure glow discharges. Journal of Applied Physics. 1999;85.

[195] Choi JH, Lee TI, Han I, Oh B, Jeong M, young J, et al. Improvement of plasma uniformity using ZnOcoated dielectric barrier discharge in open air Appl Phys Lett 2006;89 
[196] Kogelschatz U. Dielectric-barrier discharges: their history, discharge physics, and industrial applications Plasma Chem Plasma Processing. 2003;23:1-46.

[197] Garamoon AA, El-zeer DM. Atmospheric pressure glow discharge plasma in air at frequency $50 \mathrm{~Hz}$. Plasma Sources Sci Technol 2009;18:(8pp).

[198] Massines F, Rabehi A, Decomps P, Gadri RB, Ségur P, Mayoux C. Experimental and theoretical study of a glow discharge at atmospheric pressure controlled by dielectric barrier. Journal of Applied Physics. 1998;83: 2950

[199] Park J, Henins I, Herrmann HW, Selwyn GS. An atmospheric pressure plasma source. Appl Phys Lett. 2000;76:288.

[200] Morshuis PHF. Partial Discharge Mechanisms. Delft University Press; 1993.

[201] Spence P, Roth JR. Electrical and plasma characteristics of a one atmosphere glow discharge plasma reactor. IEEE Conference on plasma Science. Santa Fe, NM1994.

[202] Botticher W. Filamentation of high pressure glow discharges. Proceedings of the XXI ICPIG. Bochum, Germany1993. p. 128-31.

[203] Pai DZ, Lacoste DA, Laux CO. Transitions between corona, glow, and spark regimes of nanosecond repetitively pulsed discharges in air at atmospheric pressure. Journal of Applied Physics 2010;107:093303. [204] Samanta K, Jassal M, Agrawal AK. Atmospheric pressure glow discharge plasma and its applications in textile. Indian Journal of Fibre and Textile Research. 2006;31:83-98.

[205] Chang J, K. Urashima. Removal of organic compounds from air streams and industrial flue gases by non- thermal plasma technology. IEEE Trans Dielectric Electric Insul 2000;7:602-14.

[206] Maezono I, Chang JS. Reduction of carbon dioxide from combustion gases by dc corona torches, . IEEE Trans Ind Appl. 1990;26:651-5.

[207] Kim HH. Nonthermal plasma processing for air pollution control, a historical review, current issues and future prospects. Plasma proc Polym. 2004;1:91-110.

[208] Jogan K, Mizuno A, Yamamoto T, Chang JS. The effect of residence time on the carbon dioxide reduction from combustion flue gases by an ac ferroelectric packed bed reactor. IEEE Trans Ind Appl. 1993;29:876-81.

[209] McAdams R. Prospects for non-thermal atmospheric plasmas for pollution abatement. J Phys D Appl Phys. 2001;34:2810.

[210] Aziznia A, Bozorgzadeh HR, S.-Matin N, Baghalha M, Mohamadalizadeh A. Comparison of dry reforming of methane in low temperature hybrid plasma-catalytic corona with thermal catalytic reactor over $\mathrm{Ni} / \mathrm{Y}-\mathrm{Al}_{2} \mathrm{O}_{3}$. J of Natural Gas Chem 2012;21:466-75.

[211] Hoeben WFLM, Boekhoven W, Beckers FJCM, Heesch EJMv, Pemen AJM. Partial oxidation of methane by pulsed corona discharges. J Phys D: Appl Phys. 2014;47 (10pp).

[212] Wen $\mathrm{Y}$, Jiang X. Decomposition of $\mathrm{CO}_{2}$ Using Pulsed Corona Discharges Combined with Catalyst. Plasma Chem and Plasma Processing. 2001;21:4.

[213] Istadi, Amin NAS. Co-generation of synthesis gas and C2+ hydrocarbons from methane and carbon dioxide in a hybrid catalytic-plasma reactor: a review. Fuel. 2006;85:577-92.

[214] Matzing H, Baumann W, Paur HR. Chemistry of the electron beam process and its application to emission control. Pure Appl Chem. 1996;68:1089-92.

[215] Getoff N. Radiation chemistry and the environment. Radiat Phys Chem. 1999;54: 377-84.

[216] El-Shobaky GA, El-Nabarawy T, Fagal GA, Dessouki AM. Surface and catalytic properties of gamma irradiated $\mathrm{CuO} / \mathrm{Al}_{2} \mathrm{O}_{3}$ solids. Radiat Phys Chem. 1988;30:773-8.

[217] Youssef AM, El-Hakam SA, El-Shobaky GA. Effect of gamma-irradiation on catalytic activity and selectivity of $\mathrm{CuO}-\mathrm{Al}_{2} \mathrm{O}_{3}$ solids. Radiat Phys Chem. 1992;40:575-8.

[218] Jun J, Kim J-C, Shin JH, Lee KW, Baek YS. Effect of electron beam irradiation on $\mathrm{CO}_{2}$ reforming of methane over Ni/ $/ \mathrm{Al}_{2} \mathrm{O}_{3}$ catalysts. Radiation Phys and Chem. 2004;71:1095-101. 
[219] Kim JC, Getoff N, Jun J. Catalytic conversion of $\mathrm{CO}_{2}-\mathrm{CH}_{4}$ mixture into synthetic gas-Effect of electron-beam radiation. Radiation Phycs and Chem. 2006;75:243-6.

[220] Chang-jun L, Gen-hui X, Timing W. Non-thermal plasma approaches in $\mathrm{CO}_{2}$ utilization Fuel Process Technol. 1999;58:119-34.

[221] Rooij GJv, Bekerom DCMvd, Harder Nd, T. Minea GB, Bongers WA, Engeln R, et al. Taming microwave plasma to beat thermodynamics in $\mathrm{CO}_{2}$ dissociation. Faraday Discuss 2015;183:233-48.

[222] Rusanov VD, Fridman AA, Sholin GV. The physics of a chemically active plasma with nonequilibrium vibrational excitation of molecules Sov Phys Usp. 1981;24:447-74

[223] Li S, Lim J-P, Kang JG, Uhm HS. Comparison of atmospheric pressure helium and argon plasmas generated by capacitively coupled radio-frequency discharge. Phys Plasmas. 2006;13,:093 503.

[224] Oks E. Plasma Cathode Electron Sources Wiley-VCH; 2006.

[225] Berkane A, Rebiai S, Bouanaka F, Bahouh H. Computational study of RF micro-hollow cathode discharge. Phys Scr 2015;90: (9pp).

[226] Feng HE, Shoujie HE, Xiaofei Z, Bingang G, O. Jiting. Study of the Discharge Mode in Micro-Hollow Cathode. Plasma Sci \& Technol. 2012;14:1079.

[227] Schoenbach KH, El-Habachi A, Shi W, Ciocca M. High-pressure hollow cathode discharges. Plasma Sources Sci Technol. 1997;6 468.

[228] Taylan O, Berberoglu H. Dissociation of carbon dioxide using a micro hollow cathode discharge plasma reactor: effects of applied voltage, flow rate and concentration. Plasma Sources Sci Technol. 2015 2415006.

[229] Besser RS, Lindner PJ. Microplasma reforming of hydrocarbons for fluel cell power J Power Sources 2011;196:9008-12.

[230] Barankova H, Bardos L. Fused hollow cathode atmospheric plasma source for gas treatment Catalysis Today 2002;72:237-41.

[231] Rahul R, Stan O, Rahman A, Littlefield E, Hoshimiya K, Yalin AP, et al. Optical and RF electrical characteristics of atmospheric pressure open-air hollow slot microplasmas and application to bacterial inactivation. J Phys D: Appl Phys. 2005;38:1750.

[232] Moselhy M, Shi W, Stark RH, Schoenbach KH. A Flat Glow Discharge Excimer Radiation Source IEEE Trans Plasma Sci. 2002;30 198.

[233] Guangqing X, Genwang M, Sadeghi N. Experimental investigation of micro-hollow cathode discharge for the application to microplasma thrusters Tsinghua Sci Technol. 2009;14:49-53.

[234] Yang Z, Shirai H, Kobayashi T, Hasegawa Y. Synthesis of Si nanocones using RF microplasma at atmospheric pressure Thin Solid films 2007;515 4153-8.

[235] Takao Y, Ono K, Takahashi K, Eriguchi K. Plasma Diagnostics and Thrust Performance Analysis of a Microwave-Excited Microplasma Thruster Japan J Appl Phys 2006;45 8235.

[236] Mihailova D, Dijk Jv, Hagelaar GJM, Karatodorov S, Zahariev P, Grozeva M, et al. Geometrical features in longitudinal sputtering hollow cathode discharges for laser applications. J Phys D: Appl Phys. 2012;45:65201

[237] Lazzaroni C, Chabert P. A global model of micro-hollow cathode discharges in the stationary regime. J Phys D: Appl Phys 2011;44:445202.

[238] Bada J. Spark Discharge. Gargaud M et al (eds) Encyclopedia of Astrobiology. Berlin, Heidelberg: Springer,; 2011.

[239] Shapoval V, Marotta E, Ceretta C, Konjevi N, Ivkovi M, Schiorlin M, et al. Development and Testing of a Self-Triggered Spark Reactor for Plasma Driven Dry Reforming of Methane. Plasma Process Polym. 2014;11:787-97.

[240] Shapoval V, Marotta E. Investigation on Plasma-Driven Methane Dry Reforming in a Self-Triggered Spark Reactor. Plasma Process Polym. 2015;12: 808-16. 
[241] Conrads H, Schmidt M. Plasma Generation and Plasma Sources. Plasma Sources Sci Tech. 2000;9:441-54.

[242] Calo JM, Perkins MT. A heterogeneous surface model for the "steady-state" kinetics of the Boudouard reaction. Carbon. 1987;25:395-407.

[243] Lahijani P, Mohammadi M, Zainal ZA, Mohamed AR. Advances in $\mathrm{CO}_{2}$ gasification reactivity of biomass char through utilization of radio frequency irradiation. Energy 2015;93:976-83.

[244] Spencer LF, Gallimore AD. Efficiency of $\mathrm{CO}_{2}$ Dissociation in a Radio-Frequency Discharge. Plasma Chem Plasma Process. 2011;31:79-89.

[245] V. NS. Hydrogen production in a radio-frequency plasma source operating on water vapor: University of Michigan; 2009.

[246] Nguyen SV, Foster JE, Gallimore AD. Operating a radio-frequency plasma source on water vapor. 80. Rev Sci Instrum. 2009;80:083503.

[247] Varghese OK, Paulose M, LaTempa TJ, Grime CA. High-rate solar photocatalytic conversion of $\mathrm{CO}_{2}$ and water vapor to hydrocarbon fuels. Nano Lett. 2009;9:731-7.

[248] B VH. the inductively coupled plasma source internal report: FOM Institute DIFFER 2014 p. 5-19.

[249] Lee H, Savinov YS, Song HK, Na BK. Estimation of the Methane Conversion in a Capacitively Coupled Radio-Frequency Discharge. J Chem Eng Jpn. 2001;34:1356.

[250] Tsai CH, Hsieh TH. New approach for methane conversion using rf discharge reactor. 1. Influences of operating conditions on syngas production. Ind Eng Chem Res. 2004;43:4043.

[251] Raizer YP, Shneider UN, Yatsenko NA. Radio-Frequency Capacitive Discharges. CRC Press; 1995.

[252] Savinov YS, Lee H, Song HK, Na BK. Decomposition of Methane and Carbon Dioxide in a RadioFrequency Discharge. Ind Eng Chem Res. 1999;38:2540

[253] Belov I. Plasma-assisted conversion of carbon dioxide [PhD Thesis]. Belgium: University of Antwerp; 2017.

[254] Aerts R, Martens T, Bogaerts A. Influence of Vibrational States on $\mathrm{CO}_{2}$ Splitting by Dielectric Barrier Discharges. Journal of Physical Chem C. 2012;116:23257.

[255] Neyts EC, Ostrikov K, Sunkara MK, Bogaerts A. Plasma Catalysis: Synergistic Effects at the Nanoscale. Chem Rev 2015;115:13408-46.

[256] Gholami R, Stere CE, Goguet A, Hardacre C. Non-thermal-plasma-activated de- $\mathrm{NO}_{x}$ catalysis. Phil Trans R Soc A. 2017 376:20170054.

[257] Tu X, Whitehead JC. Plasma-Catalytic Dry Reforming Of Methane In An Atmospheric Dielectric Barrier Discharge: Understanding The Synergistic Effect At Low Temperature Appl Catal B. 2012;125:439-48.

[258] Chiremba E, Zhang K, Kazak C, Akay G. Direct Nonoxidative Conversion of Methane to Hydrogen and Higher Hydrocarbons by Dielectric Barrier Discharge Plasma with Plasma Catalysis Promoters. AIChE Journal. 2017;63:4418-29.

[259] Deutschmann O, Knözinger H, Kochloefl K, Turek T. Heterogeneous Catalysis and Solid Catalysts. Wiley-VCH Verlag GmbH Weinheim, Germany2009.

[260] Neyts EC. Plasma-Surface Interactions in Plasma Catalysis. Plasma Chemistry and Plasma Processing. 2015;36:185-212.

[261] Vandenbroucke AM, Morent R, Geyter ND, Leys C. Non-Thermal Plasmas for Non-Catalytic and Catalytic Volatile Organic Compound Abatement. J Hazard Mater. 2011;195:30-54.

[262] Neyts EC, Bogaerts A. Understanding Plasma Catalysis Through Modelling and Simulation - A Review. J Phys D: Appl Phys. 2014;47:1-18.

[263] Zhang A, Zhu A, Guo J, Xu Y, Shi C. Conversion of greenhouse gases into syngas via combined effects of discharge activation and catalysis. Chem Eng 2010;156:601-6.

[264] Tang X, Li K, Yi H, Ning P, Xiang Y, Wang J, et al. $\mathrm{MnO}_{x}$ Catalysts Modified by Non-Thermal Plasma for NO Catalytic Oxidation. J Phys Chem C. 2012;116:10017-28. 
[265] Witvrouwen T, Paulussen S, Sels B. The Use of Non- Equilibrium Plasmas for the Synthesis of Heterogeneous Catalysts. Plasma Processes Polym. 2012;9:750-60.

[266] Guo Y-F, Ye D-Q, Chen K-F, He J-C, Chen W-L. Toluene Decomposition Using a Wire-Plate Dielectric Barrier Discharge Reactor with Manganese Oxide Catalyst In Situ. J Mol Catal A: Chem. 2006;245:93-100. [267] Beckerle JD, Yang QY, Johnson AD, Ceyer ST. Collision-Induced Dissociative Chemisorption of Adsorbates: Chemistry with a Hammer. J Chem Phys 1987;86:7236-7.

[268] Wang L, Zhao Y, Liu C, Gong W, Guo H. Plasma Driven Ammonia Decomposition on a Fe-Catalyst: Eliminating Surface Nitrogen Poisoning. Chem Commun 2013;49:3787-9.

[269] Tu X, Gallon HJ, Whitehead JC. Plasma-Assisted Reduction of a $\mathrm{NiO} / \mathrm{Al}_{2} \mathrm{O}_{3}$ Catalyst in Atmospheric Pressure $\mathrm{H}_{2} / \mathrm{Ar}$ Dielectric Barrier Discharge. Catal Today. 2013;211:120-5.

[270] Khoja AH, Tahir M, Amin NASJEc, management. Recent developments in non-thermal catalytic DBD plasma reactor for dry reforming of methane. 2019;183:529-60.

[271] Tu X, Gallon HJ, Whitehead JC. Electrical and Spectroscopic Diagnostics of a Single-Stage PlasmaCatalysis System: Effect of Packing with $\mathrm{TiO}_{2}$. J Phys D: Appl Phys. 2011;44:1-4.

[272] Hensel K, Martisovits V, Machala Z, Janda M, Lestinsky M, Tardiveau P, et al. Electrical and Optical Properties of AC Microdischarges in Porous Ceramics. Plasma Processes Polym. 2007;4:682-93.

[273] Li L, Zhang H, Li X, Kong X, Xu R, Tay K, et al. Plasma-assisted $\mathrm{CO}_{2}$ conversion in a gliding arc discharge: Improving performance by optimizing the reactor design. Journal of $\mathrm{CO}_{2}$ Utilization. 2019;29:296-303.

[274] Lu N, Sun D, Zhang C, Jiang N, Shang $K$, Bao X, et al. $\mathrm{CO}_{2}$ conversion in non-thermal plasma and plasma/g- $\mathrm{C}_{3} \mathrm{~N}_{4}$ catalyst hybrid processes. J Phys D: Appl Phys. 2018;51:094001.

[275] Huang Q, Zhang D, Wang D, Liu K, Kleyn AW. Carbon dioxide dissociation in non-thermal radiofrequency and microwave plasma. J Phys D: Appl Phys. 2017;50:294001.

[276] Xu W, Li MW, Xu GH, Tian YL. Decomposition of $\mathrm{CO}_{2}$ Using DC Corona Discharge at Atmospheric Pressure. Jpn J Appl Phys. 2004;43:8310-1.

[277] Schiorlin M, Klink R, Brandenburg R. Carbon dioxide conversion by means of coplanar dielectric barrier discharges. Eur Phys J Appl Phys. 2016;75:24704.

[278] Duan X, Li Y, Ge W, Wang B. Degradation of $\mathrm{CO}_{2}$ through dielectric barrier discharge microplasma. Greenhouse Gases Science and Technology. 2015;5:131-40.

[279] Mei D, He YL, Liu S, Yan J, Tu X. Optimization of $\mathrm{CO}_{2}$ Conversion in a Cylindrical Dielectric Barrier Discharge Reactor Using Design of Experiments. Plasma Process and Polymers. 2016;13:544-56.

[280] Mikoviny T, Kocan M, Matejcik S, Mason NJ, Skalny JD. Experimental study of negative corona discharge in pure carbon dioxide and its mixtures with oxygen. Journal of Physics D: Applied Physics. 2004;37:64-73.

[281] Asisov RI, Givotov VK, Krasheninnikov EG, Potapkin BV, Rusanov VD, Fridman A. Carbon Dioxide Dissociation in Non-Equilibrium Plasma. Proc 5th Intern Symp Plasma Chemistry1981.

[282] Silva T, Britun N, Godfroid T, Snyders R. Optical characterization of a microwave pulsed discharge used for dissociation of $\mathrm{CO}_{2}$. . Plasma Sources Sci Technol. 2014;23 025009.

[283] Chen G, Britun N, Godfroid T, Georgieva V, Snyders R, Ogletree M-PD. An overview of $\mathrm{CO}_{2}$ conversion in a microwave discharge: the role of plasma-catalysis. Journal of Physics D: Applied Physics. 2017;50:084001

[284] Bongers W, Bouwmeester H, B. Wolf FP, Welzel S, Bekerom DVD, Harder N, et al. Plasma-driven dissociation of $\mathrm{CO}_{2}$ for fuel synthesis Plasma Process Polym. 2017;14.

[285] Mitsingas CM, Rajasegar R, Hammack S, Do H, Lee T. High energy efficiency plasma conversion of $\mathrm{CO}_{2}$ at atmospheric pressure using a direct-coupled microwave plasma system. IEEE Transactions on Plasma Science. 2016;44:651-6.

[286] Azzolina-Jury F, Bento D, Henriques C, Thibault-Starzyk F. Chemical engineering aspects of plasmaassisted $\mathrm{CO}_{2}$ hydrogenation over nickel zeolites under partial vacuum. Journal of $\mathrm{CO}_{2}$ Utilization 2017;22: 97-109. 
[287] Jiang T, Li Y, Liu C-J, Xu G-H, Eliasson B, Xue. B. Plasma methane conversion using dielectric-barrier discharges with zeolite. A Catal Today. 2002;72:229-35.

[288] Paulmier T, Fulcheri L. Use of non-thermal plasma for hydrocarbon reforming. ;. Chem Eng J. 2005;106:59-71.

[289] Abbas HF, Daud WMAW. Hydrogen production by methane decomposition: a review. Int J Hydrogen Energy. 2010;35:1160-90.

[290] Pawelec B, Damyanova S, Arishtirova K, Fierro JLG, Petrov L. Structural and surface features of PtNi catalysts for reforming of methane with $\mathrm{CO}_{2}$. Appl Catal A Gen. 2007;323:188-201.

[291] Michielsen I, Uytdenhouwen Y, Pype J, Michielsen B, Mertens J, Reniers F, et al. $\mathrm{CO}_{2}$ dissociation in a packed bed DBD reactor: First steps towards a better understanding of plasma catalysis. Chem Eng J. 2017;326:477-88

[292] Zheng X, Tan S, Dong L, Li S, Chen H. LaNiO $@ \mathrm{SiO}_{2}$ core-shell nano-particles for the dry reforming of $\mathrm{CH}_{4}$ in the dielectric barrier discharge plasma. International Journal of Hydrogen Energy. 2014;39:11360-7.

[293] Nagaraja BM, Bulushev DA, Beloshapkin S, Ross JRH. The effect of potassium on the activity and stability of $\mathrm{Ni}-\mathrm{MgO}-\mathrm{ZrO}_{2}$ catalysts for the dry reforming of methane to give synthesis gas. Catalysis Today. 2011;178:132-6.

[294] Chung W-C, Pan K-L, Lee H-M, Chang M-B. Dry reforming of methane with dielectric barrier discharge and ferroelectric packed-bed reactors. Energy Fuels. 2014;28:7621-31.

[295] Tu X, Gallon HJ, Twigg MV, Gorry PA, Whitehead JC. Dry reforming of methane over a Ni/Al ${ }_{2} \mathrm{O}_{3}$ catalyst in a coaxial dielectric barrier discharge reactor. J Phys D Appl Phys. 2011;44:274007.

[296] Nguyen HH, Kim K-S. Combination of plasmas and catalytic reactions for $\mathrm{CO}_{2}$ reforming of $\mathrm{CH}_{4}$ by dielectric barrier discharge process. Catalysis Today. 2015;256:88-95.

[297] Wang Y, Craven M, Yu X, Ding J, Bryant P, Huang J, et al. Plasma-enhanced catalytic synthesis of ammonia over a Ni/Al2O3 catalyst at near-room temperature: Insights into the importance of the catalyst surface on the reaction mechanism. ACS Catalysis. 2019;9:10780-93.

[298] Lebouvier A, S. A Iwarere, P. d'Argenlieu, Ramjugernath D, Fulcheri L. Assessment of carbon dioxide dissociation as a new route for syngas production: A comparative review and potential of plasma-based technologies. Energy \& Fuels 2013;27:2712-22.

[299] Pinhao NR, Janeco A, Branco JB. Influence of He On The Conversion of Methane and $\mathrm{CO}_{2}$ in $A$ Dielectric Barrier Discharge. Plasma Chem Plasma Process. 2011;31:427-39.

[300] Ozkan A. $\mathrm{CO}_{2}$ splitting in a dielectric barrier discharge plasma: understanding of physical and chemical aspects Belgium: universiteit Antwerpen; 2016.

[301] Crim FF. Chemical Dynamics of Vibrationally Excited Molecules: Controlling Reactions in Gases and on Surfaces. Proceedings of the National Academy of Sciences. U.S.A2008. p. 12654-61.

[302] Mei D, Zhu X, Wu C, Ashford B, Williams PT, Tu X. Plasma-photocatalytic conversion of $\mathrm{CO}_{2}$ at low temperatures: Understanding the synergistic effect of plasma-catalysis. Applied Catalysis B: Environmental 2016;182 525-32.

[303] Bahri M, Haghighat F. Plasma-based indoor air cleaning technologies: the state of the art-review Clean -Soil, Air, Water. 2014;42:1667-80.

[304] Gallon HJ, Tu X, Whitehead JC. Effects of reactor packing materials on $\mathrm{H}_{2}$ production by $\mathrm{CO}_{2}$ reforming of $\mathrm{CH}_{4}$ in a dielectric barrier discharge. Plasma Process Polym 2012;9:90-7.

[305] Wang WZ, Berthelot A, Kolev S, Tu X, Bogaerts A. $\mathrm{CO}_{2}$ conversion in a gliding arc plasma: 1D cylindrical discharge mode. Plasma sources Sci Technol 2016;25.

[306] Tsuji M, Tanoue T, Nakano K, Nishimura Y. Decomposition of $\mathrm{CO}_{2}$ into $\mathrm{CO}$ and $\mathrm{O}$ in a microwaveexcited discharge flow of $\mathrm{CO}_{2} / \mathrm{He}$ or $\mathrm{CO}_{2} / \mathrm{Ar}$ mixtures. Chem Lett 2001;1:22-3.

[307] Wang J, Xia G, Huang A, Suib SL, Hayashi Y, Matsumoto H. $\mathrm{CO}_{2}$ decomposition using glow discharge plasmas. J Catal. 1999;185:152- 9. 
[308] Zhang K, Zhang G, Liu X, Phan AN, Luo K. A study on $\mathrm{CO}_{2}$ decomposition to $\mathrm{CO}$ and $\mathrm{O}_{2}$ by the combination of catalysis and dielectric-barrier discharges at low temperatures and ambient pressure. Industrial Eng Chem Research. 2017;56:3204-16.

[309] Heijkers S, Snoeckx R, Kozak T, Silva T, Godfroid T, Britun N, et al. $\mathrm{CO}_{2}$ Conversion in a Microwave Plasma Reactor in the Presence of $\mathrm{N}_{2}$ : Elucidating the Role of Vibrational Levels. J Phys Chem C 2015;119 12815-28.

[310] Yu QQ, Kong M, Liu T, Fei JH, Zheng XM. Characteristics of the Decomposition of $\mathrm{CO}_{2}$ in a Dielectric Packed-Bed Plasma Reactor. Plasma Chem Plasma Process. 2012;32:153-63.

[311] Wang Y, Yao L, Wang S, Mao D, Hu C. Low-temperature catalytic $\mathrm{CO}_{2}$ dry reforming of methane on Ni-based catalysts: A review. Fuel Proc Technol. 2018;169:199-206.

[312] Elsayed NH, Roberts NR, Joseph B, Kuhn JN. Low temperature dry reforming of methane over Pt$\mathrm{Ni}-\mathrm{Mg}$ /ceria-zirconia catalysts. Appl Catal B Environ. 2015;179:213-9.

[313] Gao X, Ashok J, Widjaja S, Hidajat K, Kawi S. Ni/SiO 2 catalyst prepared via Nialiphatic amine complexation for dry reforming of methane: effect of carbon chain number and amine concentration Appl Catal A Gen 2015;503:34-42.

[314] Olsbye AU, Wurzel LT, Mleczko. Kinetic and reaction engineering studies of dry reforming of methane over a Ni/La/ $/ \mathrm{Al}_{2} \mathrm{O}_{3}$ catalyst Ind Eng Chem Res 1997;36:5180-8.

[315] Dębek R, Motak M, Grzybek T, Galvez M, Costa PD. A Short Review, On the catalytic activity of Hydrotalcite-derived materials for dry reforming of methane. Catalysts. 2017;7:32.

[316] Snoeckx R, Aerts R, Tu X, Bogaerts A. Plasma-based dry reforming: a computational study ranging from nanoseconds to seconds timescale. Journal of Physical Chemistry C. 2013;117:4957-70.

[317] Mei D, Tu X. Atmospheric pressure non-thermal plasma activation of $\mathrm{CO}_{2}$ in a packed-bed dielectric barrier discharge reactor. ChemPhysChem. 2017;18:3253-9.

[318] Aresta M, Angelini A. The Carbon Dioxide Molecule and the Effects of Its Interaction with Electrophiles and Nucleophiles. Carbon Dioxide and Organometallics 2015;53:1-39.

[319] Angeli SD, Turchetti L, Monteleone G, Lemonidou AA. Catalyst development for steam reforming of methane and model biogas at low temperature. Appl Catal B Environ. 2015;181:34-46.

[320] Al-Fatesh AS, Amin A, Ibrahim AA, Khan WU, Soliman MA, Al-Otaibi RL, et al. Effect of Ce and Co addition to $\mathrm{Fe} / \mathrm{Al}_{2} \mathrm{O}_{3}$ for catalytic methane decomposition. Catalysts 2016;6:41-15.

[321] Bian Z, Kawi S. Highly carbon-resistant $\mathrm{Ni}-\mathrm{Co} / \mathrm{SiO}_{2}$ catalysts derived from phyllosilicates for dry reforming of methane. Journal of $\mathrm{CO}_{2}$ Utilization. 2017;18:345-52.

[322] Labinger JA, Bercaw JE. Understanding and exploiting C-H bond activation. Nature 2002;417 50714.

[323] Yao L, Shi J, Xu H, Shen W, Hu C. Low-temperature $\mathrm{CO}_{2}$ reforming of methane on $\mathrm{Zr}$-promoted Ni/SiO catalyst. Fuel Process Technol 2016;144:1-7.

[324] Sentek J, Krawczyk K, Młotek M, Kalczewska M, Kroker T, Kolb T, et al. Plasma-catalytic methane conversion with carbon dioxide in dielectric barrier discharges. Applied Catalysis B: Environmental. 2010;94:19-26.

[325] Pu Y-K, Guo Z-G, Yu Z-D, Ma J. Tuning effect of inert gas mixing on electron energy distribution function in inductively coupled discharges. Plasma Physics Controlled Fusion. 2005;48:61.

[326] Kraus M, Egli W, Haffner K, Eliasson B, Kogelschatz U, Wokaun A. Investigation of mechanistic aspects of the catalytic $\mathrm{CO}_{2}$ reforming of methane in a dielectric-barrier discharge using optical emission spectroscopy and kinetic modeling. Phys Chem Chem Phys. 2002;4:668-75.

[327] Baulch DL, Cobos CJ, Cox RA, Esser C, Frank P, Just T, et al. Ref. Data J Phys Chem 1992;21:411-29.

[328] Baulch DL, Cobos CJ, Cox RA, Esser C, Frank P, Just T, et al. Evaluated Kinetic Data for Combustion Modeling: Supplement II J Phys Chem Ref Data. 2005;34.

[329] Harding LB, Georgievskii Y, Klippenstein SJ. Predictive Theory for Hydrogen Atom-Hydrocarbon Radical Association Kinetics. J Phys Chem A. 2005;109:4646-56. 
[330] Zhang K, Mukhriza T, Liu X, Greco PP, Chiremba E. A study on $\mathrm{CO}_{2}$ and $\mathrm{CH}_{4}$ conversion to synthesis gas and higher hydrocarbons by the combination of catalysts and dielectric-barrier discharges. Applied Catalysis A: General. 2015;502:138-49.

[331] Janev RK, Reiter D. Collision processes of $\mathrm{CH}_{\mathrm{y}}$ and $\mathrm{CH}_{\mathrm{y}^{+}}$hydrocarbons with plasma electrons and protons. . Phys Plasmas 2002;9:4071-81.

[332] Florescu-Mitchell Al, Mitchell JBA. Dissociative Recombination. Phys Rep 2006;430: 277-374.

[333] Woodall J, ndez MA, Markwick-Kemper AJ, Millar TJ. The UMIST database for astrochemistry. Astron Astrophys. (2007;466:1197-204.

[334] Hancock G, Haverd V, Morrison M. Infrared emission accompanying the gas phase recombination of alkyl radicals. Phys Chem Chem Phys. 2003;5:2981-7.

[335] Tsang W, Hampson RF. Chemical Kinetic Data Base for Combustion Chemistry. Part I. Methane and Related Compounds. J Phys Chem Ref Data. 1986;15:1087-279.

[336] Fang DC, Fu XY. CASSCF and CAS+1+2 Studies on the Potential Energy Surface and the Rate Constants for the Reactions between $\mathrm{CH}_{2}$ and $\mathrm{O}_{2}$ J Phys Chem A. 2002;106:2988-93.

[337] Hadj-Ziane S, Held B, Pignolet P, Peyrous R, Coste C. Ozone generation in an oxygen-fed wire-tocylinder ozonizer at atmospheric pressure. J Phys D: Appl Phys 1992;25:677-85.

[338] Zhang H, Li X, Zhu F, Cen K, Du C, Tin X. Plasma assisted dry reforming of methanol for clean syngas production and high efficiency $\mathrm{CO}_{2}$ conversion. J Chem Eng 2017;310:114-9.

[339] Itikawa Y. Cross sections for electrons collisions with carbon dioxide. J Phys Chem Ref Data 2002;31:749-67.

[340] Veraki MA-. Study of carbon dioxide gas treatment based on equations of kinematics in plasma discharge reactor. Modern Physics Letters B 2017;31:1750210.

[341] Gauthier MJE, Snelling DR. The energy pooling reaction $2 \mathrm{O} 2(1 \Delta \mathrm{g}) \rightarrow \mathrm{O} 2(3 \Sigma-\mathrm{g})+\mathrm{O} 2(1 \Sigma+\mathrm{g}$; formation, relaxation, and quenching of vibrationally excited O2 $(1 \Sigma+\mathrm{g})$. J Photochem. 1975;4:215-26.

[342] Janev RK, Reiter D. Collision processes of C 2, $3 \mathrm{H} \mathrm{y}$ and C 2, $3 \mathrm{H} \mathrm{y}+$ hydrocarbons with electrons and protons. Phys Plasmas 2004;11:780-829.

[343] Usman M, Daud WMAW, Abbas HF. Dry reforming of methane: Influence of process parametersA review. Renewable and Sustainable Energy Reviews. 2015;45:710-44.

[344] Xu S. Plasma-Assisted Conversion of $\mathrm{CO}_{2}$. United Kingdom: The University of Manchester 2017.

[345] Rahemi N, Haghighi M, Babaluo AA, Allahyari S, Estifaee P, Jafari MF. Plasma-Assisted Dispersion of Bimetallic Ni-Co over $\mathrm{Al}_{2} \mathrm{O}_{3}-\mathrm{ZrO}_{2}$ for $\mathrm{CO}_{2}$ Reforming of Methane: Influence of Voltage on Catalytic Properties. Top Catal 2017;60:843-54.

[346] Long $\mathrm{H}$, Shang $\mathrm{S}$, Tao $\mathrm{X}$, Yin $\mathrm{Y}$, Dai X. $\mathrm{CO}_{2}$ reforming of $\mathrm{CH}_{4}$ by combination of cold plasma jet and $\mathrm{Ni} / \mathrm{Y}-\mathrm{Al}_{2} \mathrm{O}_{3}$ catalyst. Int J of hydrogen energy. 2008;33:5510-5.

[347] Li MW, Liu CP, Tian YL, Xu GH, Zhang FC. Effects of HZSM-5 Zeolite on Carbon Dioxide Reforming of Methane via Corona Discharge. Jpn J of Applied Physics. 2006;45:946-7.

[348] Wang L, Yi Y, Wu C, Guo H, Tu X. One-Step Reforming of $\mathrm{CO}_{2}$ and $\mathrm{CH}_{4}$ into High-Value Liquid Chemicals and Fuels at Room Temperature by Plasma-Driven Catalysis. Angew Chem Int Ed. 2017;56:13679-83.

[349] Zou J-J, Zhang Y-p, Liu C-J, Li Y, Eliasson B. Starch-enhanced Synthesis of Oxygenates from Methane and Carbon Dioxide using Dielectric-barrier Discharges. Plasma Chem Plasma Process. 2003;23:69- 82.

[350] Scapinello M, Martini LM, Tosi P. $\mathrm{CO}_{2}$ Hydrogenation by $\mathrm{CH}_{4}$ in a Dielectric Barrier Discharge: Catalytic Effects of Nickel and Copper. Plasma Process Polym. 2014;11:624-8.

[351] Dey GR, Das TN. Gas-phase and On-Surface Chemical Reduction of $\mathrm{CO}_{2}$ to $\mathrm{HCHO}$ and $\mathrm{CO}$ under Dielectric Barrier Discharge. Plasma Chem Plasma Process. 2006;26:495-505.

[352] Su YS, Ying JY, Green WH. Upper bound on the yield for oxidative coupling of methane. J of Catalysis. 2003;218 321-33. 
[353] Lee MR, Park M-J, Jeon W, Choi J-W, Suh Y-W, Suh DJ. A kinetic model for the oxidative coupling of methane over $\mathrm{Na}_{2} \mathrm{WO}_{4} / \mathrm{Mn} / \mathrm{SiO}_{2}$. Fuel Proc Technol 2012;96:175-82.

[354] Ghiasi M, Malekzadeh A, Hoseini S, Mortazavi Y, Khodadadi A, Talebizadeh A. Kinetic study of oxidative coupling of methane over $\mathrm{Mn}$ and/or W promoted $\mathrm{Na}_{2} \mathrm{SO}_{4} / \mathrm{SiO}_{2}$ catalysts. J of Natural Gas Chemistry. 2011;20:428 - 34.

[355] Nishiyama T, Aika K-I. Mechanism of the oxidative coupling of methane using $\mathrm{CO}_{2}$ as an oxidant over PbO- MgO. . J Catal 1990;122:346-51.

[356] Liu C-J. Oxidation synthesis of higher hydrocarbon from $\mathrm{CO}_{2}$ and $\mathrm{CH}_{4}$ by streamer discharges. Chem Lett. 1996: 979-50.

[357] Fotouh KH, Liu C-J. $\mathrm{CO}_{2}$ utilization by gas discharges. The 212th ACS National meeting1996. p. 13826.

[358] Biloen P, Sachtler WMH. Mechanism of Hydrocarbon Synthesis over Fischer-Tropsch Catalysts. Advances in Catalysis. 1981;30:165-216.

[359] Wang Y, Ohtsuka YY. Mn-based binary oxides as catalyst for the conversion of methane to C2C hydrocarbon with carbon dioxide as an oxidant. Appl Catal A. 2001;219:183-93.

[360] Wang Y, Takahashi Y, Ohtsuka Y. Carbon dioxide-induced selective conversion of methane to $C_{2}$ hydrocarbons on $\mathrm{CeO}_{2}$ modified with CaO. Appl Catal A 1998;172:L203-L6.

[361] Chen C, Xu Y, Lin G, Guo X. Oxidative coupling of methane by carbon dioxide: a highly C2 selective $\mathrm{La}_{2} \mathrm{O}_{3} / \mathrm{ZnO}$ catalyst. Catal Lett 1996;42:149-53.

[362] Wang Y, Takahashi Y, Ohtsuka Y. Effective catalyst for conversion of methane to ethane and ethylene using carbon dioxide. Chem Lett 1998;27:1209-10.

[363] Cai Y, Chou L, Li S, Zhang B, Zhao J. Selective conversion of methane to C2 hydrocarbons Using carbon dioxide over $\mathrm{Mn}-\mathrm{SrCO}_{3}$ catalysts. Catal Lett 2003;86:191-5.

[364] Zhang X, Dai B, Zhu A, Gong W, Liu CJ. The simultaneous activation of methane and carbon dioxide to $\mathrm{C}_{2}$ hydrocarbons under pulse corona plasma over $\mathrm{La}_{2} \mathrm{O}_{3} / \mathrm{\gamma}-\mathrm{Al}_{2} \mathrm{O}_{3}$ catalyst. Catal Today. 2002;72:223-7. [365] Khoja AH, Tahir M, Amin NAS. Process optimization of DBD plasma dry reforming of methane over $\mathrm{Ni} / \mathrm{La}_{2} \mathrm{O}_{3} \mathrm{MgAl}_{2} \mathrm{O}_{4}$ using multiple response surface methodology. International Journal of Hydrogen Energy. 2019;44:11774-87.

[366] Song HK, Choi J-W, Yue SH, Lee H, Na B-K. Synthesis Gas Production via Dielectric Barrier Discharge over Ni/ $\mathrm{Y}-\mathrm{Al}_{2} \mathrm{O}_{3}$ Catalyst. Catal Today. 2004;89:27-33.

[367] Eliasson B, Liu CJ, Kogelschatz U. Direct Conversion of Methane and Carbon Dioxide to Higher Hydrocarbons Using Catalytic DielectricBarrier Discharges with Zeolites. Ind Eng Chem Res. 2000;39:12217.

[368] Zhang K, Kogelschatz U, Eliasson B. Conversion of Greenhouse Gases to Synthesis Gas and Higher Hydrocarbons. Energ Fuel. 2001;15:395-402.

[369] Zhang K, Eliasson B, Kogelschatz U. Direct Conversion of Greenhouse Gases to Synthesis Gas and $C_{4}$ Hydrocarbons over Zeolite HY Promoted by a Dielectric-Barrier Discharge. Ind Eng Chem Res. 2002;41:1462-8.

[370] Rahemi N, Haghighi M, Babaluo AA, Estifaee JMF. Synthesis and physicochemical characterizations of $\mathrm{Ni} / \mathrm{Al}_{2} \mathrm{O}_{3}-\mathrm{ZrO}_{2}$ nanocatalyst prepared via impregnation method and treated with non-thermal plasma for $\mathrm{CO}_{2}$ reforming of $\mathrm{CH}_{4}$. J Ind Eng Chem 2013;19:1566-76.

[371] Zhu X, Huo P, Zhang YP, Cheng DG, Liu CJ. Structure and reactivity of plasma treated $\mathrm{Ni} / \mathrm{Al}_{2} \mathrm{O}_{3}$ catalyst for $\mathrm{CO}_{2}$ reforming of methane. Appl Catal B Environ. 2008;81:132-40.

[372] Hua W, Jin L, He X, Liu J, Hu H. Preparation of $\mathrm{Ni} / \mathrm{MgO}$ catalyst for $\mathrm{CO}_{2}$ reforming of methane by dielectric-barrier discharge plasma. Catal Commun. 2010;11:968-72.

[373] Tursunov O, Kustov L, Kustov A. A brief review of carbon dioxide hydrogenation to methanol over copper and iron based catalysts. J Oil Gas Sciences Technology-Revue d'IFP Energies nouvelles. 2017;72:30. 
[374] Inui T, Takeguchi T. Effective conversion of carbon dioxide and hydrogen to hydrocarbons. Catalysis Today. 1991;10:95-106.

[375] Zeng $\mathrm{YX}, \mathrm{Tu} \mathrm{X}$. Plasma-catalytic hydrogenation of $\mathrm{CO}_{2}$ for the cogeneration of $\mathrm{CO}$ and $\mathrm{CH}_{4}$ in a dielectric barrier discharge reactor: Effect of argon addition. Journal of Physics D: Applied Physics. 2017;50:184004.

[376] Wang L, Yi YH, Guo HC, Tu X. Atmospheric pressure and room temperature synthesis of methanol through plasma-catalytic hydrogenation of $\mathrm{CO}_{2}$. ACS Catalysis 2018;8:90-100.

[377] Nakagawa Y, Kohchi A, Nishitani T. Deoxidization of carbon dioxide by pulse power discharge. Jpn J Appl Phys. 1993;32:L1568- L70.

[378] Snoeckx R, Ozkan A, Aerts R, Dufour T, Raniers F, Bogaerts A. A combined study for turning $\mathrm{CO}_{2}$ and $\mathrm{H}_{2} \mathrm{O}$ into value-added products in a dielectric barrier discharge. ISPC-22. University of Antwerp, 2610 Antwerpen-Wilrijk, Belgium2015.

[379] Tsang W, Hampson RF. Chemical kinetic database for combustion chemistry .1. Methane and related-compounds. J Phys Chem Ref Data 1986;15:1087-279.

[380] Machrafi $\mathrm{H}$, Cavadias $\mathrm{S}$, Amouroux $\mathrm{J} \mathrm{CO}_{2}$ valorization by means of dielectric barrier discharge. Journal of Physics: Conference Series; 2011. p. 012016.

[381] Kozak T, Bogaerts A. Evaluation of the energy efficiency of $\mathrm{CO}_{2}$ conversion in microwave discharges using a reaction kinetics model. Plasma Sources Sci Tech. 2015;24.

[382] Jadhav SG, Vaidya PD, Bhanage BM, Joshi JB. Catalytic Carbon Dioxide Hydrogenation to Methanol: A Review of Recent Studies. Chemical Engineering Research Design. 2014;92:2557-67.

[383] Bie CD, Dijk Jv, Bogaerts A. $\mathrm{CO}_{2}$ Hydrogenation in a Dielectric Barrier Discharge Plasma Revealed. J Phys Chem C. 2016;120:25210-24.

[384] Eliasson B, Kogelschatz U, Xue BZ, Zhou LM. Hydrogenation of Carbon Dioxide to Methanol with a Discharge Activated Catalyst. Ind Eng Chem Res. 1998;37:3350-7.

[385] Bill A, Eliasson B, Kogelschatz U, Zhou L-M. Compasision of CO2 hydrogenation in a catalytic reactor and in a dielectric barrier discharge,. Stud Surf Sci Catal 1998;114:541-4.

[386] Hayashi N, Yamakawa T, Baba S. Effect of Additive Gases on Synthesis of Organic Compounds from Carbon Dioxide Using Non-Thermal Plasma Produced by Atmospheric Surface Discharges. Vacuum 2006;80:1299-304.

[387] Mallinson RG, Sliepcevich CM, Rusek S. Mathane partial oxidation in alternating electric fields. Preprints Am Chem Soc Fuel Chem Div 1987;32:226.

[388] Bhatnagar R, Mallinson RG. Methane conversion in ac electric discharge at ambient conditions, in: M.N. Bhasin, D.W. Slocue (Eds), methane and alkane conversion chemistry. Plenum, NY,. 1995: 249-64.

[389] Wolfson A, Dlugy C, Shotland Y, Tavor D. Glycerol as solvent and hydrogen donor in transfer hydrogenation-dehydrogenation reactions. Tetrahedron Lett. 2009;50:5951-3.

[390] Gray ML, Soong Y, Champagne KJ, Baltrus J, R.W. Stevens Jr, Toochind P, et al. $\mathrm{CO}_{2}$ capture by amineenriched fly ash carbon sorbents. Separation and Purification Technol. 2004;35:31-6.

[391] Lashaki MJ, Sayari A. $\mathrm{CO}_{2}$ capture using triamine-grafted SBA-15: The impact of the support pore structure. Chem Eng J 2018;334:1260-9.

[392] Zhang L, Wang X, Fujii M, Yang L, Song C. $\mathrm{CO}_{2}$ capture over molecular basket sorbents: Effects of $\mathrm{SiO}_{2}$ supports and PEG additive J of Energy Chem. 2017;26:1030-8.

[393] Dowson GRM, Styring P. Demonstration of $\mathrm{CO}_{2}$ Conversion to Synthetic Transport Fuel at Flue Gas Concentrations. Frontiers in Energy Research. 2017;5:26.

[394] Steinberg M. Synthetic carbonaceous fuels and feedstocks from oxides of carbon and nuclear-power Fuel. 1978;58:460-8.

[395] Dang VD, Steinberg M. Production of synthetic methanol from air and water using controlled thermonuclear reactor power-II. Capital investment and production costs. Energy Conversion 1977;17:133-40. 
[396] Steinberg M. Production of synthetic methanol from air and water using controlled thermonuclear reactor power-I. Technology and energy requirement. Energy Conversion. 1977;17:97-112.

[397] Lee S-Y, Park S-J. A review on solid adsorbents for carbon dioxide capture. J of Industrial and Eng Chem. 2015;23:1-11.

[398] Graves C, Ebbesen SD, Mogensen M, Lackner KS. Sustainable hydrocarbon fuels by recycling $\mathrm{CO}_{2}$ and $\mathrm{H}_{2} \mathrm{O}$ with renewable or nuclear energy. Renewable and Sustainable Energy Reviews 2011;15: 1-23.

[399] Jensen R, Lyman J. Solar conversion of $\mathrm{CO}_{2}$ to Fuel. Proceedings of the 4th international conference on greenhouse gas control technology1998. p. 989-96.

[400] Mignard D, Sahibzada M, Duthie JM, Whittington HW. Methanol synthesis from flue-gas $\mathrm{CO}_{2}$ and renewable electricity: a feasibility study. Int J of Hydrogen Energy. 2003;28:455-64.

[401] Weimer T, Schaber K, Specht M, Bandi A. Methanol from atmospheric carbon dioxide: a liquid zero emission fuel for the future. Energy Conversion and Management 1996;37:1351-6.

[402] Zeman FS, Lackner KS. Capturing carbon dioxide directly from the atmosphere. World Resource Review 2004;16:157-72.

[403] Hartvigsen J, Joshi AV, Elangovan S, Balagopal S, Gordon JH, Hollist M. Electrochemical cell for the production of synthesis gas using atmospheric air and water. : Google Patents; 2007.

[404] Jensen SH, Larsen PH, Mogensen. M. Hydrogen and synthetic fuel production from renewable energy sources. Int J Hydrogen Energy. 2007;32:3253-7.

[405] Bonaventura D, Chacartegui R, Valverde JM, Becerra JA, Ortiz C, Lizana J. Dry carbonate process for $\mathrm{CO}_{2}$ capture and storage: Integration with solar thermal power. Renewable and Sustainable Energy Reviews. 2018;82:1796-812.

[406] Park S, Lee $S$, Lee $\mathrm{Y}$, Seo $\mathrm{Y}$. $\mathrm{CO}_{2}$ capture from simulated fuel gas mixtures using semiclathrate hydrates formed by quaternary ammonium salts. Environ Sci Technol. 2013;47:7571-7.

[407] Song C, Liu Q, Ji N, Deng S, Zhao J, Li Y, et al. Alternative pathways for efficient $\mathrm{CO}_{2}$ capture by hybrid processes-A review. Renewable and Sustainable Energy Reviews. 2018;82:215-31.

[408] Alonso A, Moral-Vico J, Markeb AA, Busquets-Fité M, Komilis D, Puntes V, et al. Critical review of existing nanomaterial adsorbents to capture carbon dioxide and methane. Science of the Total Environment 2017;595:51-62.

[409] Yuan Z, Eden MR, Gani R. Toward the Development and Deployment of Large-Scale Carbon Dioxide Capture and Conversion Processes Ind Eng Chem Res. 2016;55:3383-419.

[410] Moss M, Reed DG, Allen RWK, Styring P. Integrated $\mathrm{CO}_{2}$ capture and utilization using non-thermal plasmolysis. Frontiers in Energy Research. 2017;20.

[411] Nakajima K, Takahashi K, Tanaka M, Kuroki T, Okubo M. $\mathrm{CO}_{2}$ reduction using adsorption followed by nonthermal plasma treatment, . J of Physics: Conference Series 2015;646:012056.

[412] Frusteri F, Bonura G, Cannilla C, Ferrante GD, Aloise A, Catizzone E, et al. Stepwise tuning of metaloxide and acid sites of CuZnZr-MFI hybrid catalysts for the direct DME synthesis by $\mathrm{CO}_{2}$ hydrogenation. Appl Catal B Environ. 2015;176-177:522-31.

[413] Centi G, Perathoner S. Opportunities and prospects in the chemical recycling of carbon dioxide to fuels. Catal Today. Nov. 2009;148:191-205.

[414] Zhang Y, Li D, Zhang Y, Cao Y, Zhang S, Wang K, et al. V-modified CuO-ZnO-ZrO $2 / \mathrm{HZSM}-5$ catalyst for efficient direct synthesis of DME from $\mathrm{CO}_{2}$ hydrogenation. Catal Commun 2014;55:49-52.

[415] Qiao J, Liu Y, Hong F, Zhang J. A review of catalysts for the electro-reduction of carbon dioxide to produce low-carbon fuels. Chem Soc Rev. 2014;43:631-75.

[416] Kong PC, Nelson LO, Detering BA. Nonthermal plasma systems and methods for natural gas and heavy hydrocarbon co-conversion. Google Patents; 2005.

[417] Kiss AA, Pragt JJ, Vos HJ, Bargeman G, Groot MTd. Novel efficient process for methanol synthesis by $\mathrm{CO}_{2}$ hydrogenation. Chem Eng J. 2016;284:260-9. 
[418] Sanchez AL. Method and apparatus for plasma gasification of carbonic material by means of microwave radiation. Google Patents; 2010. 